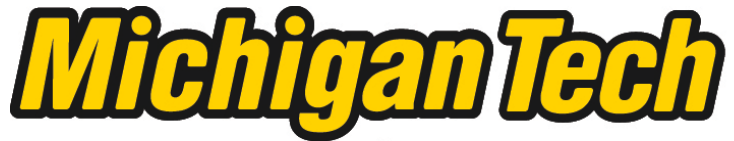 \\ Michigan Technological University Create the Future Digital Commons @ Michigan Tech
}

Nitrogen Oxides in the North Atlantic Troposphere: Impacts of Boreal Wildfire and Anthropogenic Emissions

Maria Val Martin

Michigan Technological University

Follow this and additional works at: https://digitalcommons.mtu.edu/etds

Part of the Environmental Engineering Commons

Copyright 2007 Maria Val Martin

\section{Recommended Citation}

Val Martin, Maria, "Nitrogen Oxides in the North Atlantic Troposphere: Impacts of Boreal Wildfire and Anthropogenic Emissions", Dissertation, Michigan Technological University, 2007.

https://doi.org/10.37099/mtu.dc.etds/722

Follow this and additional works at: https://digitalcommons.mtu.edu/etds

3 Part of the Environmental Engineering Commons 


\title{
Nitrogen Oxides in the North Atlantic Troposphere: Impacts of Boreal Wildfire and Anthropogenic Emissions
}

\author{
By \\ María Val Martín \\ A DISSERTATION \\ Submitted in partial fulfillment of the requirements \\ for the degree of \\ DOCTOR OF PHILOSOPHY \\ (Engineering - Environmental) \\ MICHIGAN TECHNOLOGICAL UNIVERSITY
}

July 2007

Copyright (c) 2007 María Val Martín 
This dissertation, "Nitrogen Oxides in the North Atlantic Troposphere: Impacts of Boreal Wildfire and Anthropogenic Emissions," is hereby approved in partial fulfillment of the requirements for the degree of DOCTOR OF PHILOSOPHY in the field of Engineering - Environmental.

Department of Civil and Environmental Engineering

Dr. Richard E. Honrath, Dissertation Advisor

Dr. Judith Perlinger, Non-Departamental Program Chair

Date 


\section{Abstract}

Nitrogen oxides play a crucial role in the budget of tropospheric ozone $\left(\mathrm{O}_{3}\right)$ and the formation of the hydroxyl radical. Anthropogenic activities and boreal wildfires are large sources of emissions in the atmosphere. However, the influence of the transport of these emissions on nitrogen oxides and $\mathrm{O}_{3}$ levels at hemispheric scales is not well understood, in particular due to a lack of nitrogen oxides measurements in remote regions. In order to address these deficiencies, measurements of $\mathrm{NO}, \mathrm{NO}_{2}$ and $\mathrm{NO}_{y}$ (total reactive nitrogen oxides) were made in the lower free troposphere (FT) over the central North Atlantic region (Pico Mountain station, $38^{\circ} \mathrm{N} 28^{\circ} \mathrm{W}, 2.3 \mathrm{~km}$ asl) from July 2002 to August 2005.

These measurements reveal a well-defined seasonal cycle of nitrogen oxides $\left(\mathrm{NO}_{x}=\right.$ $\mathrm{NO}+\mathrm{NO}_{2}$ and $\mathrm{NO}_{y}$ ) in the background central North Atlantic lower FT, with higher mixing ratios during the summertime. Observed $\mathrm{NO}_{x}$ and $\mathrm{NO}_{y}$ levels are consistent with long-range transport of emissions, but with significant removal en-route to the measurement site. Reactive nitrogen largely exists in the form of PAN and $\mathrm{HNO}_{3}$ ( $\sim 80-90 \%$ of $\left.\mathrm{NO}_{y}\right)$ all year round. A shift in the composition of $\mathrm{NO}_{y}$ from dominance of PAN to dominance of $\mathrm{HNO}_{3}$ occurs from winter-spring to summer-fall, as a result of changes in temperature and photochemistry over the region.

Analysis of the long-range transport of boreal wildfire emissions on nitrogen oxides provides evidence of the very large-scale impacts of boreal wildfires on the tropospheric $\mathrm{NO}_{x}$ and $\mathrm{O}_{3}$ budgets. Boreal wildfire emissions are responsible for significant shifts in the nitrogen oxides distributions toward higher levels during the summer, 
with medians of $\mathrm{NO}_{y}(117-175 \mathrm{pptv})$ and $\mathrm{NO}_{x}$ (9-30 pptv) greater in the presence of boreal wildfire emissions. Extreme levels of $\mathrm{NO}_{x}$ (up to $150 \mathrm{pptv}$ ) and $\mathrm{NO}_{y}$ (up to 1100 pptv) observed in boreal wildfire plumes suggest that decomposition of PAN to $\mathrm{NO}_{x}$ is a significant source of $\mathrm{NO}_{x}$, and imply that $\mathrm{O}_{3}$ formation occurs during transport. Ozone levels are also significantly enhanced in boreal wildfire plumes. However, a complex behavior of $\mathrm{O}_{3}$ is observed in the plumes, which varies from significant to lower $\mathrm{O}_{3}$ production to $\mathrm{O}_{3}$ destruction.

Long-range transport of anthropogenic emissions from North America also has a significant influence on the regional $\mathrm{NO}_{x}$ and $\mathrm{O}_{3}$ budgets. Transport of pollution from North America causes significant enhancements on nitrogen oxides year-round. Enhancements of $\mathrm{CO}, \mathrm{NO}_{y}$ and $\mathrm{NO}_{x}$ indicate that, consistent with previous studies, more than $95 \%$ of the $\mathrm{NO}_{x}$ emitted over the U.S. is removed before and during export out of the U.S. boundary layer. However, about $30 \%$ of the $\mathrm{NO}_{x}$ emissions exported out of the U.S. boundary layer remain in the airmasses. Since the lifetime of $\mathrm{NO}_{x}$ is shorter than the transport timescale, PAN decomposition and potentially photolysis of $\mathrm{HNO}_{3}$ provide a supply of $\mathrm{NO}_{x}$ over the central North Atlantic lower FT. Observed $\Delta \mathrm{O}_{3} / \Delta \mathrm{NO}_{y}$ and large $\mathrm{NO}_{y}$ levels remaining in the North American plumes suggest potential $\mathrm{O}_{3}$ formation well downwind from North America.

Finally, a comparison of the nitrogen oxides measurements with results from the global chemical transport (GCT) model GEOS-Chem identifies differences between the observations and the model. GEOS-Chem reproduces the seasonal variation of nitrogen oxides over the central North Atlantic lower FT, but does not capture the magnitude of the cycles. Improvements in our understanding of nitrogen oxides chemistry in the remote FT and emission sources are necessary for the current GCT models to adequately estimate the impacts of emissions on tropospheric $\mathrm{NO}_{x}$ and the resulting impacts on the $\mathrm{O}_{3}$ budget. 
Copyright (C) 2007 María Val Martín All rights reserved. 


\section{Acknowledgements}

I wish to thank everyone who has contributed to this work. First, I would like to thank Dr. Richard Honrath, my advisor, for all his guidance, his patience and his support throughout this research. In addition, I would also like to thank the members of my committee - Drs. Judith Perlinger, Jim Mihelcic and William Cantrell— for their advice in my PhD proposal and dissertation. Thank you also to my research group for all their help during my years as a graduate student. In particular, I thank Chris Owen for providing the FLEXPART simulations used in Chapter 2 and the HYSPLIT backward trajectories, and for his help in interpreting transport patterns; Dr. Jan Kleissl for supplying the analysis of upslope flow periods; Kateryna Lapina for letting me use her FLEXPART Fire-CO tracer simulations and her comments on boreal wildfire emission factors; and Jessica Strane for her assistance in airflow analyses.

I also appreciate the help of many people involved in the Pico Mountain project. In particular, Mike Dziobak for helping me run the $\mathrm{NO}_{x, y}$ system and survive weather conditions at the Pico Mountain. I would also like to thank Dr. Paulo Fialho (Azores University, Portugal) for providing the aerosol black carbon data, Dr. Gabriele Pfister (National Center for Atmospheric Research) for providing the MOZART simulations, Dr. Qinbin Li (Jet Propulsion Lab) for supplying the GEOS-Chem simulations and Dr. Andrea Stohl (Norwegian Institute for Air Research) for providing the FLEXPART stratospheric $\mathrm{O}_{3}$ tracer simulations used in Chapter 3. I thank the National Science Foundation, the National Oceanic and Atmospheric Administration and the 
Civil and Environmental Engineering Department at Michigan Tech for financial support.

Finally, a very special thank you goes to my family, Toni Rubert Godoy and my friends, in particular Domenico Baú, for their support and their encouragement to complete this work, and their belief in my abilities. 


\section{Contents}

$\begin{array}{lll}\text { Abstract } & \text { iii }\end{array}$

Acknowledgments $\quad$ vi

List of Figures $\quad$ xi

List of Tables $\quad$ xiii

$\begin{array}{lll}1 & \text { Introduction } & 1\end{array}$

1.1 Research Objectives and Approach . . . . . . . . . . . . . . 8

1.2 Dissertation Overview $\ldots \ldots \ldots \ldots \ldots$

2 Seasonal Variation of Nitrogen Oxides in the Central North Atlantic

Lower Free Troposphere and Impacts of Transport of Pollution 13

2.1 Methodology . . . . . . . . . . . . . . . . . . . . . . . . . . . . . . . 17

2.1 .1 Measurement Site . . . . . . . . . . . . . . . . . . . . 17

2.1 .2 Measurements . . . . . . . . . . . . . . . . . . . . . . . 19

$2.1 .3 \quad$ FLEXPART and GEOS-Chem Simulations . . . . . . . . . . 22

2.2 Results and Discussion . . . . . . . . . . . . . . . . . . . . . . . . 24

$2.2 .1 \quad$ Diurnal Cycles $\ldots \ldots \ldots \ldots \ldots$

2.2 .2 Seasonal Variation $\ldots \ldots \ldots \ldots$

$2.2 .3 \quad$ Average Partitioning of $\mathrm{NO}_{y} \ldots \ldots \ldots \ldots \ldots$ 
$2.2 .3 .1 \quad$ Estimation of $\mathrm{NO}_{y}$ Partition $\ldots \ldots \ldots \ldots \ldots$

2.2 .3 .2 Variation of $\mathrm{NO}_{y}$ Partitioning . . . . . . . . . 42

$2.2 .3 .3 \quad$ Comparison to Previous Observations . . . . . . . 45

2.2 .3 .4 Comparison to GEOS-Chem . . . . . . . . . . . 45

2.3 Influence of Transport of Pollution $\ldots \ldots \ldots \ldots$

$2.3 .1 \quad$ Impacts of North American Anthropogenic Emissions . . . . . 50

2.3.1.1 Identification of North American Anthropogenic Impact 50

$2.3 .1 .2 \quad$ Example Episodes . . . . . . . . . . . . . . 51

2.3.1.3 Nitrogen Oxides Enhancements in North America Outflow and Estimates of $\mathrm{NO}_{y}$ Transport Efficiency . . . 55

2.3.1.4 Implications for the $\mathrm{O}_{3}$ Production and Budget . . . 60

2.3 .2 Influence of Boreal Wildfires . . . . . . . . . . . . . . 63

2.4 Summary and Conclusions . . . . . . . . . . . . . . . . . 66

3 Impacts of North American Boreal Wildfire Emissions on the North

$\begin{array}{ll}\text { Atlantic Lower Free Troposphere } & 69\end{array}$

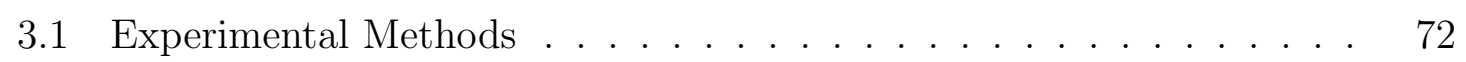

3.1 .1 Pico Mountain Station . . . . . . . . . . . . . . . . 72

3.1 .2 Measurements . . . . . . . . . . . . . . . . . . 73

$3.1 .2 .1 \quad$ Nitrogen oxides . . . . . . . . . . . . . . . . 73

$3.1 .2 .2 \quad \mathrm{CO}$ and $\mathrm{O}_{3} \ldots \ldots \ldots \ldots \ldots \ldots$

3.1.2.3 Aerosol Black Carbon . . . . . . . . . . . . . 77

$3.1 .3 \quad$ Model Simulations and Transport Analysis . . . . . . . . . 77

3.2 Results and Discussion $\ldots \ldots \ldots \ldots \ldots$

$3.2 .1 \quad$ Identification of Fire-Impacted Periods $\ldots \ldots \ldots \ldots$

3.2 .2 Overview of Summer 2004 Boreal Wildfire Observations. . . . 83

$3.2 .3 \quad$ Impacts of Boreal Wildfire Emissions $\ldots \ldots \ldots \ldots$

3.2.3.1 Estimation of Levels in Absence of Fires . . . . . . . 85 
3.2.3.2 Comparison of Levels in Boreal Region Outflow with and without Fire Emissions . . . . . . . . . . 88

3.2.4 Analysis of Enhancement Ratios in the Boreal Wildfire Plumes 90

3.2.4.1 Aerosol Black Carbon . . . . . . . . . . . . . . . 92

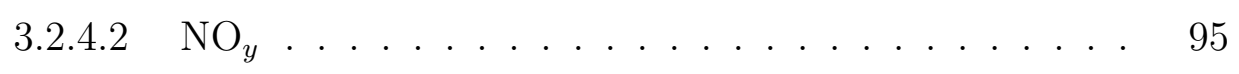

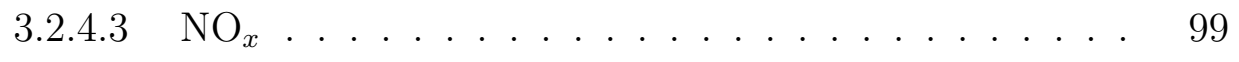

3.2 .4 .4 Ozone . . . . . . . . . . . . . . . 100

3.2 .5 Implications of Boreal Wildfires for the $\mathrm{NO}_{x}$ and $\mathrm{O}_{3}$ Budgets. 104

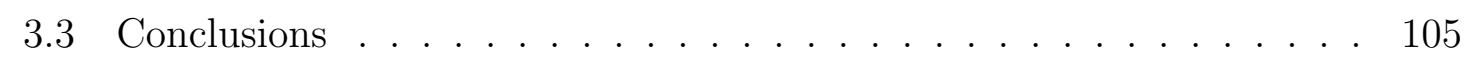

$\begin{array}{lll}4 & \text { Summary and Conclusions } & 108\end{array}$

4.1 Seasonal Variation of Nitrogen Oxides … . . . . . . . . . . . . 109

4.2 Impacts of Boreal Wildfire Emissions . . . . . . . . . . . . . . . . 109

4.3 Impacts of Anthropogenic Emissions ～. . . . . . . . . . . . . . 110

4.4 Conclusions and Additional Research . . . . . . . . . . . . . . . . . 111

\begin{tabular}{ll}
\hline References & 113
\end{tabular}

\begin{tabular}{ll}
\hline A Data Documentation & 126
\end{tabular} 


\section{List of Figures}

1.1 Schematic of photochemical cycles among reactive nitrogen species in the troposphere . . . . . . . . . . . . . . . . . . . 2

1.2 Mean tropospheric $\mathrm{NO}_{2}$ columns retrieved from the SCIAMACHY satellite instrument for May 2004 to April 2005 . . . . . . . . . . . 3

1.3 Location of the Pico Mountain station . . . . . . . . . . . . . . . . 10

$1.4 \quad \mathrm{NO}_{x, y}$ system at the Pico Mountain station . . . . . . . . . . . . . . 11

2.1 Time series of daytime $\mathrm{NO}, \mathrm{NO}_{x}$ and $\mathrm{NO}_{y}$ from July 20, 2002 to August 25, 2005 at the Pico Mountain station . . . . . . . . . . . . 26

$2.2 \quad$ Springtime diurnal cycles of $\mathrm{NO}, \mathrm{NO} / \mathrm{NO}_{2}, \mathrm{NO}_{2}$ and $\mathrm{NO}_{y}$. . . . . . 28

$2.3 \quad$ Seasonal cycle of $\mathrm{NO}_{x}$, daytime $\mathrm{NO}, \mathrm{NO}_{y}$ and $\mathrm{CO}$. . . . . . . . . . 31

$2.4 \quad$ Relationship between $\mathrm{NO}_{y}$ and CO during fall . . . . . . . . . . . . 32

2.5 Seasonal cycle of $\mathrm{HNO}_{3}{ }^{*}, \mathrm{PAN}^{*}$ and $\mathrm{NO}_{x}$, and $\mathrm{CO}$ in "in-cloud" and "out-of-cloud" periods and PAN lifetime . . . . . . . . . . . . . . . 44

2.6 Comparison of observations $\mathrm{NO}_{y}$ in dry conditions, $\mathrm{HNO}_{3}{ }^{*}, \mathrm{PAN}^{*}$, $\mathrm{NO}_{x}$ and CO to GEOS-Chem simulations . . . . . . . . . . . . . . . 48

2.7 Time series of 30-min average $\mathrm{CO}, \mathrm{NO}_{y}$ and $\mathrm{O}_{3}$ measurements, and FLEXPART NA-CO at the Pico Mountain station during two North American outflow events . . . . . . . . . . . . . . . . . . . . . 52

$2.8 \quad$ Results for retroplumes for two example transport episodes . . . . . 53 
2.9 Relationship between $\mathrm{CO}$ and $\mathrm{NO}_{y}, \mathrm{CO}$ and $\mathrm{NO}_{x}$ and $\mathrm{NO}_{y}$ and $\mathrm{O}_{3}$ during $2002-2005 \ldots \ldots \ldots \ldots \ldots$

2.10 Histograms of $\mathrm{CO}, \mathrm{NO}_{x}$ and $\mathrm{NO}_{y}$ of all summertime observations, all fire observations and all non-fire observations . . . . . . . . . . . . . 64

$3.1 \quad$ Summer 2004 time series of $\mathrm{CO}, \mathrm{BC}, \mathrm{NO}_{y}, \mathrm{NO}_{x}, \mathrm{O}_{3}$ measurements, and MOZART fire-CO fraction at the Pico Mountain station . . . . 79

$3.2 \quad$ Backward trajectories arriving at the measurement site during boreal region outflow . . . . . . . . . . . . . . . . . . . . . 82

3.3 Time series of 30-min average $\mathrm{CO}, \mathrm{NO}_{x}, \mathrm{NO}_{y}$ and $\mathrm{O}_{3}$, and 1-hr average BC observations during two boreal wildfire events and one boreal outflow period without upwind fire emissions . . . . . . . . . . 86

$3.4 \quad$ Relationship between CO and the indicated species during summer

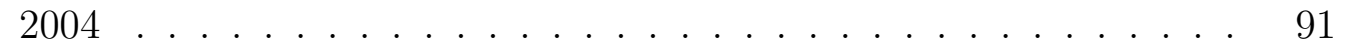

$3.5 \quad$ Relationship between $\mathrm{BC}$ and $\mathrm{NO}_{y}$ during summer 2004. . . . . . . 96

$3.6 \quad$ Relationship between $\mathrm{O}_{3}$ and $\mathrm{NO}_{y}$ during summer 2004 . . . . . . . 103 


\section{List of Tables}

1.1 Measurements at the Pico Mountain station and other tools used in this work . . . . . . . . . . . . . . . . . . . . . . . . . . . . . . . . . . 12

$2.1 \quad$ Statistical parameters of the nitrogen oxides diurnal cycle . . . . . . . 27

2.2 Summary of monthly mixing ratios of nitrogen oxides and CO at the Pico Mountain station . . . . . . . . . . . . . . . . . . . . . . . . 33

2.3 Observation of nitrogen oxides in the lower free troposphere of remote regions . . . . . . . . . . . . . . . . . . . . . . . 38

2.4 Partitioning of $\mathrm{NO}_{y}$ at the Pico Mountain station . . . . . . . . . . . 41

$2.5 \quad$ Partitioning of $\mathrm{NO}_{y}$ and $\mathrm{NO}_{y}$ export efficiency estimates reported from ICARTT, NARE and Pico Mountain studies . . . . . . . . . . . . . . 46

2.6 Enhancement ratios of nitrogen oxides during the North American outflow events . . . . . . . . . . . . . . . . . . . . 57

2.7 Statistics of summertime $\mathrm{NO}_{y}, \mathrm{NO}_{x}$ and $\mathrm{CO}$ distribution . . . . . . 65

3.1 Comparison of $\mathrm{CO}, \mathrm{BC}, \mathrm{NO}_{y}, \mathrm{NO}_{x}$ and $\mathrm{O}_{3}$ levels during the boreal fire events with observations during periods of flow from boreal region in absence of fires and with all observations during summer 2004 . . . . 84

$3.2 \quad$ Estimated background levels over the North American boreal region . 89

3.3 Enhancement ratios of the species during the boreal wildfire events . 93 
3.4 Enhancement ratios of $\mathrm{NO}_{y}, \mathrm{NO}_{x}$ and $\mathrm{O}_{3}$ relative to $\mathrm{CO}$ observed in boreal fire plumes. . . . . . . . . . . . . . . . . . . . . . . 98 


\section{Chapter 1}

\section{Introduction}

Nitrogen oxides play a central role in the chemistry of the atmosphere since they critically determine levels of ozone $\left(\mathrm{O}_{3}\right)$ and acidity Levy II, 1971; Crutzen, 1979; Logan, 1983. Ozone is both an important anthropogenic greenhouse gas Alley et al. 2007 and a regulator of the tropospheric oxidation strength, via controlling the concentration of tropospheric $\mathrm{OH}$ Logan, 1983. In addition, by being a strong oxidant, $\mathrm{O}_{3}$ has negative effects on human health and ecosystems, at concentrations not far above ambient.

The concentration of $\mathrm{NO}_{x}\left(\mathrm{NO}+\mathrm{NO}_{2}\right)$ in the atmosphere depends on the source strength and the rates of reactions converting $\mathrm{NO}_{x}$ to nitric acid $\left(\mathrm{HNO}_{3}\right)$, peroxyacetyl nitrate, (PAN, $\mathrm{CH}_{3} \mathrm{C}(\mathrm{O}) \mathrm{O}_{2} \mathrm{NO}_{2}$ ) or other minor compounds and their uptake into precipitation or deposition at the Earth surface Logan, 1983, as shown in Figure 1.1. Collectively, all reactive nitrogen oxides species are denoted as $\mathrm{NO}_{y}$, which is the sum of $\mathrm{NO}_{x}$ and its oxidation products, i.e., $\mathrm{NO}+\mathrm{NO}_{2}+\mathrm{HNO}_{3}+\mathrm{PAN}+2 \mathrm{~N}_{2} \mathrm{O}_{5}+$ alkyl nitrates+aerosol $\mathrm{NO}_{3}^{-}+$other minor species.

Fossil fuel combustion resulting from anthropogenic activities is the major source of $\mathrm{NO}_{x}$ emissions in the Northern Hemisphere [Alley et al., 2007, with the majority of these emissions located over industrial regions as shown in Figure 1.2. In recent 


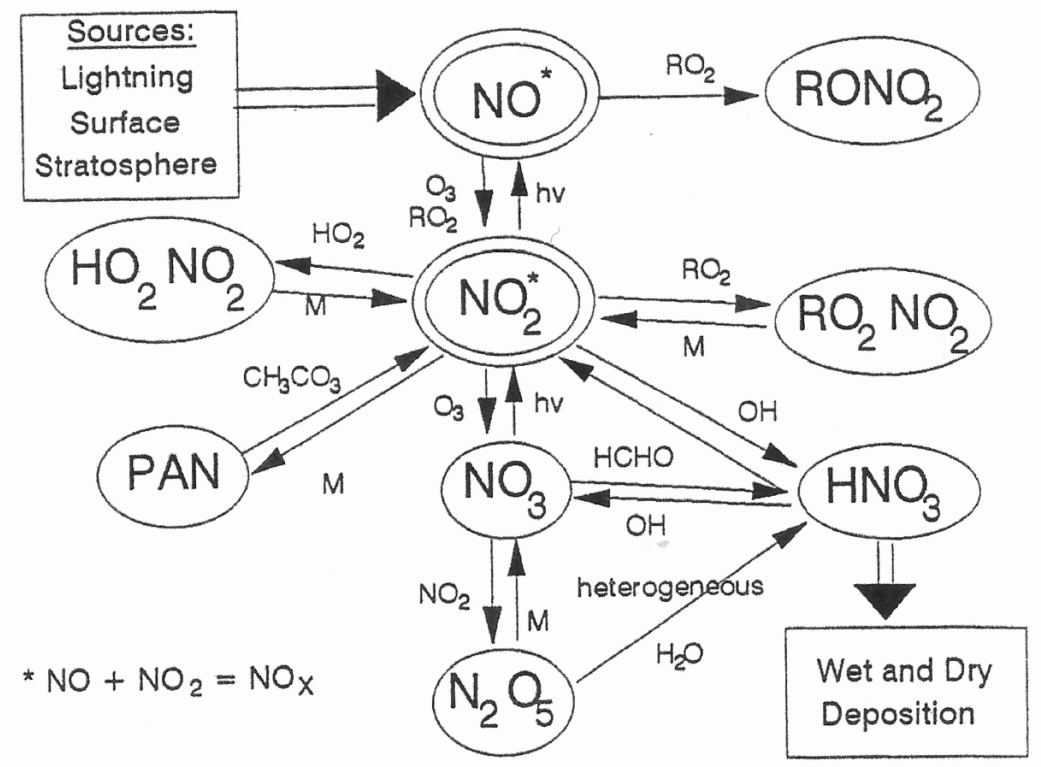

Figure 1.1 Schematic of photochemical cycles among reactive nitrogen species in the troposphere Carroll and Thompson, 1995].

years, as a result of increased area burned and fire frequency over the boreal region Kasischke and Turetsky, 2006, emissions from the boreal wildfires have resulted in a significant source of $\mathrm{NO}_{x}$ to the atmosphere during the summer season Goode et al. 2000; Andreae and Merlet, 2001]. Oxidation of $\mathrm{NO}_{x}$ emitted from these sources takes place on the order of one day within the continental boundary layer (BL). During the day, oxidation of $\mathrm{NO}_{2}$ to $\mathrm{HNO}_{3}$ by reaction with $\mathrm{OH}$ is the principal sink of tropospheric $\mathrm{NO}_{x}$. At night, reaction of $\mathrm{NO}_{2}$ with $\mathrm{O}_{3}$ followed by heterogeneous hydrolysis of $\mathrm{N}_{2} \mathrm{O}_{5}$ in aerosols is also an important sink Parrish et al., 1998; Brown et al. [2006. $\mathrm{HNO}_{3}$ leaves the atmosphere by dry or wet deposition, constituting a major component of acid deposition Logan, 1983.

Reaction of $\mathrm{NO}_{2}$ with peroxyacetyl radical, which is formed by oxidation of ethane, forms PAN:

$$
\mathrm{CH}_{3} \mathrm{C}(\mathrm{O}) \mathrm{O}_{2}+\mathrm{NO}_{2} \rightleftharpoons \mathrm{CH}_{3} \mathrm{C}(\mathrm{O}) \mathrm{O}_{2} \mathrm{NO}_{2} \text {. }
$$

PAN is a key species in the dispersal of $\mathrm{NO}_{x}$ away from the source emissions. The 


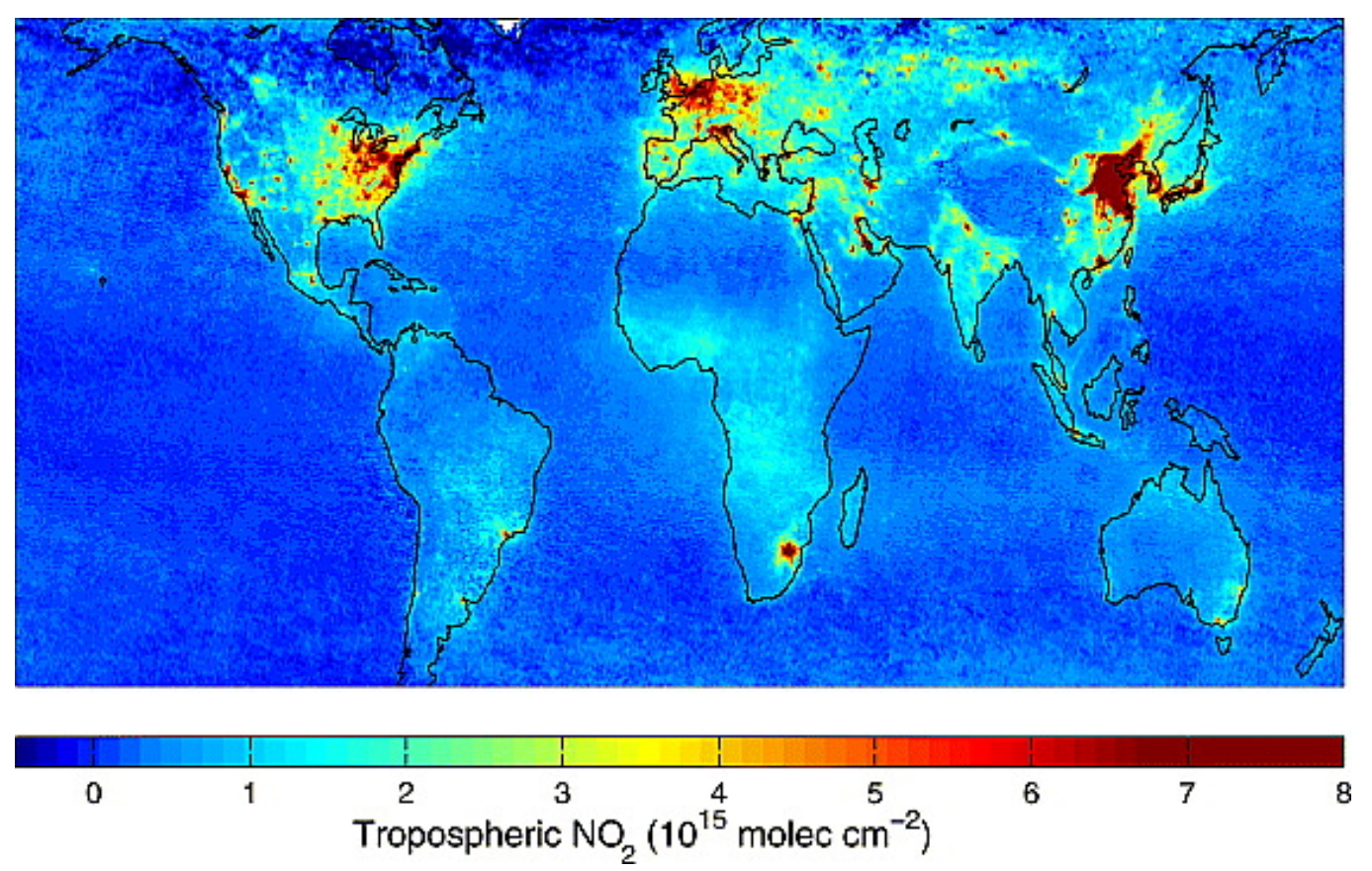

Figure 1.2 Mean tropospheric $\mathrm{NO}_{2}$ columns retrieved from the SCIAMACHY satellite instrument for May 2004 to April 2005 [Martin et al. 2006].

lifetime of PAN is strongly temperature dependent ( $\sim 30$ days at $-10^{\circ} \mathrm{C}$ and $\sim 3$ days at $2^{\circ} \mathrm{C}$ ) Singh, 1987]. In the FT, at lower temperatures and pressures, the equilibrium of reaction 1.1 is shifted to the right side. In a later stage, when the airmasses subside or advect to warmer regions, $\mathrm{NO}_{2}$ and peroxyacetyl radical are released. It has also been suggested that, similar to PAN, the export of $\mathrm{HNO}_{3}$ followed by photolysis to $\mathrm{NO}_{x}$ can be an important source of $\mathrm{NO}_{x}$ in the troposphere Neuman et al., 2006.

Quantifying the sources and fate of nitrogen oxides in the troposphere is critical for assessing the influence of anthropogenic and boreal wildfire emissions on global tropospheric $\mathrm{O}_{3}$. Tropospheric $\mathrm{O}_{3}$ is controlled by production and reaction processes and is principally limited by the presence of $\mathrm{NO}_{x}$. The primary loss mechanism of $\mathrm{O}_{3}$ is via photolysis and subsequent reaction of $\mathrm{O}\left({ }^{1} \mathrm{D}\right)$ with $\mathrm{H}_{2} \mathrm{O}$, which occurs in competition with deactivation to $\mathrm{O}\left({ }^{3} \mathrm{P}\right)$ :

$$
\mathrm{O}_{3}+h \nu \longrightarrow \mathrm{O}\left({ }^{1} \mathrm{D}\right)+\mathrm{O}_{2}
$$




$$
\begin{aligned}
\mathrm{O}\left({ }^{1} \mathrm{D}\right)+\mathrm{H}_{2} \mathrm{O} & \longrightarrow 2 \mathrm{OH} \\
\mathrm{O}\left({ }^{1} \mathrm{D}\right) & \stackrel{\mathrm{M}}{\longrightarrow} \mathrm{O}\left({ }^{3} \mathrm{P}\right),
\end{aligned}
$$

where $\mathrm{M}$ denotes $\mathrm{N}_{2}$ or $\mathrm{O}_{2}$.

The hydroxyl radical $(\mathrm{OH})$ formed in reaction 1.3 oxidizes $\mathrm{CO}$, methane $\left(\mathrm{CH}_{4}\right)$, and other hydrocarbons $(\mathrm{RH})$ and thereby produces peroxy radicals $\left(\mathrm{PO}_{2}=\mathrm{HO}_{2}+\mathrm{CH}_{3} \mathrm{O}_{2}+\mathrm{RO}_{2}\right)$ :

$$
\begin{array}{lll}
\mathrm{CO}+\mathrm{OH} & \stackrel{\mathrm{O}_{2}}{\longrightarrow} & \mathrm{CO}_{2}+\mathrm{HO}_{2} \\
\mathrm{CH}_{4}+\mathrm{OH} & \stackrel{\mathrm{O}_{2}}{\longrightarrow} & \mathrm{CH}_{3} \mathrm{O}_{2}+\mathrm{H}_{2} \mathrm{O} \\
\mathrm{RH}+\mathrm{OH} & \stackrel{\mathrm{O}_{2}}{\longrightarrow} & \mathrm{RO}_{2}+\mathrm{H}_{2} \mathrm{O} .
\end{array}
$$

Peroxy radicals are responsible for the photochemical production or destruction of tropospheric $\mathrm{O}_{3}$, depending critically on the availability of $\mathrm{NO}$ Liu et al., 1992, Cox, 1999. In regions, where levels of $\mathrm{NO}_{x}$ are higher than 10-50 pptv Fishman et al. 1979 Lin et al., 1988, $\mathrm{PO}_{2}$ oxidation of $\mathrm{NO}$ results in formation of $\mathrm{O}_{3}$ through:

$$
\begin{aligned}
\mathrm{NO}+\mathrm{PO}_{2} & \longrightarrow \mathrm{NO}_{2}+\mathrm{PO} \\
\mathrm{NO}_{2}+h \nu & \longrightarrow \mathrm{NO}+\mathrm{O} \\
\mathrm{O}+\mathrm{O}_{2} & \stackrel{\mathrm{M}}{\longrightarrow} \mathrm{O}_{3},
\end{aligned}
$$

where $\mathrm{PO}$ is the alkoxy radical or $\mathrm{OH}$. In remote clean regions, where $\mathrm{NO}_{x}$ mixing ratios are lower than 10-50 pptv, the occurrence of reaction 1.8 is reduced, resulting in reduced $\mathrm{O}_{3}$ formation and an increased rate of $\mathrm{O}_{3}$ destruction through reaction 1.11 :

$$
\mathrm{O}_{3}+\mathrm{HO}_{2} \longrightarrow \mathrm{OH}+2 \mathrm{O}_{2} .
$$

In addition to reactions 1.21 .3 and $1.11, \mathrm{O}_{3}$ is also removed by deposition to the surface and heterogeneous loss in clouds, and destroyed to a lesser extent via reaction with $\mathrm{OH}$ :

$$
\mathrm{O}_{3}+\mathrm{OH} \longrightarrow \mathrm{HO}_{2}+2 \mathrm{O}_{2}
$$


The dependence of $\mathrm{O}_{3}$ production of $\mathrm{NO}_{x}$ is highly non-linear, i.e., the ozone production efficiency per molecule of $\mathrm{NO}_{x}$ consumed increases rapidly as $\mathrm{NO}_{x}$ concentration decreases [Liu et al., 1987]. As a result, the in-situ production of $\mathrm{O}_{3}$ in clean remote regions is more efficient than is production in source regions [Jacob et al. 1993. Regardless of the $\mathrm{NO}_{x}$ level, an increase in $\mathrm{NO}_{x}$ may result in increased $\mathrm{O}_{3}$, due to either a reduction in the $\mathrm{O}_{3}$ loss rate (via reaction 1.11) or an increase in the $\mathrm{O}_{3}$ production rate (via reaction 1.8 ).

To quantify the impacts of $\mathrm{NO}_{x}$ emissions on tropospheric $\mathrm{O}_{3}$ at hemispheric scales, it is necessary to quantify both the export of $\mathrm{O}_{3}$ produced in polluted source regions and the formation of $\mathrm{O}_{3}$ from the export of precursors (e.g., $\mathrm{PAN}$ and $\mathrm{HNO}_{3}$, which may eventually release $\mathrm{NO}_{x}$ ).

Field measurement campaigns have been conducted in the last two decades to characterize the spatial and temporal distribution of tropospheric $\mathrm{NO}_{x}$ and to determine the resulting effect of $\mathrm{NO}_{x}$ emissions on the $\mathrm{O}_{3}$ budget. However, data composites of results from many of these campaigns show that the spatial and temporal coverage of remote tropospheric $\mathrm{NO}_{x}$ measurements is still quite sparse and reflects a strong seasonal and regional bias Emmons et al. 1997; Bradshaw et al., 2000; Emmons et al., 2000, DiNunno et al. 2003.

In addition to measurement campaigns, global chemical transport (GCT) models have been developed to derive the global impact of anthropogenic and boreal wildfire emissions on the $\mathrm{O}_{3}$ budget. However, it is difficult to assess the uncertainty of the resulting estimates, in particular those related to $\mathrm{NO}_{x}$ sources and photochemical processes. The evaluation of GCT models using nitrogen oxides observations in the FT has been limited by a lack of data in remote regions [e.g. Thakur et al., 1999; Lawrence and Crutzen, 1999.

Recently, satellite-derived data have been used to derive global and regional $\mathrm{NO}_{x}$ budgets [e.g. Leue et al., 2001; Martin et al., 2004; Jaeglé et al., 2005; Richter et al., 2005 and detect intercontinental transport of nitrogen oxides plumes from boreal 
wildfires Spichtinger et al., 2001] and anthropogenic sources Wenig et al., 2003, Stohl et al. 2003. More recently, satellite data have been used to evaluate GCT models [e.g. Liu et al., 2006; Chandra et al., 2004. However, the limited measurements of nitrogen oxides in the remote lower FT make the evaluation of satellite-derived data difficult Leue et al., 2001; Martin et al., 2004].

In the central North Atlantic FT, the lack of data is particularly evident. Measurements of $\mathrm{O}_{3}$ and nitrogen oxides at several Canadian marine sites indicated that $\mathrm{O}_{3}$ levels in the $\mathrm{BL}$ are significantly influence by the export of $\mathrm{O}_{3}$ and $\mathrm{O}_{3}$ precursors during spring to fall Parrish et al., 1998; Val Martín, 2002]. During the winter, in the absence of significant photochemistry, $\mathrm{O}_{3}$ is removed by reaction with $\mathrm{NO}$ and $\mathrm{NO}_{2}$ and deposition Parrish et al. 1998. These studies suggested that the ultimate impact of anthropogenic emissions could be even larger as additional in-situ formation of $\mathrm{O}_{3}$ from these emissions may occur during transit over the ocean. Consistent with this expectation, measurements further downwind, over the Azores, indicated significant $\mathrm{O}_{3}$ export in U.S. outflow during spring (Parrish et al., 1998, although an absence of transport impacts during the summer Peterson and Honrath, 1999. However, all these studies were made in the $\mathrm{BL}$ and loss of $\mathrm{NO}_{y}$ and $\mathrm{O}_{3}$ may have resulted in an underestimation of the importance of the impact of anthropogenic emissions Derwent et al., 1998; Auvray and Bey, 2005.

Aircraft measurements over the western North Atlantic region and GCT model simulations indicated that the majority of the $\mathrm{NO}_{x}$ emitted over the U.S. is removed before or during the export out of the U.S. BL [e.g. Stohl et al., 2002; Parrish et al., 2004 Li et al., 2004; Hudman et al., 2007. The large fraction of $\mathrm{NO}_{x}$ emitted that is removed from the plumes and the large $\mathrm{HNO}_{3} / \mathrm{NO}_{y}$ ratio observed in these studies imply that the potential for future $\mathrm{O}_{3}$ production in these plumes in the FT must be limited. Further, modeling analyses estimated that most of the $\mathrm{O}_{3}$ production from North America $\mathrm{NO}_{x}$ emissions occurs near North America.

Although it is believed that most of the photochemical $\mathrm{O}_{3}$ production takes place 
near North America, observations over the North Atlantic Ocean FT showed that it also occurs during long-range transport Reeves et al., 2002; Honrath et al., 2004]. In fact, the magnitude of the $\mathrm{O}_{3}$ enhancements observed in U.S. outflow over the central North Atlantic lower FT is unusually large, implying that a significant amount of additional $\mathrm{O}_{3}$ formation occurs during transport over the ocean Honrath et al. 2004. However, the ultimate fate of the nitrogen oxides export and its implication on the $\mathrm{O}_{3}$ production well downwind is still uncertain due to a lack of nitrogen oxides measurements over this region.

In addition to anthropogenic emissions, attention has recently been paid to the effect of boreal wildfire emissions on the hemispheric $\mathrm{NO}_{x}$ and $\mathrm{O}_{3}$ budgets. In recent years, as a result of an increase in dry and warm conditions over the boreal region Hassol, 2004, and increase in human-ignited fires Mollicone et al., 2006, fire activity has increased [Kasischke and Turetsky, 2006]. In addition, global circulation model simulations predict a further increase in the near future as a result of climate change Stocks et al. 1998]. Boreal wildfire emissions have a large degree of variability, and are a function of fuel type (e.g., peat fires versus crown fires) and burning conditions (e.g., smoldering versus flaming) Goode et al., 2000, Kasischke et al., 2005. This behavior causes a large uncertainty and variability in the emissions of $\mathrm{NO}_{x}$.

Boreal wildfires are recognized to be an important source of CO. On a seasonal basis, total boreal wildfire $\mathrm{CO}$ emissions can be at times as large as total anthropogenic $\mathrm{CO}$ emissions in the midlatitude northern hemisphere Kasischke et al. 2005. Boreal wildfires also affect background $\mathrm{CO}$ levels in large regions of the northern hemisphere Novelli et al., 2003; Honrath et al., 2004. In addition, prior studies have detected enhancements of $\mathrm{O}_{3}$ in boreal wildfire plumes [e.g. Lapina et al., 2006; Bertschi and Jaffe, 2005. However, the magnitude of the resulting impact of boreal wildfire $\mathrm{NO}_{x}$ emissions on global tropospheric $\mathrm{O}_{3}$ is not yet well characterized. Thus, an understanding of the impact of boreal wildfires on tropospheric $\mathrm{NO}_{x}$ levels is needed to further understand the influence of this source on tropospheric $\mathrm{O}_{3}$, both at present 
and in the future.

This discussion demonstrates the importance of understanding the impacts of both anthropogenic and boreal wildfire $\mathrm{NO}_{x}$ emissions on the tropospheric $\mathrm{NO}_{x}$ and $\mathrm{O}_{3}$ budgets. However, the current understanding of these budgets is limited by gaps in our knowledge of nitrogen oxides levels in remote regions. In addition, the paucity of nitrogen oxides observations inhibits the evaluation of the adequacy of GCT models and spaced-based observations.

\subsection{Research Objectives and Approach}

This research was motivated by the current deficiencies in the understanding of the nitrogen oxides and the resulting influence on the tropospheric $\mathrm{O}_{3}$ budget in the North Atlantic troposphere. The objectives of this research include to:

1. determine the seasonal variation of $\mathrm{NO}, \mathrm{NO}_{x}$ and $\mathrm{NO}_{y}$ levels in the background central North Atlantic lower FT;

2. characterize the composition of $\mathrm{NO}_{y}$ in the background central North Atlantic lower FT;

3. assess the influence of transport of anthropogenic emissions from the U.S. on levels of $\mathrm{NO}_{x}$ and $\mathrm{NO}_{y}$ in the remote central North Atlantic lower FT;

4. determine the impact of boreal wildfire emissions on levels of $\mathrm{NO}_{x}$ and $\mathrm{NO}_{y}$ in the remote North Atlantic lower FT and, the degree to which boreal wildfires affect the annual distribution of nitrogen oxides; and

5. assess the resulting implications of the North American boreal wildfire and anthropogenic emissions for the regional and hemispheric $\mathrm{O}_{3}$ budget.

To achieve these goals, measurements of $\mathrm{NO}, \mathrm{NO}_{2}$ and $\mathrm{NO}_{y}$ were made at the Pico Mountain station in the central North Atlantic lower free troposphere from July 
2002 to August 2005. The Pico Mountain station is located on the summit caldera of the Pico Mountain, at $2225 \mathrm{~m}$, in the Azores Islands, Portugal $\left(38^{\circ} \mathrm{N}, 28^{\circ} \mathrm{W}\right)$. The Azores Islands are a remote island group located approximately $1500 \mathrm{~km}$ from west of Portugal and $3900 \mathrm{~km}$ from the east coast of North America, as shown in Figure 1.3. The Pico Mountain station station was established during the summer 2001, beginning with measurements of $\mathrm{CO}, \mathrm{O}_{3}$, aerosol black carbon and meteorological parameters. Measurements of $\mathrm{NO}, \mathrm{NO}_{2}$, and $\mathrm{NO}_{y}$ began during late summer 2002, and non-methane hydrocarbons began during spring 2004. Due to the remoteness and the difficulty of access to the measurement site, an existing high sensitivity $\mathrm{NO}_{x, y}$ system developed at Michigan Tech Peterson and Honrath, 1999 was modified to automatically operate at the Pico Mountain station. Figure 1.4 displays two images of the Pico Mountain station and the $\mathrm{NO}_{x, y}$ system, and Table 1.1 summarizes the measurements and the tools used to address the objectives of this work.

\subsection{Dissertation Overview}

The following chapters present analyses, results and conclusions of the nitrogen oxides measurements made at the Pico Mountain station. Chapter 2 covers the seasonal variation of nitrogen oxides over the central North Atlantic lower FT and impacts of the transport of pollution on the nitrogen oxides levels, with a focus on eastern North American pollution. This chapter presents analyses of measurements made from July 2002 to August 2005. Chapter 3 presents the impacts of boreal wildfire emissions on the nitrogen oxides levels based on analysis of data from summer 2004. The last chapter summarizes the main results and conclusions. The appendix contains the documentation of the nitrogen oxides data reduction and information on the performance of the system. 


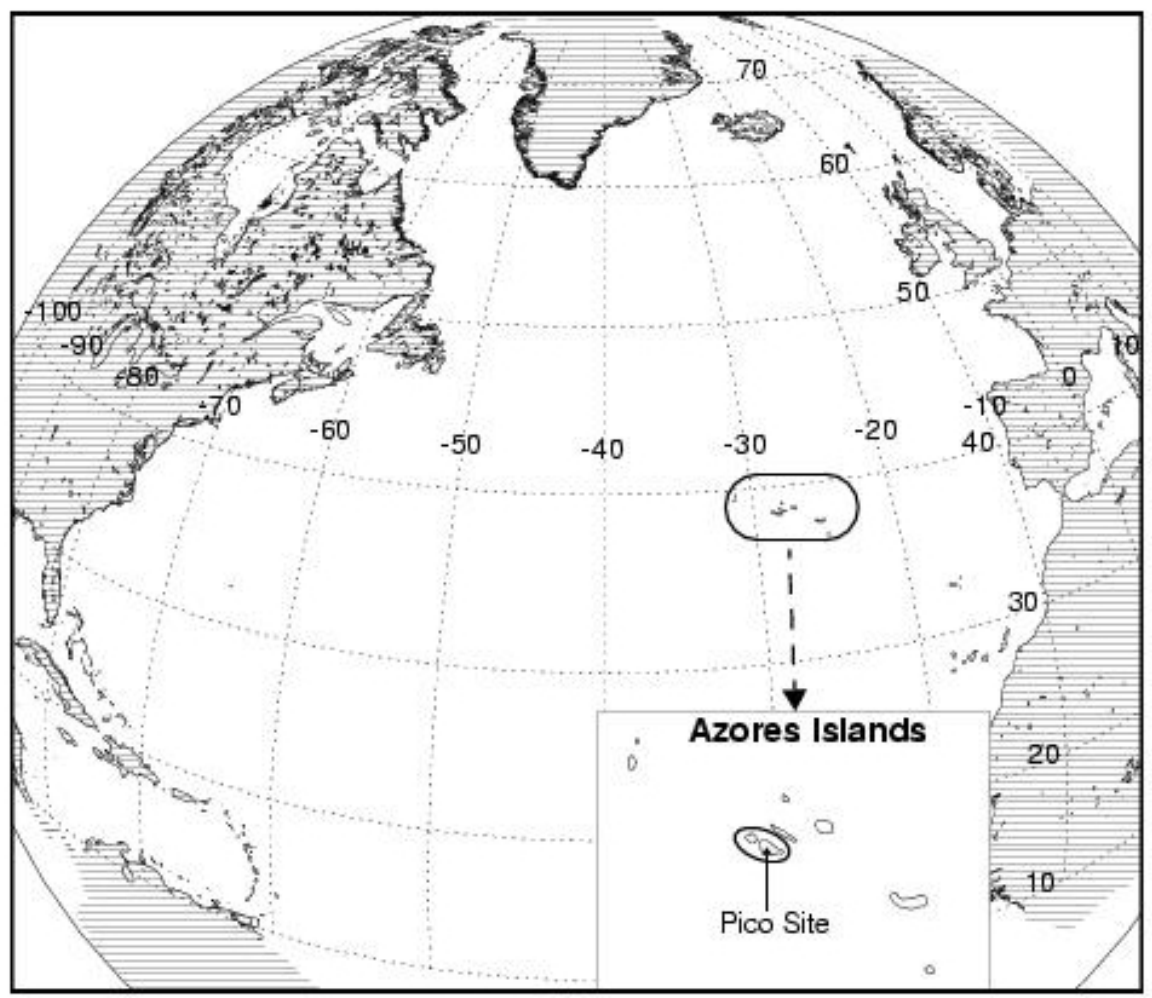

Figure 1.3 Location of the Pico Mountain station. 
a)

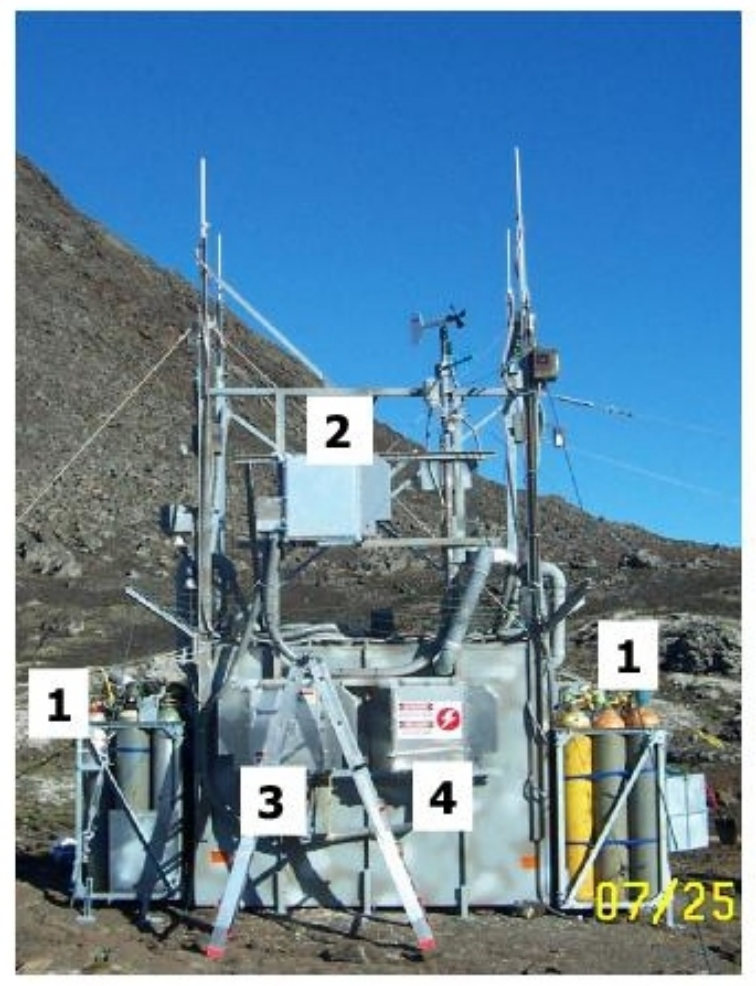

b)

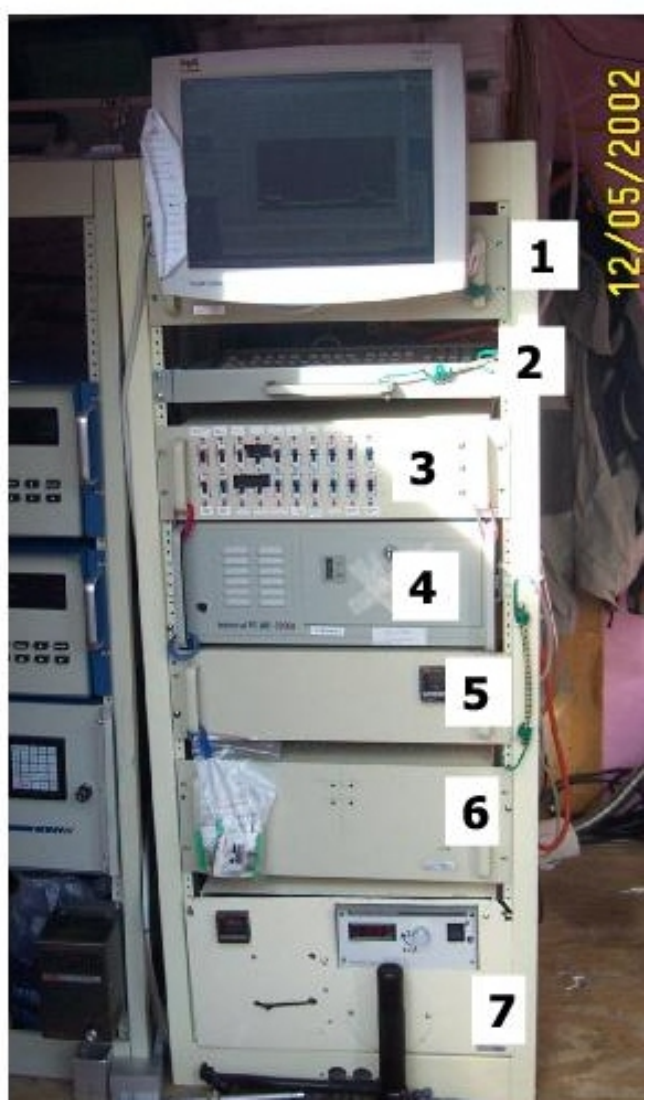

Figure 1.4 $\mathrm{NO}_{x, y}$ system at the Pico Mountain station: a) Components outside the station: 1.Calibration and reagent gases, 2. $\mathrm{NO}_{x}$ inlet (to sample $\mathrm{NO}$ or $\mathrm{NO}_{2}$ ) and $\mathrm{NO}_{y}$ inlet, and $\mathrm{NO}_{y}$ converter $3 . \mathrm{NO}_{2}$ converter, and 4. $\mathrm{NO}_{2}$ lamp power supply ; b) Components inside the station: 1.Ozone generator, 2.Computer keyboard, 3.Analog and Digital Input/Output box, 4.Computer, $5 . \mathrm{CH}_{3} \mathrm{CN}$ calibration source, 6.System power supplies, and 7.NO detector. 
Table 1.1 Measurements at the Pico Mountain station and other tools used in this work.

\begin{tabular}{|c|c|}
\hline Measurement/Tool & Technique/Source \\
\hline NO & $\mathrm{O}_{3}$ chemiluminesce (developed at Michigan Tech) \\
\hline $\mathrm{NO}_{2}$ & $\mathrm{NO}_{2}$ photolysis (developed at Michigan Tech ) \\
\hline $\mathrm{NO}_{y}$ & Au-catalytic reduction (developed at Michigan Tech) \\
\hline $\mathrm{CO}$ & Non-dispersive IR (TEI 48C-TL) \\
\hline $\mathrm{O}_{3}$ & UV absorption (TEI 49C) \\
\hline Aerosol black carbor $a$ & UV-vis absorption (AE31 Aethalometer) \\
\hline Wind speed and direction & standard (R.M. Young 05103) \\
\hline RH and Temperature & standard (Rotronic TM12R) \\
\hline Pressure & standard (R.M. Young 61201) \\
\hline \multicolumn{2}{|c|}{ Global Chemical Transport Models } \\
\hline MOZART & National Center for Atmospheric Research \\
\hline GEOS-Chem & Jet Propulsion Lab \\
\hline \multicolumn{2}{|l|}{ Transport Models } \\
\hline FLEXPART & Michigan Tech/Norwegian Institute for Air Research \\
\hline HYSPLIT & Michigan Tech \\
\hline
\end{tabular}

${ }^{a}$ University of the Azores. 


\section{Chapter 2}

\section{Seasonal Variation of Nitrogen}

\section{Oxides in the Central North}

\section{Atlantic Lower Free Troposphere and Impacts of Transport of Pollution $^{\dagger}$}

Reactive nitrogen species are critical for the chemistry of the atmosphere. Photochemical production of $\mathrm{O}_{3}$ depends on the concentration of $\mathrm{NO}_{x}\left(\mathrm{NO}+\mathrm{NO}_{2}\right)$, which in turn, influences the concentration of tropospheric OH. Species that affect $\mathrm{OH}$ are important, as reaction of $\mathrm{OH}$ provides the dominant path for removal of a variety of atmospheric pollutants Crutzen, 1979; Logan, 1983. In addition, nitric acid, the primary end product of $\mathrm{NO}_{x}$ oxidation, is one of the major components of acid deposition.

†This chapter is based on material to be submitted, with minor changes, as Val Martín M., R. Honrath, R. C. Owen, K. Lapina and Q. Li (2007), Seasonal variation of nitrogen oxides in the central North Atlantic lower free troposphere, J. Geosphys. Res. 
Understanding the impact of $\mathrm{NO}_{x}$ on tropospheric $\mathrm{O}_{3}$ on a global scale is important for several reasons. Ozone is considered the third most important anthropogenic greenhouse gas Alley et al., 2007. In addition, slightly elevated levels of $\mathrm{O}_{3}$, at concentrations not far above ambient, pose a serious concern because of their effects on the human respiratory system and ecosystems. In particular, there is an increasing concern regarding intercontinental transport of $\mathrm{O}_{3}$ pollution since it appears to be changing the composition of the background troposphere Simmonds et al. 2004; Jaffe et al. 2003 and make difficult for the countries downwind to achieve their air quality standards Li et al., 2002; Derwent et al., 2004.

In the Northern Hemisphere, emissions of nitrogen oxides are dominated by anthropogenic sources in urban and industrial regions Logan, 1983. The impact of $\mathrm{NO}_{x}$ emissions from these regions on global $\mathrm{O}_{3}$ is limited as oxidation of $\mathrm{NO}_{x}$ to $\mathrm{HNO}_{3}$, peroxyacetyl nitrate (PAN) and other minor compounds occurs in less than one day in the continental boundary layer (BL). However, the dependence of $\mathrm{O}_{3}$ production of $\mathrm{NO}_{x}$ is highly non-linear Liu et al., 1987. This means that the number of $\mathrm{O}_{3}$ molecules produced per molecule of $\mathrm{NO}_{x}$ consumed, known as the $\mathrm{O}_{3}$ production efficiency, increases as $\mathrm{NO}_{x}$ concentration decreases. As a result, the export of small fractions of emitted $\mathrm{NO}_{x}$ may lead to significant $\mathrm{O}_{3}$ production in the remote troposphere Jacob et al. 1993. The export of $\mathrm{NO}_{x}$ away from the source regions is facilitated by the export of PAN, a thermally unstable, non-water-soluble species, out of the continental BL, followed by the transport of PAN on a global scale at cold temperatures, and decomposition to $\mathrm{NO}_{x}$ as the airmasses become warmer Moxim et al., 1996. It has been suggested that, similar to PAN, the export of $\mathrm{HNO}_{3}$ followed by photolysis to $\mathrm{NO}_{x}$ can be an important source of $\mathrm{NO}_{x}$ in the troposphere $\mathrm{Neu}$ man et al. 2006. Thus, quantifying the export of nitrogen oxides and their chemical evolution is fundamental to understand the impact of anthropogenic emissions on the global $\mathrm{O}_{3}$ budget.

Previous studies, based on NARE and ICARTT aircraft measurements [e.g. Par- 
rish et al., 2004, Li et al., 2004, Hudman et al., 2007, have estimated that less than $20 \%$ of the $\mathrm{NO}_{x}$ emitted over eastern U.S. is exported to the North Atlantic free troposphere (FT) as $\mathrm{NO}_{y}$ (the sum of $\mathrm{NO}_{x}$ and its oxidation products). Further analyses on the composition of the $\mathrm{NO}_{y}$ indicate that $\mathrm{NO}_{y}$ exported in the airmasses out of the North America BL is mostly $\mathrm{HNO}_{3}(Z 50 \%)$, with $\sim 35 \%$ as PAN and less than $10 \%$ as $\mathrm{NO}_{x}$ [e.g. Parrish et al., 2004; Singh et al., 2007]. The large fraction of emitted $\mathrm{NO}_{x}$ that is removed from the plumes and the large $\mathrm{HNO}_{3} / \mathrm{NO}_{y}$ ratio imply that the potential for future $\mathrm{O}_{3}$ production in these plumes in the FT must be limited.

In addition to the field studies, several model simulations have examined the export of $\mathrm{NO}_{y}$ from North America [e.g. Horowitz et al., 1998, Liang et al., 1998]. Model simulations indicate that about $30 \%$ of the $\mathrm{NO}_{x}$ emitted in the U.S. is exported out of the U.S. boundary layer as $\mathrm{NO}_{y}$ (25\% in summer, $35 \%$ in winter) and that 60 $80 \%$ of this export is in the form of $\mathrm{NO}_{x}$ and PAN, leading to an increased importance of downwind $\mathrm{O}_{3}$ production relative to direct export of $\mathrm{O}_{3}$ produced over North America Liang et al. 1998]. Results from NARE and ICARTT apparently contradict these model analyses. Li et al. 2004 reconciled these results, suggesting that these previous model simulations underestimated $\mathrm{NO}_{y}$ scavenging during export from the North America boundary layer. In this work, Li et al. 2004 showed that the potential $\mathrm{O}_{3}$ production due to exported $\mathrm{NO}_{x}$ and PAN is comparable in magnitude to the direct export of $\mathrm{O}_{3}$ pollution from North America and that more than half of the $\mathrm{O}_{3}$ production from transported $\mathrm{NO}_{x}$ and PAN occurs over the continent or nearby downwind regions.

While net photochemical $\mathrm{O}_{3}$ production typically takes place near the source regions, observations over the North Atlantic Ocean have indicated that it can also occur during long-range transport Reeves et al., 2002; Honrath et al., 2004. However, the large-scale impacts of the long-range transport of emissions on the tropospheric $\mathrm{O}_{3}$ production over the North Atlantic region is uncertain. Simulations from two global chemical transport (GCT) models Auvray et al. 2007 and a photochemical box 
model constrained by observations Reeves et al. 2002 of the impact of U.S. outflow over the North Atlantic region indicate that the export of $\mathrm{NO}_{x}$ emissions from the U.S. lead to a perturbation of the chemistry over this region through changes in the $\mathrm{O}_{3}$ production rate. As a consequence, long-range transport events significantly affect the $\mathrm{O}_{3}$ photochemical production over the entire North Atlantic troposphere all year round Auvray et al. 2007. However, other studies indicate that the North Atlantic region is in a state of net $\mathrm{O}_{3}$ destruction all year round Klonecki and Levy, 1997, or in a state of net $\mathrm{O}_{3}$ destruction during the summer and net $\mathrm{O}_{3}$ production during the winter Yienger et al., 1999.

In addition to anthropogenic emissions, wildfires over the boreal region can also result in a substantial source of nitrogen oxides to the atmosphere during the summer seasons Goode et al., 2000; Andreae and Merlet, 2001. Recently, it has been shown that $\mathrm{NO}_{x}$ emissions from the boreal wildfires can be efficiently transported to the North Atlantic region Val Martin et al., 2006; Singh et al., 2007; Real et al., 2007. Boreal wildfire $\mathrm{NO}_{x}$ emissions may be comparable in magnitude to the total eastern North America anthropogenic $\mathrm{NO}_{x}$ emissions during the boreal fire season Val Martin et al. 2006. Observations and GCT model simulations indicate that significant photochemical $\mathrm{O}_{3}$ production occurs in the fire plumes during transport, likely as a result of decomposition of PAN to $\mathrm{NO}_{x}$ Val Martin et al., 2006; Pfister et al., 2006; Real et al. 2007. The ultimate impact of the boreal wildfire $\mathrm{NO}_{x}$ emissions on the $\mathrm{O}_{3}$ budget can be significant. For example, emissions from boreal wildfires may result in a monthly ozone production on the order of 10 to $20 \%$ of the net photochemical $\mathrm{O}_{3}$ production in the northern middle and high latitudes Val Martin et al., 2006, and may increase the $\mathrm{O}_{3}$ burden in the Northern Hemisphere by up to $4 \%$ Pfister et al., 2006. However, due to the poorly constrained current estimates of $\mathrm{NO}_{x}$ emissions and the uncertainty in the injection height of the wildfire plumes [e.g. Leung et al., 2007], questions still remain regarding the impact of boreal wildfire emissions on nitrogen oxides and ozone levels over the Northern Hemisphere. 
In the last decade, GCT models and space-based observations have provided useful information to study the fate and distribution of nitrogen oxides at regional to global scales [e.g. Richter et al., 2005, Hudman et al., 2007]. However, the evaluation of model predictions and satellite observations are severely limited by an inadequate coverage of nitrogen oxides observations in remote regions [e.g. Emmons et al., 1997; Thakur et al., 1999; Martin et al., 2004.

The data presented in this paper constitute a multi-year record of $\mathrm{NO}, \mathrm{NO}_{x}$ and $\mathrm{NO}_{y}$ in the North Atlantic lower FT made at the Pico Mountain station. These data are analyzed with two purposes: to characterize the seasonal and diurnal variation of nitrogen oxides in the background lower FT over the North Atlantic region, and to assess the degree to which transport of anthropogenic and boreal wildfire emissions affect nitrogen oxides levels and the resulting implications for the hemispheric $\mathrm{NO}_{x}$ and $\mathrm{O}_{3}$ budgets.

\subsection{Methodology}

Measurements of $\mathrm{NO}, \mathrm{NO}_{2}, \mathrm{NO}_{y}$ were made at the Pico Mountain station from July 2002 to August 2005. We present here measurements of nitrogen oxides analyzed in combination with measurements of $\mathrm{CO}$ and $\mathrm{O}_{3}$ also made at the Pico Mountain station. Because the Pico Mountain station and measurement details have already been described elsewhere Honrath et al., 2004, Kleissl et al., 2007; Owen et al., 2006; Val Martin et al., 2006, , only a brief summary of the most relevant experimental aspects is presented here.

\subsubsection{Measurement Site}

The Pico Mountain station is located on the summit of Pico mountain (2.2 km asl) in the Azores Islands, Portugal $\left(38^{\circ} \mathrm{N}, 28^{\circ} \mathrm{W}\right)$. The station is well above the regional marine boundary layer during all seasons, which is typically less than $1 \mathrm{~km}$ in height 
from May to September and $1.4 \mathrm{~km}$ from October to April Kleissl et al., 2007]. Upslope flow can bring air from lower altitudes to the station, including occasionally from the marine BL. However, upslope flow affects the Pico Mountain station much less than it does many other mountain observatories. An intensive study of the occurrence of upslope flow indicated that, from May to September, less than 25\% of the measurement time presents the meteorological conditions required for an airmass from below the mountain to reach the summit via buoyant uplifting, i.e., weak synoptic winds and strong insolation. From October to April, buoyant upslope flow is unusual, but strong synoptic winds have the potential for mechanical uplifting. This potential mechanical upslope flow has a strong seasonal cycle, which depends on stronger winds and higher marine BL heights during winter. As a result, the potential frequency of marine BL lofting to the summit is $35-60 \%$ from October to April, whereas it is less than 20\% from May to September. However, at the Pico Mountain station, impacts of mechanical and buoyant upslope flow on nitrogen oxides, $\mathrm{CO}$ and $\mathrm{O}_{3}$ are small Kleissl et al., 2007], indicating that the air sampled at the site is negligibly influenced by island pollution. For example, mean $\mathrm{NO}_{x}$ was $33 \pm 5$ pptv (mean \pm 2 -standard error of the mean) in periods with potential mechanical and/or buoyant upslope flow, whereas it was $30 \pm 1 \mathrm{pptv}$ for the non-upslope flow periods.

The Azores are situated over a region that is frequently impacted by continental emissions. They are often impacted by large-scale transport patterns in the lower FT, which can transport emissions from North America to the Azores in 5 to 7 days Owen et al. 2006. Episodically, emissions exported from the eastern U.S. in warm conveyor belts with the associated convection, followed by subsidence, impact the Azores Owen et al. 2006. In addition, the Azores are affected by outflow from high latitudes, which can carry emissions from boreal wildfires in Canada, Alaska and Siberia and carry them to the Azores 6 to 15 days later Honrath et al., 2004; Val Martin et al., 2006. 


\subsubsection{Measurements}

$\mathrm{NO}, \mathrm{NO}_{2}$, and $\mathrm{NO}_{y}$ were determined by an automated $\mathrm{NO}_{x, y}$ system, which used established techniques for high sensitivity detection: NO detection by $\mathrm{O}_{3}$ chemiluminescence Ridley and Grahek, 1990], $\mathrm{NO}_{2}$ by conversion to NO via ultraviolet photodissociation [Kley and McFarland, 1980, Parrish et al., 1990], and $\mathrm{NO}_{y}$ by $\mathrm{Au}-$ catalyzed reduction to NO in the presence of CO Bollinger et al., 1983; Fahey et al., 1985. A detailed description of the $\mathrm{NO}_{x, y}$ system including operation, sensitivities, conversion efficiencies, precision and artifacts can be found in Val Martin et al. 2006] (Chapter 3).

Measurements were recorded as 30-s averages ( $\mathrm{NO}$ and $\mathrm{NO}_{2}$ ) and 20-s averages $\left(\mathrm{NO}_{y}\right)$ every $10 \mathrm{~min}$, and further averaged to obtain the 30-min averages used in this work. The instrumental detection limit $(2-\sigma)$ of the $30-$ min averages was 6.5 to 16 pptv for $\mathrm{NO}, 13$ to 17 pptv for $\mathrm{NO}_{2}, 14$ to $21 \mathrm{pptv}$ for $\mathrm{NO}_{x}$ and 7.5 to 21 pptv for $\mathrm{NO}_{y}$ based on the artifact correction uncertainty and the precision $(2-\sigma)$ of the instrument. Ninety percent of the measurements had detection limits less than 6.5 pptv for NO, 16 pptv for $\mathrm{NO}_{2}$ and $\mathrm{NO}_{x}$, and 19 pptv for $\mathrm{NO}_{y}$. Measurement accuracy was estimated to be 5\% (July 20, 2002-July 17, 2003), 7\% (July 17, 2003-May 1, 2004) and 4\% (May 1, 2004-August 27, 2005) based on total uncertainty of the sample and calibration mass flow controllers and the NO standard calibration gas mixing ratio.

Accuracy of the $\mathrm{NO}_{y}$ measurements depends on the effective conversion of $\mathrm{NO}_{y}$ compounds and the lack of significant conversion of non- $\mathrm{NO}_{y}$ compounds Fahey et al. 1985, Kliner et al., 1997; Kondo et al., 1997, in addition to the accurate determination of the resulting NO. Based on regular calibrations and standard addition tests with $\mathrm{NO}_{2}$, i-propyl nitrate and $\mathrm{HNO}_{3}$ in ambient air, the observed $\mathrm{NO}_{y}$ included 80-100\% of the actual $\mathrm{NO}_{2}$ level (typically $>97 \%$ ), with similar values expected for PAN Fahey et al. 1985], 62-100\% of the actual $\mathrm{HNO}_{3}$ level (typically $>80 \%$ ), and $61-100 \%$ of the actual i-propyl nitrate (typically $>80 \%$ ). Due to occasional degra- 
dation of the $\mathrm{NO}_{y}$ converter, measurements of $\mathrm{NO}_{y}$ were corrected for non-unity $\mathrm{NO}_{y}$ conversion by using the $\mathrm{NO}_{2}$ conversion efficiencies measured at the system. A maximum correction of $20 \%$ was applied to a few of the measurements made before March 2003 and a maximum correction of 8\% was applied to measurements made from mid-July to mid-August 2004. No correction was made after mid-August 2004 as the $\mathrm{NO}_{2}$ conversion efficiency was constant to the expected value of $97-100 \%$. In addition, $\mathrm{NO}_{y}$ observations in March-May 2003 and May-June 2004 presented an additional uncertainty of $13 \%$ and $5 \%$ due to uncertainty in the $\mathrm{NO}_{y}$ sensitivity determination. Based on the $\mathrm{NO}_{y}$ composition estimated at the Pico Mountain station (section 2.2.3.1) and the uncertainty of $\mathrm{NO}$ determination, the total $\mathrm{NO}_{y}$ uncertainty mainly due to potentially incomplete conversion to NO, was estimated to be at worst 55\%, from March to May 2003 (less than 3\% of the total dataset). During most periods, total measured uncertainty was $\lesssim 20 \%$ at $\mathrm{NO}_{y}$ levels of 100 pptv and $\lesssim 15 \%$ at $\mathrm{NO}_{y}$ levels of 500 pptv. Interference of non- $\mathrm{NO}_{y}$ species was not a problem in this study as inferred from the very low conversion efficiencies (always less than 0.5\%; typically $0.3 \%$ ) during regular testing using standard addition of $\mathrm{CH}_{3} \mathrm{CN}$.

As discussed by Val Martin et al. [2006], unexpected spikes were sometimes observed in ambient $\mathrm{NO}_{x}$ and $\mathrm{NO}_{y}$, and were attributed to volcanic emanations. To avoid including these observations in our analysis, we used methods similar to but slightly more stringent than those used previously Val Martin et al., 2006. First, we excluded measurements made during calm winds (wind speed below $2 \mathrm{~m} \mathrm{~s}^{-1}$ ) and when wind data were not available. Two exceptions were made. The fire-impacted period of September 1-5, 2004, which did not present the typical spikes associated with volcanic emissions $\mid$ Val Martin et al., 2006 was included, although wind speeds were lower than $2 \mathrm{~m} \mathrm{~s}^{-1}$. During the periods of October-May and June 2004, wind data were scarce due to ice blockage or malfunctioning of the sensor and observations when wind data were not available were included. However, including these observations did not compromise our results as the nitrogen oxides levels in the limited 
calm wind periods during these months were not significantly different than those in the overall data. (For example, from October to May, mean $\mathrm{NO}_{x}$ was $26 \pm 2 \mathrm{pptv}$ (mean \pm 2 -standard error of the mean) in periods with wind speeds below $2 \mathrm{~m} \mathrm{~s}^{-1}$, whereas it was $28 \pm 1 \mathrm{pptv}$ for the overall period.) Second, we excluded observations that exhibited high ambient variability. For this purpose, periods with high ambient variability were defined as those when the standard deviation of the 30-s points in a 30-min period (SD) was above 8 pptv for $\mathrm{NO}$ or above $20 \mathrm{pptv}$ for $\mathrm{NO}_{2}$ and $\mathrm{NO}_{x}$, or the $\mathrm{NO}_{y} \mathrm{SD}$ exceeded $20 \mathrm{pptv}+0.5\left(\left[\mathrm{NO}_{y}\right]-50\right)$, where the second term was included to allow increased variability during periods of high $\left[\mathrm{NO}_{y}\right]$. Observations made within \pm 3 hours of the identified high variability observation were also excluded. The wind speed criterion removed about $20 \%$ of the measurements from the overall dataset, and the ambient variability screen criterion removed an additional $20 \%$ for $\mathrm{NO}_{y}$ and $34 \%$ for $\mathrm{NO}_{x}$. Finally, with the purpose of identifying additional periods with potential influence of volcanic emissions, we excluded observations made during buoyant upslope flow as described by Kleissl et al. [2007]. These periods were characterized by a strong radiation and low wind speeds, conditions in which volcanic emissions may potentially be detectable. This screening removed an additional $6 \%$ and $3 \%$ of the $\mathrm{NO}_{y}$ and $\mathrm{NO}_{x}$ measurements, respectively, mostly during the summer.

In remote regions, nighttime $\mathrm{NO}$ values are expected to be zero due to the rapid oxidation of $\mathrm{NO}$ by $\mathrm{O}_{3}$ and the expected absence of local sources Ridley et al. 1998; Peterson et al., 1998. This was true for all seasons, with the exception of summer 2004, which presented a nighttime median of 3 pptv. It was not possible to conclusively determine the reason for the generally non-zero nighttime NO levels during summer 2004. However, the weather at Pico that summer was unusual since it was dominated by high relative humidity $(\mathrm{RH})$ and calm wind periods. This may have resulted in a very small but detectable flux of NO from soil bacteria around the station. This unclear source could not be removed by any screening criteria and systematically affected the measurements during this season. These emissions 
would presumably affect $\mathrm{NO}$ during the daytime and $\mathrm{NO}_{x}$ both day and night as well. However, the interference from this source does not appear to compromise the results: if we exclude the 2004 NO summertime observations, the diurnal cycle and seasonal variation presented below do not significantly change. For example, summer daytime median NO was 7.9 pptv in 2002-2005, whereas it was 7.7 pptv excluding the summer 2004 dataset.

As will be discussed in section 2.2.1, observations of $\mathrm{NO}_{2}$ were also influenced by a small unknown source during the daytime. We could not find any consistent indication of the presence of a source in the vicinity of the station. We thus hypothesize that the excess $\mathrm{NO}_{2}$ may be due to the interference from PAN decomposition to $\mathrm{NO}_{2}$ in the sampling lines or the photolysis cell since relatively elevated temperatures were registered in the $\mathrm{NO}_{2}$ converter during the day. Using the maximum temperature registered $\left(39^{\circ} \mathrm{C}\right)$, the residence time in the photolysis lamp $(\sim 8 \mathrm{sec})$ and the typical levels of PAN estimated at the measurement site (section 2.2.3.1), we calculate that the contribution of PAN decomposition may account for about 2-4 pptv to the $\mathrm{NO}_{2}$ observations, mainly during the summer. This small interference may partially explain the additional source of $\mathrm{NO}_{2}$ detected in our observations during the summer and early fall. However, it is small and does not compromise the results presented below.

We also analyzed measurements of $\mathrm{CO}$ and $\mathrm{O}_{3}$ made from July 2002 to August 2005 and from July 2003 to August 2005, respectively. The CO and $\mathrm{O}_{3}$ instruments are described in detail elsewhere Owen et al., 2006; Honrath et al., 2004.

\subsubsection{FLEXPART and GEOS-Chem Simulations}

To investigate the sensitivity of our measurements to upwind emissions, we used the FLEXPART particle dispersion model version 6.2 Stohl, 1998; Stohl et al., 2005. FLEXPART was driven with data from the European Centre for Medium Range 
Weather Forecasts (ECMWF) ECMWF, 2005 with a $1^{\circ} \times 1^{\circ}$ horizontal resolution, 60 vertical levels and a temporal resolution of three hours, using meteorological analyses at 0000, 0600, 1200, and 1800 UTC, and ECMWF 3-hr forecasts at 0300, 0900, 1500 and 2100 UTC.

We ran FLEXPART in its backward mode to create retroplumes. Retroplumes were initiated every three hours with 4,000 particles released over a one-hour time interval into a $1^{\circ} \mathrm{x} 1^{\circ}$ grid box centered on the Pico Mountain station, over the altitude range of 2000-2500 m asl. Particles were followed backward in time for 20 days. To account for differences in air density between the release cell and upwind sources, the residence time of the particles was normalized by the air density in each cell to yield the specific volume weighted residence time (SVWRT).

To evaluate the contribution of anthropogenic emissions, anthropogenic CO tracers at the Pico Mountain station from North American, Asian and European emissions were calculated by multiplying the upwind-time-integrated SVWRT in the footprint layer (0-300 m) with emissions, using the approach of Seibert and Frank 2004. These tracers are referred as FLEXPART NA-CO, FLEXPART Asia-CO and FLEXPART Euro-CO in the remainder of this paper. Anthropogenic emissions were based on the EDGAR 3.2 Fast Track 2000 dataset Olivier and Berdowski, 2001.

A fourth CO tracer, from the boreal wildfire emissions in North America (referred as FLEXPART Fire-CO) was calculated to assess the magnitude of fire impact at the Pico Mountain station. For this purpose, SVWRT in the column 0-7500 m was multiplied with emissions distributed according to air density in the column. Boreal wildfire CO emissions were based on an inventory created by the Boreal WildlandFire Emissions Model Kasischke et al. 2005. Further details on the boreal wildfire inventory and the FLEXPART Fire-CO are presented elsewhere [Lapina al., Evidence of late-season decrease in $\mathrm{NO}_{x} / \mathrm{CO}$ emission ratios from boreal fires, manuscript in preparation, 2007 (hereinafter Lapina et al., in preparation)].

To study the influence of stratospheric transport to the measurement site, we 
ran FLEXPART in its forward mode to create a stratospheric $\mathrm{O}_{3}$ tracer. This was done by first determining the potential vorticity (PV) of each particle upon creation. Particles with a PV greater than 2.0 pvu were given a specific mass according to $\mathrm{MO}_{3}=$ Mair $\times \mathrm{PV} \times \mathrm{C}$, where Mair was the mass of air represented by a particle and $\mathrm{C}=60 \times 10^{-9} \mathrm{pvu}^{-1}$ was the ozone/PV relationship Stohl et al., 2000]. Particles were then allowed to advect through the stratosphere and into the troposphere according to the winds. At any one time, approximately 4 million particles were present in the model for the stratospheric tracer runs. Particles were carried in the model for 20 days before being removed. This tracer is referred here as FLEXPART Strat- $\mathrm{O}_{3}$.

Simulations from the global chemical transport model GEOS-Chem were also used to further analyze the nitrogen oxides observations. GEOS-Chem version 7.01 was driven by 3-hourly assimilated meteorological fields from the Goddard Earth Observing System of NASA Bey et al., 2001. The spatial resolution of the model was $2^{\circ}$ latitude by $2.5^{\circ}$ longitude with 26 levels between the surface to $0.1 \mathrm{hPa}$. Global anthropogenic emissions were determined following the procedure described by Bey et al. 2001]. Over the continental U.S. and Europe, the anthropogenic emissions were based on the U.S. EPA NEI-97 EPA, 1997 and the European Monitoring and Evaluation Program for European countries EMEP, 1997]. Biomass burning emissions were obtained from Duncan et al. 2003 with monthly mean estimates relocated using Moderate-resolution Imaging Spectroradiometer fire counts. More information

on these emissions and additional sources (e.g., lightning, stratospheric injection) is presented elsewhere Bey et al., 2001.

\subsection{Results and Discussion}

Figure 2.1 presents an overview of the nitrogen oxides measurements at the Pico Mountain site from July 2002 to August 2005. All 30-min averages of daytime NO, 
$\mathrm{NO}_{x}$ and $\mathrm{NO}_{y}$ are shown as time series, and bar plots represent the distribution of the data by season and year.

Significant variability is apparent in the data at all times of the year. A large number of factors contribute to the magnitude and the changes of the nitrogen oxides levels. In this section, five aspects of the data are analyzed: diurnal cycle, seasonal variation, partitioning of $\mathrm{NO}_{y}$, impacts of anthropogenic pollution and influence of boreal wildfire emissions. These aspects are not entirely independent but provide a structure for the discussion.

\subsubsection{Diurnal Cycles}

Diurnal cycles of nitrogen oxides can be caused by photochemical, transport and emission processes whose strength vary between day and night. Table 2.1 summarizes the statistical parameters of the diurnal cycles of $\mathrm{NO},[\mathrm{NO}] /\left[\mathrm{NO}_{2}\right], \mathrm{NO}_{2}$ and $\mathrm{NO}_{y}$ for each season. As an example, Figure 2.2 displays the diurnal variation for the springtime measurements. (Similar variation was present in the other seasons.) For the $[\mathrm{NO}] /\left[\mathrm{NO}_{2}\right]$ analysis, values that deviated from the mean by more than three times of the standard deviation were removed. This was done because $\mathrm{NO}_{2}$ and $\mathrm{NO}$ measurements are related as the calculation of $\mathrm{NO}_{2}$ includes the $\mathrm{NO}$ mixing ratio. Hence, rare outliers in the $\mathrm{NO}$ measurements may result in $\mathrm{NO}_{2}$ outliers, which

produces unrealistic $[\mathrm{NO}] /\left[\mathrm{NO}_{2}\right]$ values that may significantly affect the mean Yang et al. 2002.

To test for the existence of a consistent diurnal variation, we examined both the median and the mean of the data in the nighttime and daytime subsets. Nighttime values were observations made between 23:00 and 5:00 UTC; daytime values were those made when the solar zenith angle was below $62^{\circ}$. These cutoffs were chosen to allow significant number of data points in both subsets while ensuring daylight and nighttime conditions in all seasons. As expected, Table 2.1 indicates that robust 

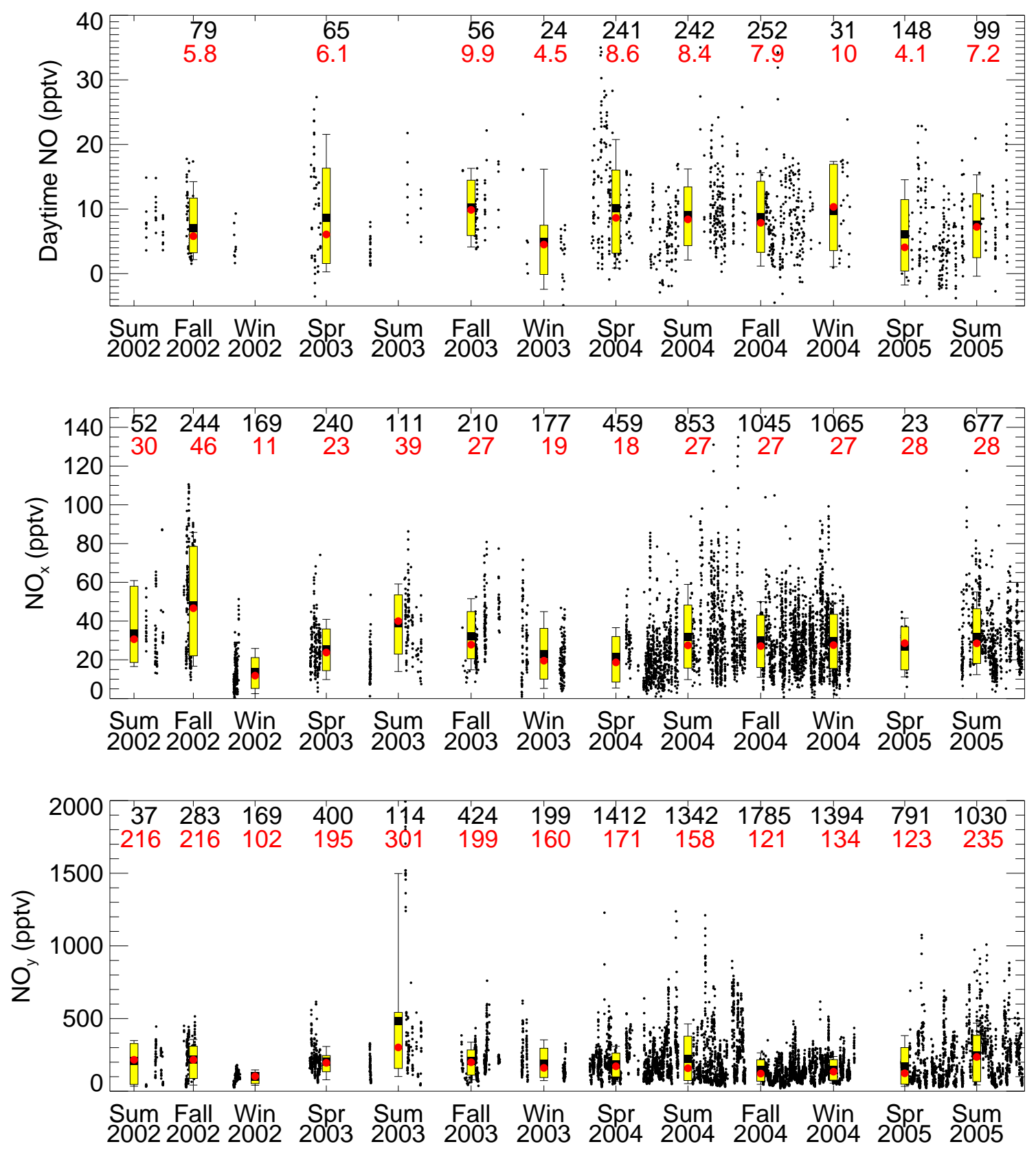

Figure 2.1 Time series of daytime $\mathrm{NO}$ (top), $\mathrm{NO}_{x}$ (middle) and $\mathrm{NO}_{y}$ (bottom) from July 20, 2002 to August 25, 2005 at the Pico Mountain station. Daytime NO are observations when the solar zenith angle was below $62^{\circ}$ (see text for explanation). Each data point represents a 30-min average. Bar plots indicate the distribution of the data for each season and year. The medians (red circles) and the means (black squares) are shown along with the central $67 \%$ (yellow box) and the central $95 \%$ (thin black lines). The number of 30 -min average measurements (in black) and the median (in red) included in each distribution are given above the plot for each bar. Distributions with fewer than 20 data points are not shown. 
Table 2.1 Statistical parameters of the nitrogen oxides diurnal cycle. Reported average, standard deviation (SD), median and number (N) of the 30-min average observations in pptv for $\mathrm{NO}, \mathrm{NO}_{2}$ and $\mathrm{NO}_{y}$.

\begin{tabular}{|c|c|c|c|c|c|c|c|c|c|}
\hline \multirow[b]{2}{*}{ Season } & \multirow[b]{2}{*}{ Data } & \multicolumn{3}{|c|}{ Daytime ${ }^{a}$} & \multicolumn{3}{|c|}{ Nighttime $^{a}$} & \multicolumn{2}{|c|}{ Amplitude ${ }^{b}$} \\
\hline & & Mean \pm SD & Median & $\mathrm{N}$ & Mean \pm SD & Median & $\mathrm{N}$ & $\Delta$ mean & $\Delta$ median \\
\hline \multirow[t]{4}{*}{ Spring ${ }^{c}$} & $\mathrm{NO}$ & $9 \pm 8$ & 7 & 448 & $1 \pm 3$ & 1 & 886 & $8 \pm 2$ & 7 \\
\hline & $\mathrm{NO} / \mathrm{NO}_{2}$ & $0.4 \pm 0.5$ & 0.3 & 81 & $0.1 \pm 0.4$ & 0.0 & 274 & $0.3 \pm 0.3$ & 0.3 \\
\hline & $\mathrm{NO}_{2}$ & $20 \pm 11$ & 20 & 135 & $19 \pm 12$ & 18 & 307 & $1 \pm 5$ & 2 \\
\hline & $\mathrm{NO}_{y}$ & $184 \pm 123$ & 178 & 702 & $184 \pm 111$ & 166 & 905 & $-1 \pm 24$ & 12 \\
\hline \multirow[t]{4}{*}{ Summer ${ }^{c}$} & $\mathrm{NO}$ & $9 \pm 5$ & 8 & 350 & $2 \pm 4$ & 2 & 918 & $6 \pm 1$ & 6 \\
\hline & $\mathrm{NO} / \mathrm{NO}_{2}$ & $0.4 \pm 0.3$ & 0.3 & 221 & $0.1 \pm 0.3$ & 0.0 & 614 & $0.3 \pm 0.1$ & 0.3 \\
\hline & $\mathrm{NO}_{2}$ & $25 \pm 13$ & 22 & 279 & $28 \pm 15$ & 24 & 695 & $-3 \pm 4$ & -3 \\
\hline & $\mathrm{NO}_{y}$ & $221 \pm 181$ & 163 & 536 & $248 \pm 208$ & 204 & 1098 & $-27 \pm 40$ & -41 \\
\hline \multirow[t]{4}{*}{ Fall $^{c}$} & $\mathrm{NO}$ & $9 \pm 5$ & 8 & 371 & $1 \pm 3$ & 0 & 652 & $8 \pm 1$ & 7 \\
\hline & $\mathrm{NO} / \mathrm{NO}_{2}$ & $0.3 \pm 0.2$ & 0.3 & 244 & $0.0 \pm 0.1$ & 0.0 & 392 & $0.3 \pm 0.1$ & 0.3 \\
\hline & $\mathrm{NO}_{2}$ & $28 \pm 16$ & 24 & 276 & $30 \pm 16$ & 26 & 430 & $-1 \pm 5$ & -2 \\
\hline & $\mathrm{NO}_{y}$ & $161 \pm 102$ & 142 & 506 & $164 \pm 108$ & 136 & 733 & $-3 \pm 24$ & 6 \\
\hline \multirow[t]{4}{*}{ Winter $^{c}$} & NO & $7 \pm 6$ & 5 & 64 & $0 \pm 2$ & 0 & 561 & $7 \pm 3$ & 5 \\
\hline & $\mathrm{NO} / \mathrm{NO}_{2}$ & $0.4 \pm 0.3$ & 0.4 & 40 & $0.0 \pm 0.2$ & 0.0 & 440 & $0.4 \pm 0.2$ & 0.4 \\
\hline & $\mathrm{NO}_{2}$ & $24 \pm 13$ & 24 & 50 & $25 \pm 16$ & 23 & 455 & $-1 \pm 8$ & 1 \\
\hline & $\mathrm{NO}_{y}$ & $156 \pm 79$ & 145 & 76 & $152 \pm 88$ & 128 & 511 & $4 \pm 39$ & 17 \\
\hline
\end{tabular}

${ }^{a}$ Daytime are observations when the solar zenith angle was $<62^{\circ}$; Nighttime are observations made between 23:00-5:00 UTC.

${ }^{b}$ Amplitude is expressed as the difference between the means $(\Delta$ mean $)$ and the medians $(\Delta$ median) of daytime and nighttime. Uncertainty $(2-\sigma)$ is based on propagation of errors.

${ }^{c}$ Seasons are: spring (March, April, May), summer (June, July, August), fall (September, October, November) and winter (December, January, February). 

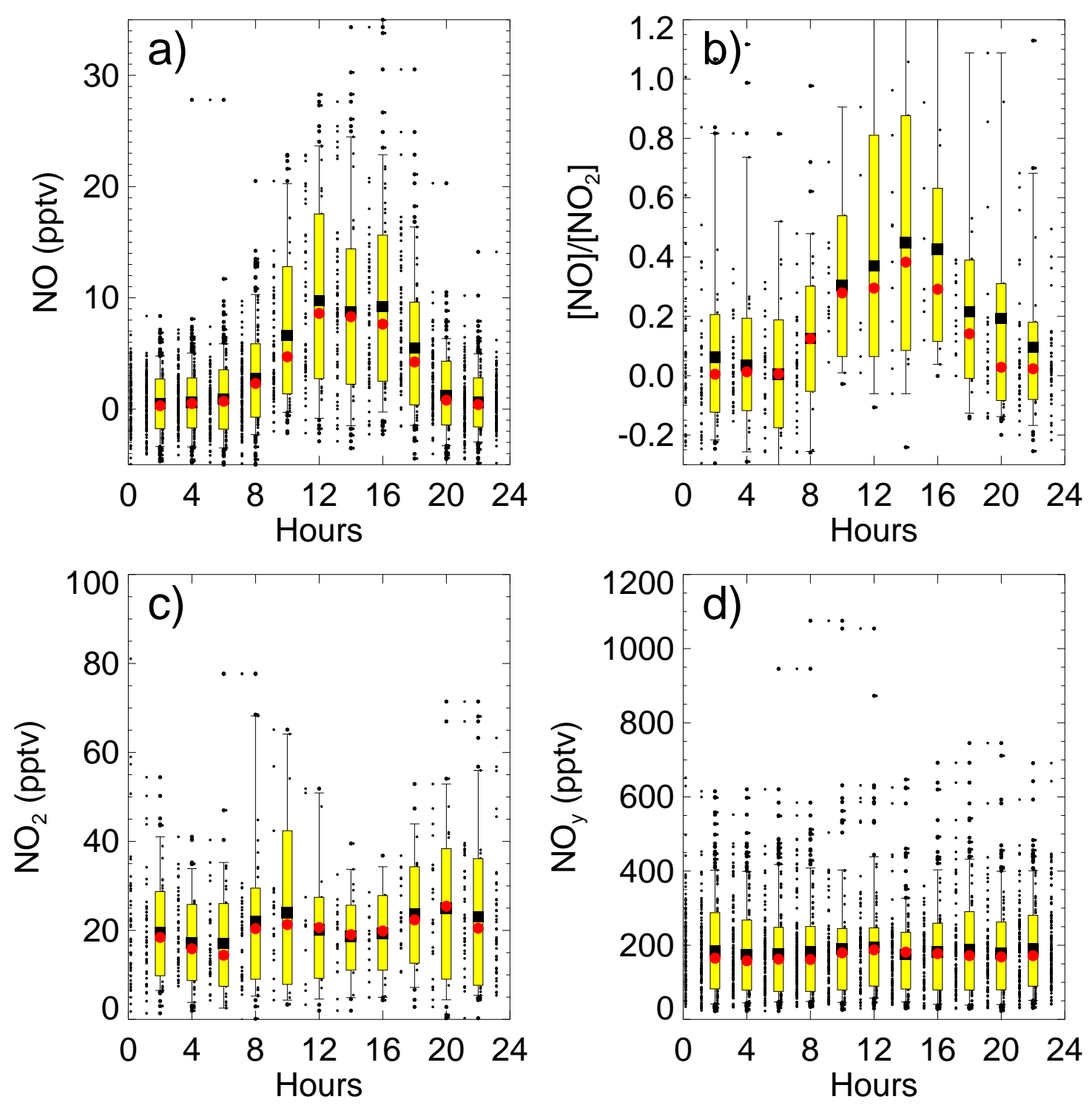

Figure 2.2 Springtime diurnal cycles of (a) $\mathrm{NO}$, (b) $[\mathrm{NO}] /\left[\mathrm{NO}_{2}\right]$, (c) $\mathrm{NO}_{2}$ and (d) $\mathrm{NO}_{y}$. All 30-min average data are plotted centered in each hour, with the exception of [NO]/[NO $\left.\mathrm{NO}_{2}\right]$ (see text for explanation). Few data points outside the plot boundaries are not shown to make the cycle more apparent ( 25 for $\mathrm{NO}$ and $\mathrm{NO} / \mathrm{NO}_{2}, 8$ for $\mathrm{NO}_{2}$ and 1 for $\mathrm{NO}_{y}$ ). Symbols and error bars are the same as in Figure 2.1 . 
diurnal cycles exist for $\mathrm{NO}$ and $[\mathrm{NO}] /\left[\mathrm{NO}_{2}\right]$ ratios in all seasons, with median diurnal amplitudes of 5-7 pptv and $0.3-0.4$, respectively. The phase of these cycles is consistent with photochemical causes: the maximum occurs around the time of maximum insolation, during the local solar noon time (14:00 UTC for spring; Figure 2.2), indicating a dominance of production of $\mathrm{NO}$ from photolysis of $\mathrm{NO}_{2}$, whereas the minimum occurs at nighttime, indicating dominance of NO destruction by reaction with $\mathrm{O}_{3}$.

Given the observed NO cycle amplitude, a negative amplitude of similar magnitude should be present in the $\mathrm{NO}_{2}$ cycle as $\mathrm{NO}_{2}$ is photolyzed to $\mathrm{NO}$ during daytime. Figure 2.2. and Table 2.1 indicate that a very weak negative diurnal variation or no variation was present for $\mathrm{NO}_{2}$, with median diurnal amplitudes of -3 to 1 pptv. This small negative or non-existent amplitude suggests the presence of a small source of $\mathrm{NO}_{2}$ during daytime. As discussed in section 2.1, this may be partially the result of interference of PAN decomposition in the photolysis cell, mainly during summer and early fall.

Consistent with our expectation that diurnal varying upslope flow does not affect the measurements Kleissl et al., 2007, Figure $2.2 \mathrm{~d}$ and Table 2.1 show that no significant diurnal variation was present for $\mathrm{NO}_{y}$, with the exception of the summer, which exhibited a negative median amplitude of $-41 \mathrm{pptv}$. This may be due to the strong removal nature of summertime $\mathrm{NO}_{y}$, which is composed primarily by $\mathrm{HNO}_{3}$ (section 2.2.3.1). Summertime RH measurements at the Pico Mountain station indicate that the percentage of $\mathrm{NO}_{y}$ observations made in the presence of clouds $(\mathrm{RH}$ above $96 \%$, section 2.2.3.1 was larger during the daytime (24\%) than at nighttime $(16 \%)$, which may result in a stronger wet removal of $\mathrm{HNO}_{3}$ during the day.

Comparisons of the diurnal variation observed at the Pico Mountain station to those observed at other remote marine FT stations are not straightforward. As opposed to the Pico Mountain station, ground-based mountaintop stations (e.g., Mauna Loa Observatory (MLO) over the North Pacific Ocean and Izaña over the eastern At- 
lantic Ocean) are typically characterized by a diurnal downslope-upslope flow regime Ridley et al., 1998; Fischer et al., 2004. However, spring diurnal amplitudes of $\sim 8$ pptv for $\mathrm{NO}$ and $\sim 0.4$ for $\mathrm{NO} / \mathrm{NO}_{2}$ were observed at MLO during a rare event in which free tropospheric air was sampled all day Ridley et al., 1998, similar to the spring amplitude observed at the Pico Mountain station for NO ( $8 \pm 2 \mathrm{pptv})$ and for $[\mathrm{NO}] /\left[\mathrm{NO}_{2}\right](0.3 \pm 0.3)$.

\subsubsection{Seasonal Variation}

Figures $2.3 \mathrm{a}$-c present the annual cycle of nitrogen oxides at the Pico Mountain site. $\mathrm{NO}_{y}$ measurements were influenced by washout processing, as indicated by the lower $\mathrm{NO}_{y}$ values in higher $\mathrm{RH}$ conditions shown in Figure 2.4 for fall. (Similar behavior was

found in the other seasons.) To avoid a potential bias in the seasonal variation due to washout, Figure 2.3. shows the seasonal cycle of $\mathrm{NO}_{y}$ determined in dry conditions (RH below 60\%). In Figure 2.3d, the annual cycle of CO is also shown for comparison. The distribution of all measurements is displayed by monthly periods independently of the year of study. Additionally the monthly median for years with more than 20 observations is also identified by the numerals next to the bars. The statistics of all observations are further summarized in Table 2.2 .

It is clear from Figures $2.3 \mathrm{a}$ - $\mathrm{d}$ that there is a large interannual variability in the $\mathrm{CO}$ and nitrogen oxides monthly medians within some months. Large variability of $\mathrm{CO}$ at hemispheric scales is known to occur, and has mainly been associated with variations in biomass burning emissions [e.g., Novelli et al., 2003; Edwards et al., 2004; Honrath et al., 2004]. Although interannual variability is apparent for the nitrogen oxides, we find that in some cases this variability may also be due to the limited number of observations available and the fact that the measurements are variable within each month, i.e., events. For example, $\mathrm{NO}_{x}$ in October 2002 was significantly higher (47 \pm 3 pptv; mean \pm 2 -standard error of the mean) than in 2003 (28 \pm 1 pptv) 

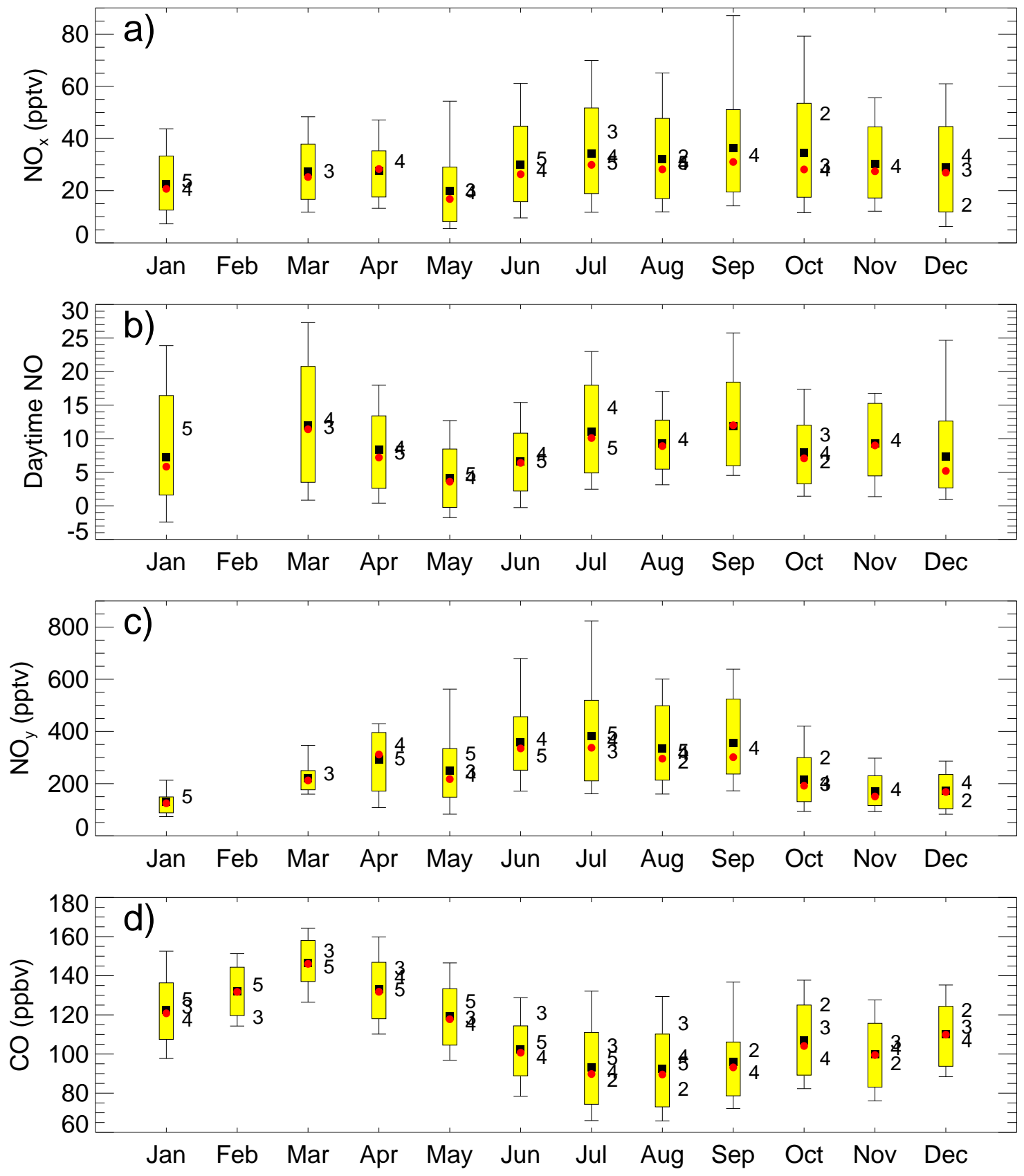

Figure 2.3 Seasonal cycle of (a) $\mathrm{NO}_{x}$, (b) daytime $\mathrm{NO}$, and (c) $\mathrm{NO}_{y}$ in dry conditions (see text for explanation) and (d) CO. Bar plots indicate the distribution of the data for each month. Symbols and error bars are the same as in Figure 2.1. Months with fewer than 20 data points are not shown. The median for each month and year are plotted by numerals to the right of the bar plots (2: year 2002, 3: year 2003, 4: year 2004 and 5: year 2005). Medians with fewer than 20 data points are not shown. 

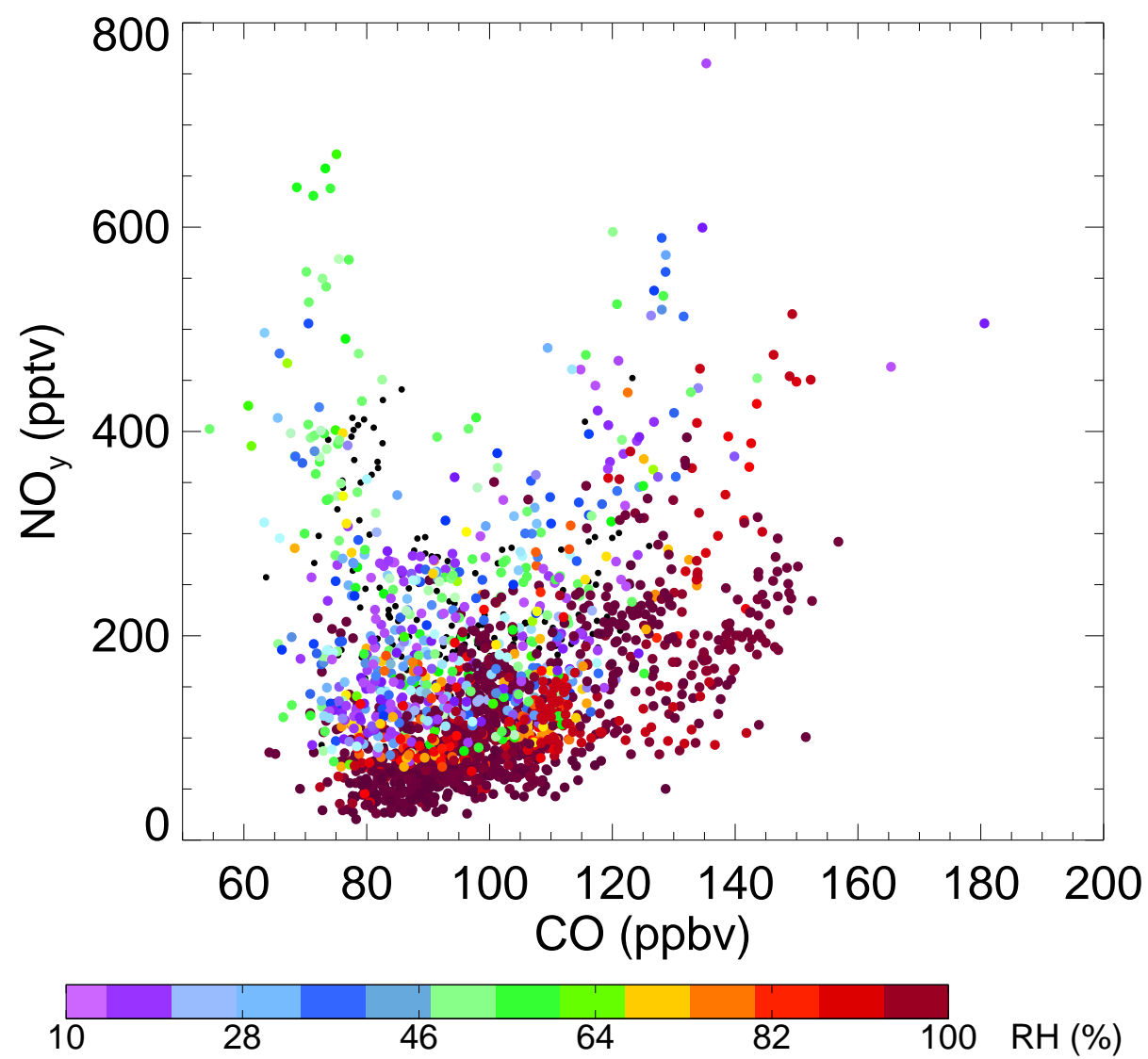

Figure 2.4 Relationship between $\mathrm{NO}_{y}$ and $\mathrm{CO}$ during fall. Dots represent simultaneous 30-min averages. Where data are available, the dots are color-coded according to simultaneous 30-min averages of $\mathrm{RH}$ as indicated in the color bar. 


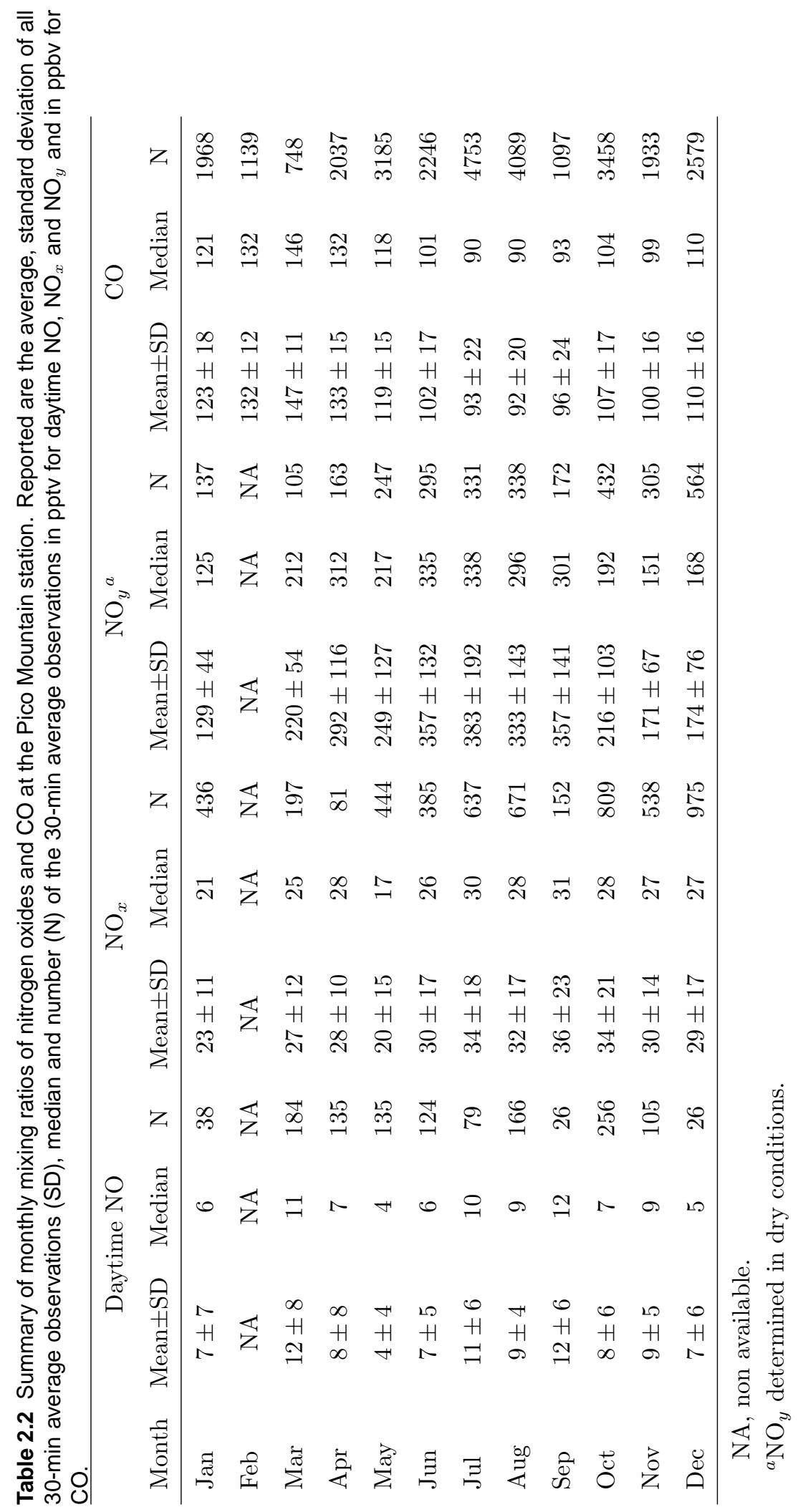


and 2004 (31 \pm 3 pptv) because $\mathrm{NO}_{x}$ observations were only available for about 10 days in 2002, which happened to coincide with North American outflow.

Figure $2.3 \mathrm{~d}$ shows a sharp seasonal cycle for CO, with a minimum median of 90 ppbv in July-August and a maximum median of 146 ppbv in March. CO is oxidized by $\mathrm{OH}$. Thus, annual variation of $\mathrm{CO}$ is driven to a large extent to the annual change in $\mathrm{OH}$, which is closely related to the water vapor and the solar intensity cycle Novelli et al., 1992. In addition to photochemical processes, seasonal variation in synoptic flow patterns, and the associated changes in source regions and transport times to the measurement site can also affect the background levels of CO. Based on a clustering analysis of backward trajectories to the Pico Mountain station [Strane et al., Major source regions to the Pico Mountain station: Transport, chemical observations, and interannual variability, manuscript in preparation], more frequent transport from the Atlantic basin and longer transit times from the North American continent in summer may also explain the lower observed summertime CO. This effect was also noted for the non-methane hydrocarbons (NMHC) sampled at the Pico Mountain station [Helmig et al., Analysis of transport and oxidation chemistry in the North Atlantic region from interpretations of NMHC measurements at Pico Mountain, Azores, submitted to J. Geophys. Res., 2007 (hereinafter Helmig et al., submitted)].

In contrast to $\mathrm{CO}$, the seasonal variation of nitrogen oxides is more complex. The variation of nitrogen oxides in the troposphere remote from sources of $\mathrm{NO}_{x}$ depends largely on the partitioning of $\mathrm{NO}_{y}$ Atlas et al., 1992, Ridley et al., 1998, which in turn, is controlled to a larger extent by the rate of loss of the reservoir species and by the recycling of $\mathrm{NO}_{x}$ from these reservoirs. Moreover, since the loss processes differ among compounds, each process may result in a different effect on $\mathrm{NO}_{y}$. For example, thermal decomposition of PAN regenerates $\mathrm{NO}_{2}$, which changes the partitioning of $\mathrm{NO}_{y}$ but not the total $\mathrm{NO}_{y}$, whereas wet and dry deposition of $\mathrm{HNO}_{3}$ results in a change in total $\mathrm{NO}_{y}$ as nitrogen is removed from the atmosphere.

Figure 2.3 a shows that $\mathrm{NO}_{x}$ observations exhibited a distinct seasonal cycle, with 
the overall variability at all percentiles larger from July to October than in the other months. However, monthly medians did not reveal a distinct pattern. Similar monthly medians were present all year round (17-31 pptv). (To avoid the possible interference from additional daytime $\mathrm{NO}_{2}$ (section 2.2.1), we also compared nighttime $\mathrm{NO}_{x}$ medians and found similar results: $16-28 \mathrm{pptv})$. Because the lifetime of $\mathrm{NO}_{x}$ in the lower FT (on the order of $\lesssim 1$ day [Liu et al. 1987 ) is shorter than the transit time from $\mathrm{NO}_{x}$ source regions to the measurement site, it is clear that in-situ sources of $\mathrm{NO}_{x}$ are required to provide these $\mathrm{NO}_{x}$ levels all year round. This implies that PAN decomposition and potentially photolysis of $\mathrm{HNO}_{3}$ in the airmasses that reach the Pico Mountain station provides a supply of $\mathrm{NO}_{x}$ to the lower FT in this region, in particular during summer seasons.

Due to the rapidly increasing solar insolation and decreasing $\mathrm{O}_{3}$ concentrations from spring to fall, one may expect a shift of $\mathrm{NO}_{x}$ partition toward $\mathrm{NO}$ as photolysis of $\mathrm{NO}_{2}$ increases and the rate of the reaction of $\mathrm{NO}$ with $\mathrm{O}_{3}$ decreases. In our observations, the actual situation was somewhat different. Figure 2.3b shows that daytime NO mixing ratios presented a small broad peak from July to September, with medians of 9-12 pptv. The increase in NO during these months is consistent with the increase in solar radiation and generally lower $\mathrm{O}_{3}$ concentrations observed at the Pico Mountain station (not shown). However, a peak was also present in March, with a median of 11 pptv. Although not fully understood, this behavior may be the result of a slower rate of reaction of NO with peroxy radicals, which may be present in low concentrations during this month due to a reduced availability of $\mathrm{OH}$.

As shown in Figure 2.3. $\mathrm{NO}_{y}$ observations exhibited a well-defined seasonal cycle, with larger values in June-September (medians 296-338 pptv) than in October-May (medians 125-312 pptv). There are several causes that may be responsible for this behavior.

First, synoptic-scale changes in the lofting mechanisms over the continents may result in seasonal changes in the export of emissions. Parrish et al. 2004 proposed 
that shallow venting of the continental BL to the lower FT, driven by surface heating and associated with fair weather cumulus breaking through the afternoon BL, may provide an important lofting mechanism for anthropogenic emissions over the eastern U.S. This mechanism, which is expected to be most frequent in summer, results in a significant export of nitrogen oxides to the North Atlantic region [e.g. Parrish et al., 2004 Li et al. 2004; Hudman et al., 2007, and is likely to contribute to the larger summertime levels of $\mathrm{NO}_{y}$ observed at the Pico Mountain station.

Second, boreal wildfires have been recently recognized to be a significant source of nitrogen oxides to the North Atlantic troposphere Val Martin et al., 2006; Singh et al. 2007. $\mathrm{NO}_{y}$ means from July to September - typically the boreal fire seasonexceeded the medians by $13-18 \%$, showing extreme excursions from the median in the positive direction. As will be shown in section 2.3.2, the higher variability of $\mathrm{NO}_{y}$ in these months reflects the high but varying influence of boreal wildfire emissions. Thus, summertime wildfire emissions result in higher levels of $\mathrm{NO}_{y}$.

Finally, variation in the input from stratospheric or upper tropospheric sources could also contribute to changes in nitrogen oxides. $\mathrm{NO}_{x}$ production by lightning varies seasonally, with the maximum production occurring in the Northern Hemisphere during summer Nesbitt et al. 2000. Stratospheric injection is found to be more important during springtime [e.g. Parrish and Fehsenfeld, 2000, Merrill and Moody, 1996, although injections are also frequent in summer Thompson et al., 2007]. To assess the impact of stratospheric and upper tropospheric transport to the Pico Mountain station, we used FLEXPART Strat- $\mathrm{O}_{3}$ values from July 2002 to August 2005. This analysis indicated that stratospheric $\mathrm{O}_{3}$ occasionally impacts the measurement site, but the overall impact is rather small: the average \pm 2 -standard deviation of all FLEXPART Strat- $\mathrm{O}_{3}$ values was $7 \pm 9$ ppbv, without significant variation on a seasonal basis. On an event basis, we did not find any consistent correlation between nitrogen oxides levels and FLEXPART Strat- $\mathrm{O}_{3}$, i.e., enhancements of $\mathrm{NO}_{y}$ were not correlated with increases in the FLEXPART Strat-O $\mathrm{O}_{3}$ values. We thus con- 
clude that stratospheric air did not significantly contribute to the changes in the nitrogen oxides observed at the Pico Mountain station.

Table 2.3 compares the mixing ratios of nitrogen oxides at the Pico Mountain station with observations from previous aircraft studies in the North Atlantic troposphere and from two ground-based stations, MLO over the North Pacific Ocean and Jungfraujoch (JFJ) station over central Europe. Values are compiled by seasons. The majority of these studies were made during the summer season. Thus, we focus here on summertime observations, unless indicated otherwise.

It is evident that nitrogen oxides levels at the Pico Mountain station (median 322 pptv for $\mathrm{NO}_{y}$ and 29 pptv for $\mathrm{NO}_{x}$; Table 2.3 rows 2 and 12) are lower than those observed at other studies over the western North Atlantic at 0.5-6 km altitudes (652-1000 pptv for $\mathrm{NO}_{y}$ and 40-55 pptv for $\mathrm{NO}_{x}$; Table 2.3 rows 5-7 and 15-17). Lower $\mathrm{NO}_{y}$ and $\mathrm{NO}_{x}$ at the Pico Mountain station indicate that removal of $\mathrm{NO}_{y}$ and rapid oxidation of $\mathrm{NO}_{x}$ in the airmasses may occur as a result of longer transport times over the ocean. In addition, lower $\mathrm{NO}_{y}$ and $\mathrm{NO}_{x}$ levels may also indicate a smaller influence of stratospheric and upper tropospheric transport. $\mathrm{NO}_{x}$ and $\mathrm{NO}_{y}$ typically exhibit a C-shaped profile near source regions with high concentrations near the surface decreasing through the FT and then with a sharp rise at altitudes generally above $6 \mathrm{~km}[$ e.g. Singh et al. 2007]. This is the result of the combination of atmospheric oxidation with the location of the emissions (BL and upper troposphere) and convection.

Nitrogen oxides levels observed at MLO (median 168-374 pptv for $\mathrm{NO}_{y}$ and 2536 pptv for $\mathrm{NO}_{x}$; Table 2.3 rows 3 and 13) were similar to those observed at the Pico Mountain station (147-322 pptv for $\mathrm{NO}_{y}$ and 21-29 pptv for $\mathrm{NO}_{x}$ ) all year round. Similar to the Pico Mountain station, MLO is a remote marine observatory, in which well-aged airmasses are sampled during downslope conditions Ridley et al., 1998. Thus, observed levels at MLO also reflect the strong removal of $\mathrm{NO}_{y}$ and rapid oxidation of $\mathrm{NO}_{x}$ in the airmasses during transport. In contrast, larger $\mathrm{NO}_{x}$ and 


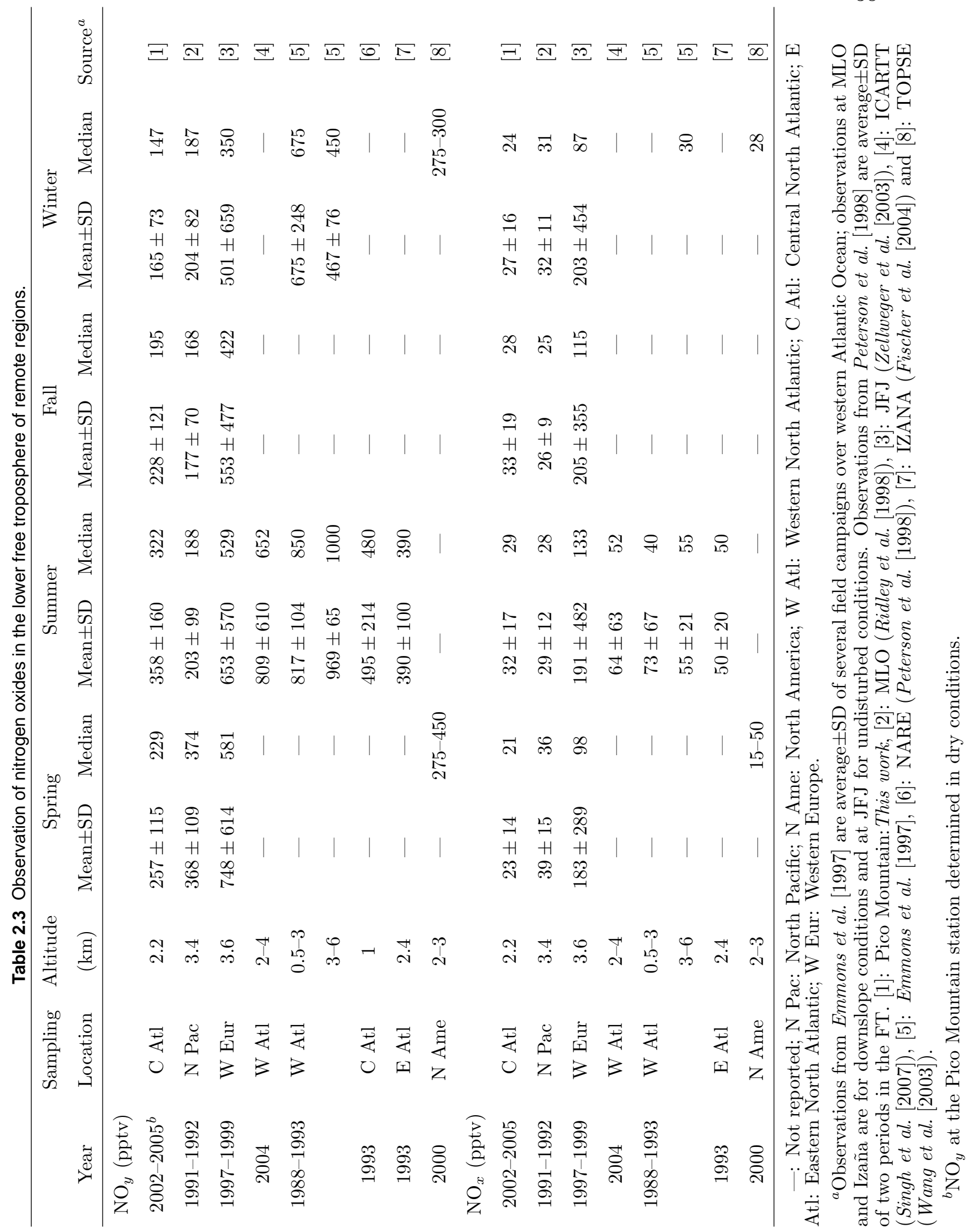


$\mathrm{NO}_{y}$ medians present at the continental JFJ observatory (350-581 pptv for $\mathrm{NO}_{y}$ and 87-133 pptv for $\mathrm{NO}_{x}$; Table 2.3 rows 4 and 14) suggest the input of relatively fresh $\mathrm{NO}_{x}$ emissions from the continental BL Zellweger et al., 2003.

\subsubsection{Average Partitioning of $\mathrm{NO}_{y}$}

To better understand the changes on the nitrogen oxides over the central North Atlantic lower FT, we examined the partitioning of $\mathrm{NO}_{y}$ into its three principal components: $\mathrm{NO}_{x}, \mathrm{HNO}_{3}$ and PAN.

\subsubsection{Estimation of $\mathrm{NO}_{y}$ Partition}

We used $\mathrm{NO}_{x}, \mathrm{NO}_{y}$ and $\mathrm{RH}$ measured at the Pico Mountain station on a regular basis to determine the partitioning of $\mathrm{NO}_{y}$. Several studies have demonstrated the rapid and efficient scavenging of nitric acid within clouds [e.g. Chameides, 1984; Peterson et al., 1998; Garrett et al., 2006]. For example, Chameides [1984] showed that $\mathrm{HNO}_{3}$ levels decreased by two orders of magnitude in less than $100 \mathrm{~s}$ after marine cloud formation. Consistent with those studies, $\mathrm{NO}_{y}$ measurements at the Pico Mountain station were affected by the presence of clouds (section 2.2.2). Thus, measurements of $\mathrm{NO}_{y}$ levels during in- and out-of-cloud periods can be used to estimate the mixing ratio of cloud-scavenged $\mathrm{NO}_{y}$ species, i.e., $\mathrm{HNO}_{3}$, by assuming that $\mathrm{HNO}_{3}$ is scavenged into clouds droplets during in-cloud periods Peterson et al., 1998. (Even for the smallest observed orographic clouds ( 1500 m radius) and typical higher wind speeds $\left(\sim 12 \mathrm{~m} \mathrm{~s}^{-1} ; 95\right.$ th percentile of wind speed observations when $\mathrm{NO}_{y}$ was available), there was enough time $(\sim 125 \mathrm{~s})$ for $\mathrm{HNO}_{3}$ to be scavenged into the cloud droplets before air reached the measurement site.) For this purpose, we subdivided the observations into periods above $96 \% \mathrm{RH}$ and below $60 \% \mathrm{RH}$ in order to identify in- and out-of-cloud intervals at the site, respectively. The RH cutoffs were selected so as both subsets contained similar numbers of data points and, at 
the same time, cloud and cloud-free periods were present at the measurement site. Archived photos of the conditions at the station confirmed cloud and cloud-free periods under those cutoffs. Monthly $\mathrm{HNO}_{3}{ }^{*}$ values were determined by subtracting the monthly averages of $\mathrm{NO}_{y}$ observed during "in-cloud" periods from those observed during "out-of-cloud" periods; $\left[\mathrm{PAN}^{*}\right]$ was determined by subtracting $\mathrm{NO}_{x}$ from $\mathrm{NO}_{y}$ in simultaneous observations during "in-cloud" periods, and $\left[\mathrm{NO}_{x}\right]$ and $\left[\mathrm{NO}_{y}\right]$ were determined using direct observations made during "out-of-cloud" periods. (The terms $\mathrm{HNO}_{3} *$ and $\mathrm{PAN}^{*}$ are used here to indicate estimated, not directly measured values of these species.) Table 2.4 summarizes the $\mathrm{NO}_{y}$ levels during "in-cloud" and "outof-cloud" periods, and the derived fraction of reactive nitrogen species on a seasonal basis, i.e., $\left[\mathrm{HNO}_{3}^{*}\right] /\left[\mathrm{NO}_{y}\right],\left[\mathrm{PAN}^{*}\right] /\left[\mathrm{NO}_{y}\right]$ and $\left[\mathrm{NO}_{x}\right] /\left[\mathrm{NO}_{y}\right]$. Figure 2.5 a shows the monthly variation of the $\left[\mathrm{HNO}_{3} *\right] /\left[\mathrm{NO}_{y}\right],\left[\mathrm{PAN}^{*}\right] /\left[\mathrm{NO}_{y}\right]$ and $\left[\mathrm{NO}_{x}\right] /\left[\mathrm{NO}_{y}\right]$. A limited number of more direct estimates of $\left[\mathrm{HNO}_{3}{ }^{*}\right]$ were also made, using alternated measurements of $\left[\mathrm{NO}_{y}\right]-\left[\mathrm{HNO}_{3}\right]$ and $\mathrm{NO}_{y}$. Measurements of $\left[\mathrm{NO}_{y}\right]-\left[\mathrm{HNO}_{3}\right]$ were made in August 2004 and 2005 by removing $\mathrm{HNO}_{3}$ from $\mathrm{NO}_{y}$ before sampling using a nylon filter attached to the $\mathrm{NO}_{y}$ inlet [e.g. Parrish et al., 1986; Yamamoto et al., 2001. $\left[\mathrm{HNO}_{3}\right]$ was determined by difference from $\mathrm{NO}_{y} ;[\mathrm{PAN} *]$ was determined as $\left(\left[\mathrm{NO}_{y}\right]-\right.$ $\left.\left[\mathrm{HNO}_{3}\right]\right)$ minus $\left[\mathrm{NO}_{x}\right]$. Results from these tests are also presented in Table 2.4. These measurements provide an additional method to test the consistency of our approach. The fraction of reactive nitrogen species estimated directly from these tests (53-62\% $\mathrm{HNO}_{3}, 23-34 \% \mathrm{PAN}^{*}$ and $9-16 \% \mathrm{NO}_{x}$ ) is similar to that deduced for the summer $\left(71 \pm 9 \% \mathrm{HNO}_{3}^{*}, 21 \pm 8 \% \mathrm{PAN}^{*}\right.$ and $\left.12 \pm 8 \% \mathrm{NO}_{x}\right)$.

To confirm that the changes in $\mathrm{RH}$ used in this analysis were independent of the origin and the chemical history on the airmasses, we inspected the variation of $\mathrm{CO}$ in the "in-cloud" and "out-of-cloud" periods when $\mathrm{NO}_{y}$ measurements were available. As shown in Figure 2.5b, CO did not exhibit a clear relationship with RH, i.e., monthly CO averages were variable all year round, independent of "in-cloud" and "out-of-cloud" conditions. However, significant larger monthly CO means for the 


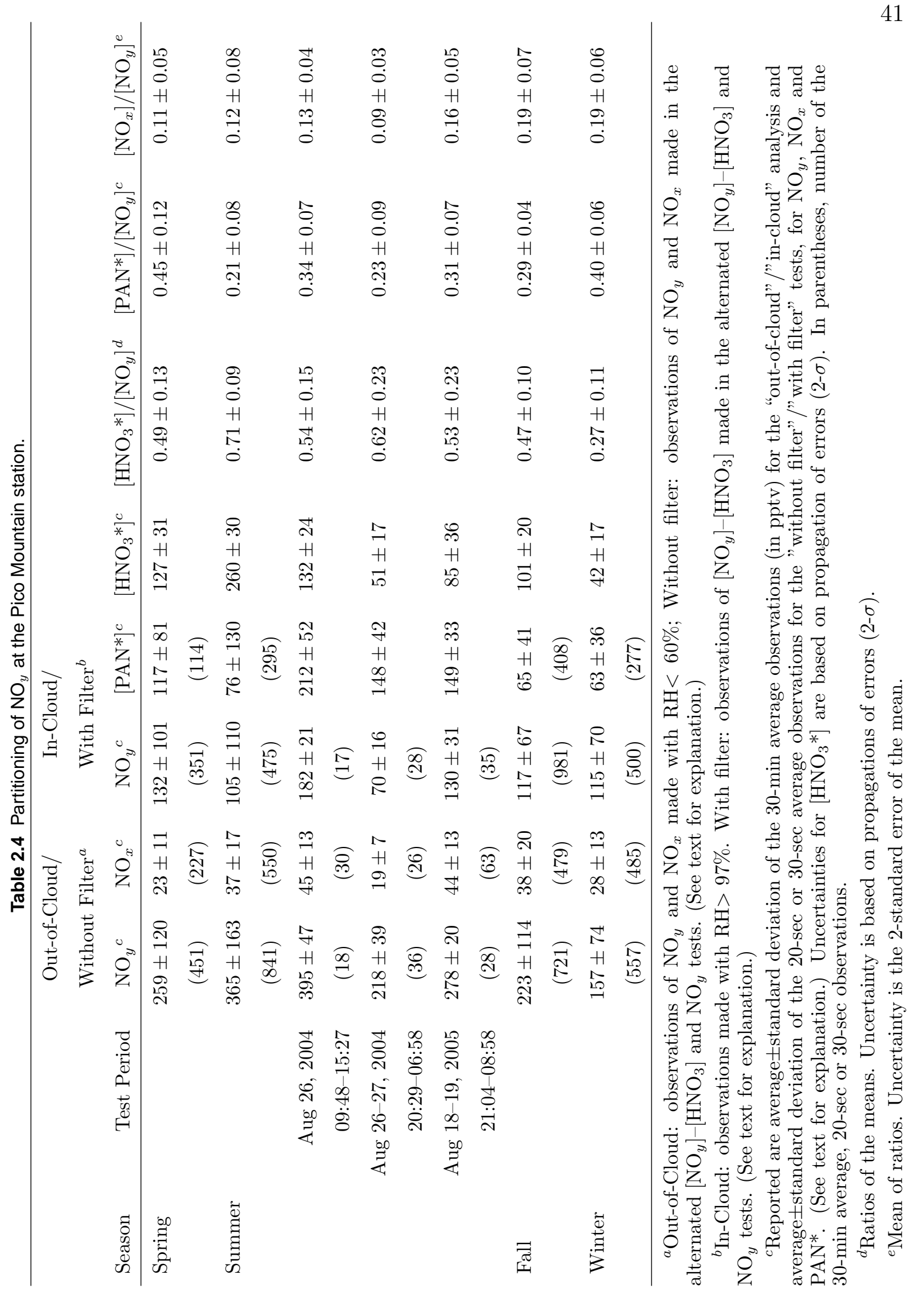


"out-of-cloud" periods from July to September may indicate a dominance of boreal region outflow, which is characterized by low $\mathrm{RH}$ and elevated $\mathrm{CO}$ levels Val Martin et al., 2006. This influence of boreal emissions during "out-of-cloud" conditions may have resulted in an overestimation of $\mathrm{HNO}_{3}$ and underestimation of PAN levels during summer, since $\mathrm{NO}_{y}$ is enhanced during boreal wildfire events.

In this analysis, we neglected the possible influence of aerosol and alkyl nitrates. The $\mathrm{NO}_{x, y}$ system inlet used at the Pico Mountain station excludes large aerosol particles, but allowed sampling of the $\lesssim 10$ micron aerosol fraction Hangal and Willeke, 1990, Peterson and Honrath, 1999. However, sub-micron size aerosol nitrates are not efficiently measured in our system as conversion efficiency for these compounds are low Miyazaki et al. 2005. The contribution of alkyl nitrates to $\mathrm{NO}_{y}$ in the remote marine troposphere is very small [Singh et al., 2007; Reeves et al., 2007. For example, alkyl nitrates accounted for less than $2 \%$ of the tropospheric $\mathrm{NO}_{y}$ in the lower $\mathrm{FT}$ over the North Atlantic Ocean during the ICARTT study Singh et al., 2007]. Thus, although the presence of alky nitrates may introduce a bias in our estimation of PAN, this bias is expected to be very small.

\subsubsection{Variation of $\mathrm{NO}_{y}$ Partitioning}

From Figure 2.5 as NO, it largely exists in its secondary reservoir forms in the central North Atlantic lower FT all year round. Low $\mathrm{NO}_{x} / \mathrm{NO}_{y}$ ratios (9-19\%; Table 2.4) are consistent with long-range transport and photochemical processing times to the measurement site. Because of the relatively short lifetime of $\mathrm{NO}_{x}$ compared to $\mathrm{NO}_{y}, \mathrm{NO}_{x} / \mathrm{NO}_{y}$ is expected to decrease with increasing airmass age. In the remote lower FT, typical $\mathrm{NO}_{x} / \mathrm{NO}_{y}$ values of $10-17 \%$ have been observed all year round Ridley et al., 1998; Atlas et al., 1992; Singh et al., 2007, consistent with the values observed at the Pico Mountain station.

The shift from dominance of PAN in winter-spring to dominance of $\mathrm{HNO}_{3}$ in 
summer-fall in Figure 2.5a is noteworthy. The small contribution of PAN during the summer (21-34\%; Table 2.4) is attributed to the strong thermal decomposition of PAN to $\mathrm{NO}_{x}$ in the North Atlantic lower FT. Conversely, the large fraction of $\mathrm{HNO}_{3}$ (53-71\%; Table 2.4) is directly related to the efficient formation of $\mathrm{HNO}_{3}$ from reaction of $\mathrm{NO}_{x}$ with $\mathrm{OH}$, as conversion of $\mathrm{NO}_{x}$ to $\mathrm{HNO}_{3}$ is 5 times faster during summer than winter Logan, 1983. Indirectly, the strong decomposition of PAN during the summer may result in the formation of $\mathrm{HNO}_{3}$ as $\mathrm{NO}_{x}$ is ultimately converted to $\mathrm{HNO}_{3}$.

To evaluate the effect of temperature on PAN, we examined the lifetime of PAN with respect to thermal decomposition in the airmasses during transit to the Pico Mountain station. For this purpose, we extracted the average temperature from the HYSPLIT model output Draxler and Rolph, 2003 for the 10-day backward trajectories arriving at the measurement site. More information on the HYSPLIT backward trajectories is presented elsewhere Honrath et al., 2004; Val Martin et al., 2006. We calculated the average temperature in the airmasses from the measurement site to 3 days upwind. This average temperature is the typical temperature that the airmasses encounter before arriving at the Pico Mountain station. We then used those average values to calculate the lifetime of PAN. Figure 2.5a shows the lifetime of PAN in the airmasses determined from the monthly average upwind temperatures from July 2002 to August 2005. The average lifetime of PAN under those conditions ranged from 5 days in March (average temperature $-4.4^{\circ} \mathrm{C}$ ) to 0.5 days in August (average temperature $8.9^{\circ} \mathrm{C}$ ). Therefore, the dominance of $\mathrm{PAN}$ in $\mathrm{NO}_{y}$ in winter-early spring is consistent with the longer lifetime of PAN in the airmasses, whereas the rapid decomposition of PAN in the airmasses during the summer results in the lower PAN fraction observed during that season. Due to the rapid oxidation of $\mathrm{NO}_{x}$ by $\mathrm{OH}$ in the summer ( $\lesssim 1$ day), PAN decomposition may result in the formation of $\mathrm{HNO}_{3}$ before the airmasses reach the Pico Mountain station. 

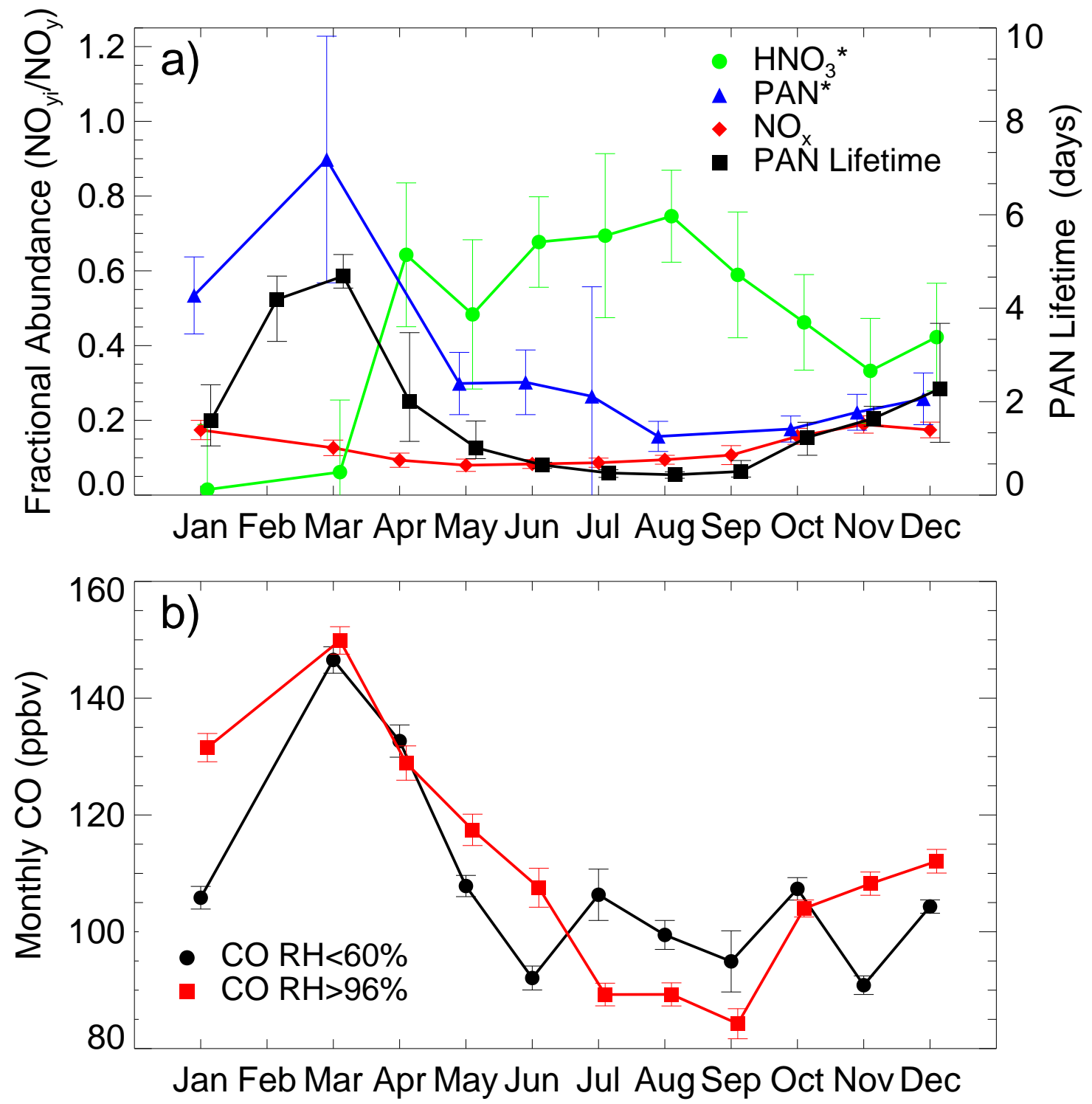

Figure 2.5 Seasonal cycle of a) partitioning of reactive nitrogen $\left(\mathrm{HNO}_{3}{ }^{*}, \mathrm{PAN}^{*}\right.$ and $\left.\mathrm{NO}_{x}\right)$ and average lifetime of PAN with respect to thermal decomposition in the air arriving at the Pico Mountain station, and b) $\mathrm{CO}$ in "in-cloud" (RH $>96 \%)$ and "out-of-cloud" ( $\mathrm{RH}<60 \%)$ periods. (See text for explanation.) Symbols represent monthly averages for $\mathrm{HNO}_{3}{ }^{*}$ (green circles), $\mathrm{PAN}^{*}$ (blue triangles), $\mathrm{NO}_{x}$ (red diamonds), $\mathrm{CO} \mathrm{RH}>96 \%$ (red squares) and $\mathrm{CO} \mathrm{RH}<60 \%$ (black circles) and average of the monthly means for PAN lifetime (black squares). Error bars indicate the 2-standard error of the mean for $\mathrm{CO}, \mathrm{NO}_{x}$ and $\mathrm{PAN}^{*}$, the uncertainty $(2-\sigma)$ based on propagation of errors for $\mathrm{HNO}_{3}{ }^{*}$ and the minimum and maximum estimated monthly PAN lifetime. 


\subsubsection{Comparison to Previous Observations}

A comparison of the distribution of $\mathrm{NO}_{y}$ species at the Pico Mountain station to those collected over the western North Atlantic Ocean during the NARE and ICARTT aircraft campaigns from spring to fall Parrish et al., 2004; Li et al., 2004, Singh et al., 2007, Hudman et al., 2007) allows for some speculation on the behavior of nitrogen oxides across the North Atlantic region. Table 2.5 compares the fractions of reactive nitrogen species measured during the ICARTT and NARE campaigns with those estimated at the Pico Mountain station.

Our spring-fall estimates of the fraction of $\mathrm{NO}_{x}(9-19 \%), \mathrm{PAN}^{*}(21-45 \%)$ and $\mathrm{HNO}_{3} *(47-71 \%)$ are similar to those observed over the western Atlantic Ocean in those other studies (8-13\% for $\mathrm{NO}_{x}, 34-47 \%$ for PAN and $40-57 \%$ for $\mathrm{HNO}_{3}$; averages in 2-8 km and $2.5-6.5 \mathrm{~km}$ altitudes from Table 2.5). However, as discussed in section 2.2.2, levels of $\mathrm{NO}_{y}$ at the Pico Mountain station are 2-3 times lower than those over the western Atlantic region (section 2.2.2), indicating the significant removal of $\mathrm{HNO}_{3}$ during transport to the measurement site. These results suggest that to maintain the observed fractions of $\mathrm{NO}_{x}$ and $\mathrm{HNO}_{3}{ }^{*}$ at the Pico Mountain station, decomposition of PAN to $\mathrm{NO}_{x}$ and further oxidation of $\mathrm{NO}_{x}$ to $\mathrm{HNO}_{3}$ must occur in the airmasses.

\subsubsection{Comparison to GEOS-Chem}

Figures $2.6 \mathrm{a}$-c compares the measurements with results obtained from the global chemical transport model GEOS-Chem for $\mathrm{NO}_{y}, \mathrm{HNO}_{3}{ }^{*}, \mathrm{PAN}^{*}$ and $\mathrm{NO}_{x}$. Additionally, the model-data comparison for $\mathrm{CO}$ is shown in Figure 2.6 d. GEOS-Chem simulations were available from January to December, 2005, whereas data from the Pico Mountain station in 2005 were available only from January to August. To be able to compare a full year cycle, we compared GEOS-Chem simulations to all data in 2002-2005. To account for any interannual variability that could bias our comparison, 


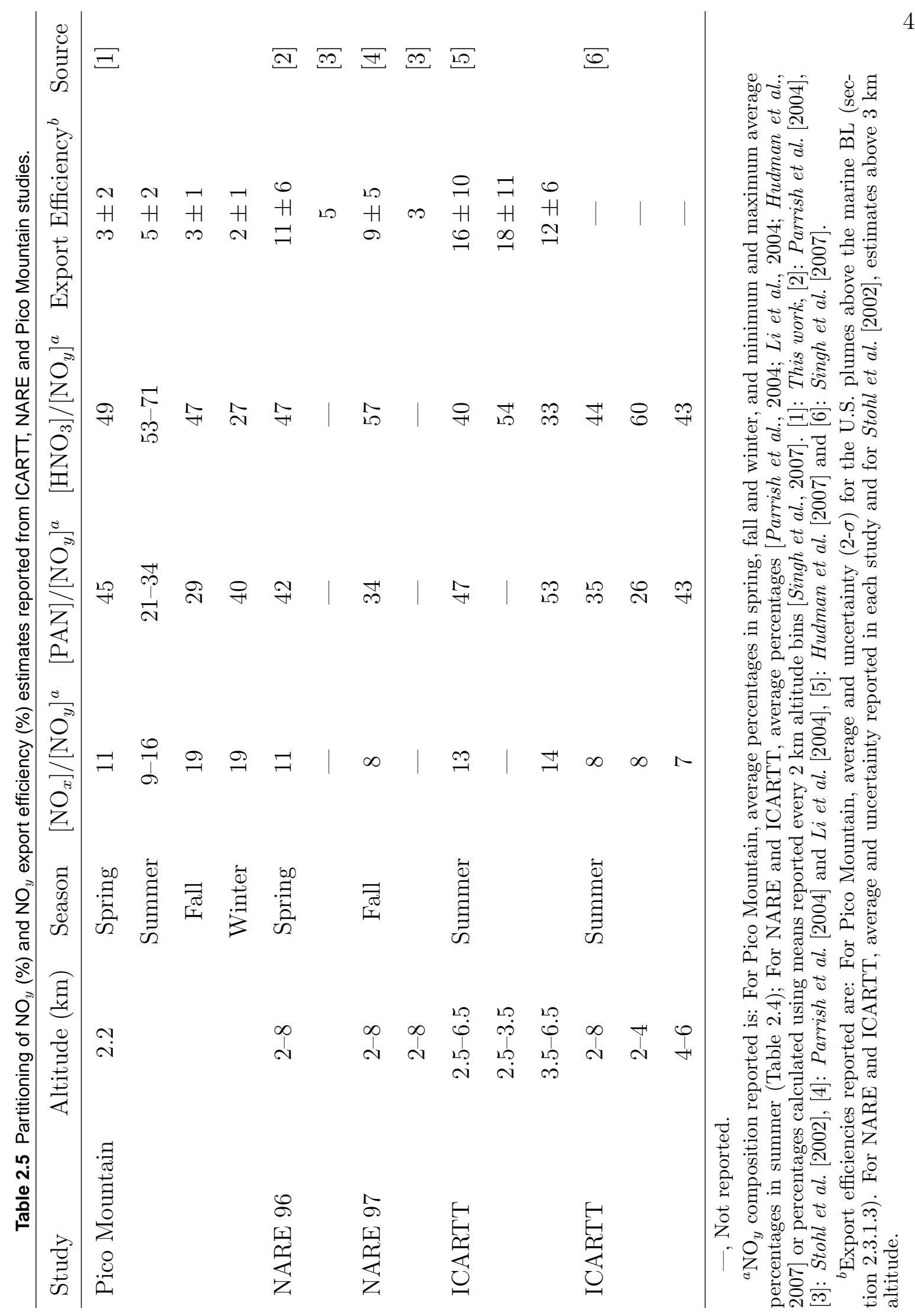


we also compared GEOS-Chem simulations to the data available in 2005 only. The model-data comparison focuses mainly on the median since this value is less affected by the variability resulting from large episodic events, with the exception of $\mathrm{HNO}_{3}$ * and PAN*, which are based on the estimated averages.

From Figure 2.6 a, it is apparent that GEOS-Chem reproduces the annual variation of $\mathrm{NO}_{y}$ observed at the Pico Mountain station. However, GEOS-Chem tends to overestimate $\mathrm{NO}_{y}$. As shown in Figure 2.6p, this overestimation is mainly due to an excess of $\mathrm{HNO}_{3}$. For example, during summer, GEOS-Chem produces monthly $\mathrm{HNO}_{3}$ medians 50-150 pptv greater than $\mathrm{NO}_{y}$ medians at the Pico Mountain station and it also overestimates $\mathrm{HNO}_{3}$ by about a factor of two during that season. This problem is known to occur in current GCT models [e.g. Lawrence and Crutzen, 1998; Bey et al., 2001; Singh et al., 2007, and may be related to an overestimation of $\mathrm{OH}$ concentrations Singh et al. 2007, to insufficient scavenging in the model Bey et al., 2001 or a combination of these and other causes.

Because of the scavenging scheme used in GEOS-Chem, it has been suggested that the model allows for significant escape of nitrogen oxides to the lower FT and it simulates reasonably well the shallow convection from the U.S. BL to the lower FT during the summer Li et al., 2004, Hudman et al., 2007]. Thus, GEOS-Chem suggests that the export of $\mathrm{NO}_{y}$ out of the U.S. BL may be partially responsible for the increased summertime $\mathrm{NO}_{y}$ levels over the central North Atlantic lower FT, consistent with our hypothesis (section 2.2.2). However, the large values produced by GEOS-Chem indicate an inability to capture the actual magnitude of $\mathrm{NO}_{y}$ over the North Atlantic lower FT.

Figure 2.6b shows the comparison between simulated PAN levels and observations. The model produces an annual variation of PAN similar to that estimated at the Pico Mountain station. However, GEOS-Chem tends to underestimate PAN, in particular from July to September, when GEOS-Chem values are a factor of 6-7 times lower than the observations. This behavior may be related to causes such as 

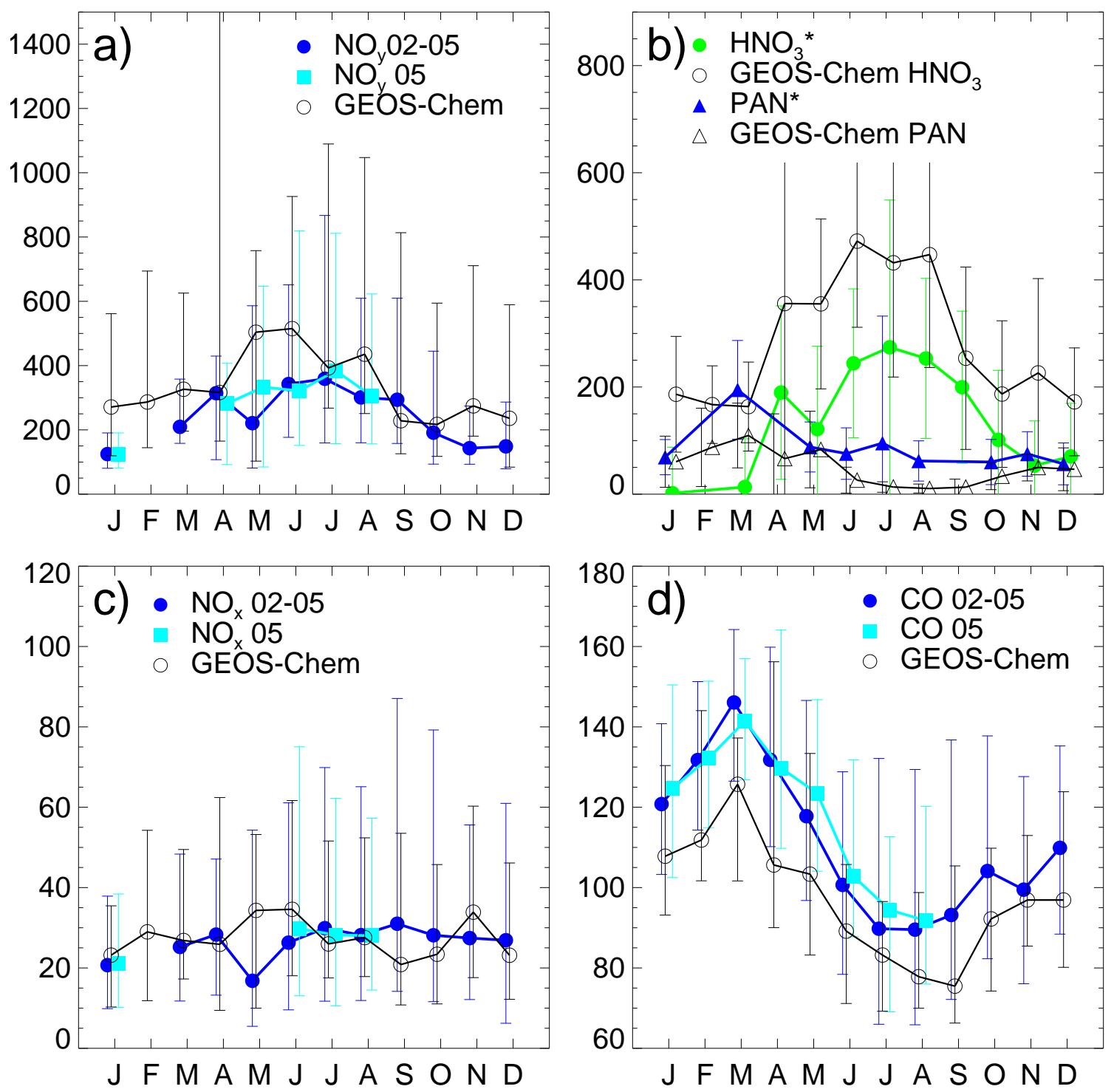

Figure 2.6 Comparison of observations a) $\mathrm{NO}_{y}$ in dry conditions (see section 2.2.2 for explanation), b) $\mathrm{HNO}_{3}$ * and $\mathrm{PAN}^{*}$, c) $\mathrm{NO}_{x}$ and d) $\mathrm{CO}$ to GEOS-Chem simulations. Symbols represent monthly medians in 2002-2005 (blue solid circles) and in 2005 (cyan solid squares) for $\mathrm{NO}_{y}, \mathrm{NO}_{x}$ and $\mathrm{CO}$; monthly medians in 2005 for GEOS-Chem $\mathrm{NO}_{y}, \mathrm{NO}_{x}$ and $\mathrm{CO}$ (black open circles); monthly averages in 2002-2005 for $\mathrm{HNO}_{3}{ }^{*}$ (green solid circles) and PAN* (blue solid triangles) and in 2005 for GEOS-Chem $\mathrm{HNO}_{3}$ (black open circles) and GEOS-Chem PAN (black open triangles). Error bars indicate the 10th and 90th percentile for observed and simulated $\mathrm{NO}_{y}, \mathrm{NO}_{x}$ and $\mathrm{CO}$, the standard deviation of all estimates of PAN ${ }^{*}$ and GEOS-Chem simulations of $\mathrm{HNO}_{3}$ and PAN, and the uncertainty (2- $\left.\sigma\right)$ based on propagation of errors for $\mathrm{HNO}_{3}{ }^{*}$. 
an excessive decomposition of PAN in the model or underestimation of $\mathrm{NO}_{x}$ and/or NMHC emissions. Finally, the model-data difference may also be related to a low removal efficiency for $\mathrm{HNO}_{3}$ within the clouds present at the Pico Mountain station, resulting in an overestimation of $\mathrm{PAN}^{*}$, since $\mathrm{PAN}^{*}$ was calculated by assuming complete removal of $\mathrm{HNO}_{3}$ in the presence of clouds at the station. Were this the case, it would also reduce the $\mathrm{HNO}_{3}$ model-data difference during summer, but only by $20 \%$, not changing the conclusion that $\left[\mathrm{HNO}_{3}\right]$ exceeds the simulated values.

A comparison of simulated and observed $\mathrm{NO}_{x}$ levels is shown in Figure 2.6. Similar to our measurements, GEOS-Chem does not simulate a clear seasonal cycle for the median $\mathrm{NO}_{x}$ values. GEOS-Chem simulations produce monthly medians (2135 pptv) similar to those observed at the Pico Mountain station (21-30 pptv in 2005 and 16-29 pptv in 2002-2005). However, the model does not capture the very large variability in the $\mathrm{NO}_{x}$ mixing ratios, particularly that associated with transport of boreal wildfires in summer 2005.

Figure 2.6 d shows observed and modeled CO values. GEOS-Chem CO exhibits a seasonal variation similar to that observed at the Pico Mountain station, but systematically underestimates the CO observations in 2005 by 10 to 25 ppbv. This behavior has been noted previously Bey et al., 2001, and may be related to an excess of $\mathrm{OH}$ in the model and/or to the underestimation of the CO emissions. During JulySeptember, this difference is more apparent. GEOS-Chem simulates a sharp decrease of CO through these months, whereas observed CO remain stable. This may be related to the strong impact of boreal wildfire emissions during these months in both 2004 and 2005, which it is not simulated by the fire emission inventory used in this GEOS-Chem simulation.

This comparison shows that, although current GCT models have become more sophisticated Singh et al., 2007, uncertainties in simulating nitrogen oxides in the remote lower FT remain. These uncertainties are clearly related to errors in emission sources and limitations in our understanding of the nitrogen oxides chemistry in the 
remote troposphere.

\subsection{Influence of Transport of Pollution}

In this section, we determine the influence of transport of pollution on the nitrogen oxides levels over the central North Atlantic lower FT. We first assess the impacts of transport of anthropogenic emissions from eastern North America and examine the resulting implications for the tropospheric $\mathrm{O}_{3}$ budget. Second, we determine the impact of boreal wildfire emissions on the distribution of the nitrogen oxides levels.

\subsubsection{Impacts of North American Anthropogenic Emissions}

To assess the influence of North American anthropogenic emissions over the central North Atlantic lower FT, we compare the enhancements of CO and nitrogen oxides in North American outflow to levels observed in clean marine air without the input of recent emissions. The following section describes the identification of North America outflow periods and presents two example episodes.

\subsubsection{Identification of North American Anthropogenic Impact}

We identified periods potentially impacted by upwind anthropogenic emissions by selecting those in which the hourly average of CO was at least 20 ppbv higher than the CO background in each season and year, and the average of FLEXPART NA-CO during the event was at least 10 ppbv. An exception was made for April 20-24, 2005: although our criteria identified two episodes (April 20 20:30 UTC-April 23 10:30 UTC and April 23 21:30 UTC-April 24 10:30 UTC), elevated CO levels recorded between the events indicated that both periods were part of a continuous event. For the analysis, we considered as background the 20th percentile of all hourly CO observations for each season and year. This value represents clean marine levels without the influence 
of emissions at the measurement site. Hourly averages of $\mathrm{CO}$ were used to smooth the variability of the $\mathrm{CO}$ measurements for comparison to the cutoff values. The average of FLEXPART NA-CO values within the periods was used instead of the individual 3-hour step values to allow for variability in the timing of the FLEXPART-simulated events. The FLEXPART NA-CO cutoff of 10 ppbv corresponds to approximately the 80th percentile of all model simulated values. Although the choice of these criteria is somewhat arbitrary, the cutoff values were designed to be conservative and ensure that the selected data represent significantly polluted airmasses from the U.S..

In addition to outflow strictly from the eastern North America, flow patterns passing over North America can also bring air that originated from the boreal regions. During these periods, air sampled at the Pico Mountain station may contain a mixture of anthropogenic and boreal wildfire emissions. To exclude the interference of boreal wildfire emissions, we removed those periods in which the corresponding average FLEXPART Fire-CO was above the 10th percentile of all simulated values for each season. This resulted in the removal of $30 \%$ of the events in summer and early fall. Additionally, transported emissions from North American sources may also be mixed

with air containing anthropogenic emissions from Europe and Asia. To limit the events studied to those dominated by North American anthropogenic emissions, we also excluded those periods in which the average FLEXPART Asia-CO or FLEXPART Euro-CO was greater than $50 \%$ of the average FLEXPART NA-CO. This screening resulted in removal of an additional $2 \%$ of events.

\subsubsection{Example Episodes}

Figure 2.7 presents two example episodes of transport of anthropogenic pollution from the eastern North America to the Pico Mountain station. These two episodes illustrate two different transport mechanisms from North America. Figure 2.8 shows an example of FLEXPART retroplumes and the source contribution map for each episode. 

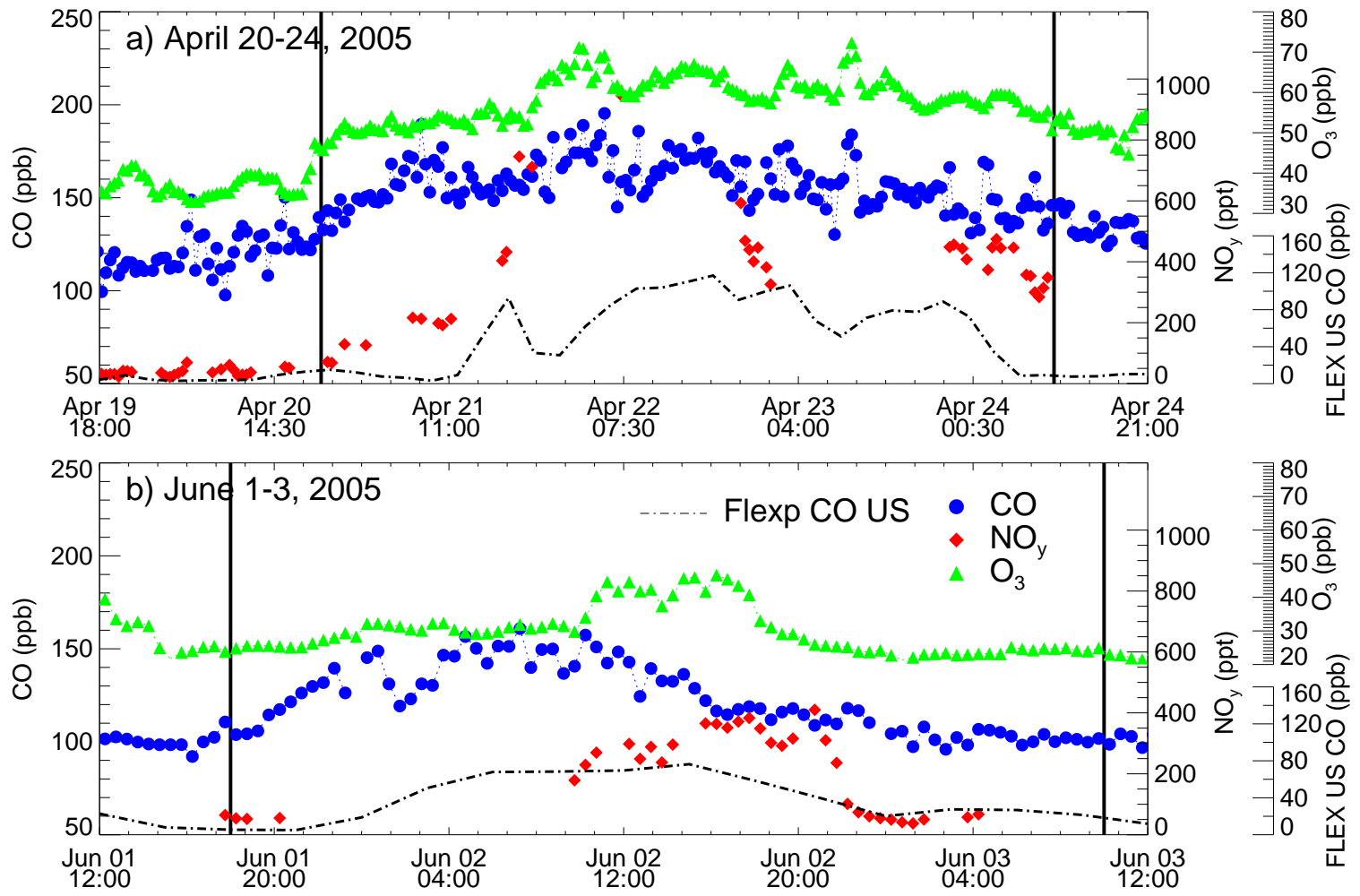

Figure 2.7 Time series of 30-min average $\mathrm{CO}, \mathrm{NO}_{y}$ and $\mathrm{O}_{3}$ measurements, and FLEXPART NA-CO at the Pico Mountain station during two North America outflow events: a) April 20-24, 2005 and b) June 1-3, 2005. $\mathrm{NO}_{x}$ measurements are not available. $\mathrm{CO}$ is plotted with blue circles, $\mathrm{NO}_{y}$ with red diamonds, $\mathrm{O}_{3}$ with green triangles and FLEXPART NA-CO with a dash-dotted line. Vertical solid lines indicate the start and end time of the event; remaining data are plotted to make the events more apparent. 

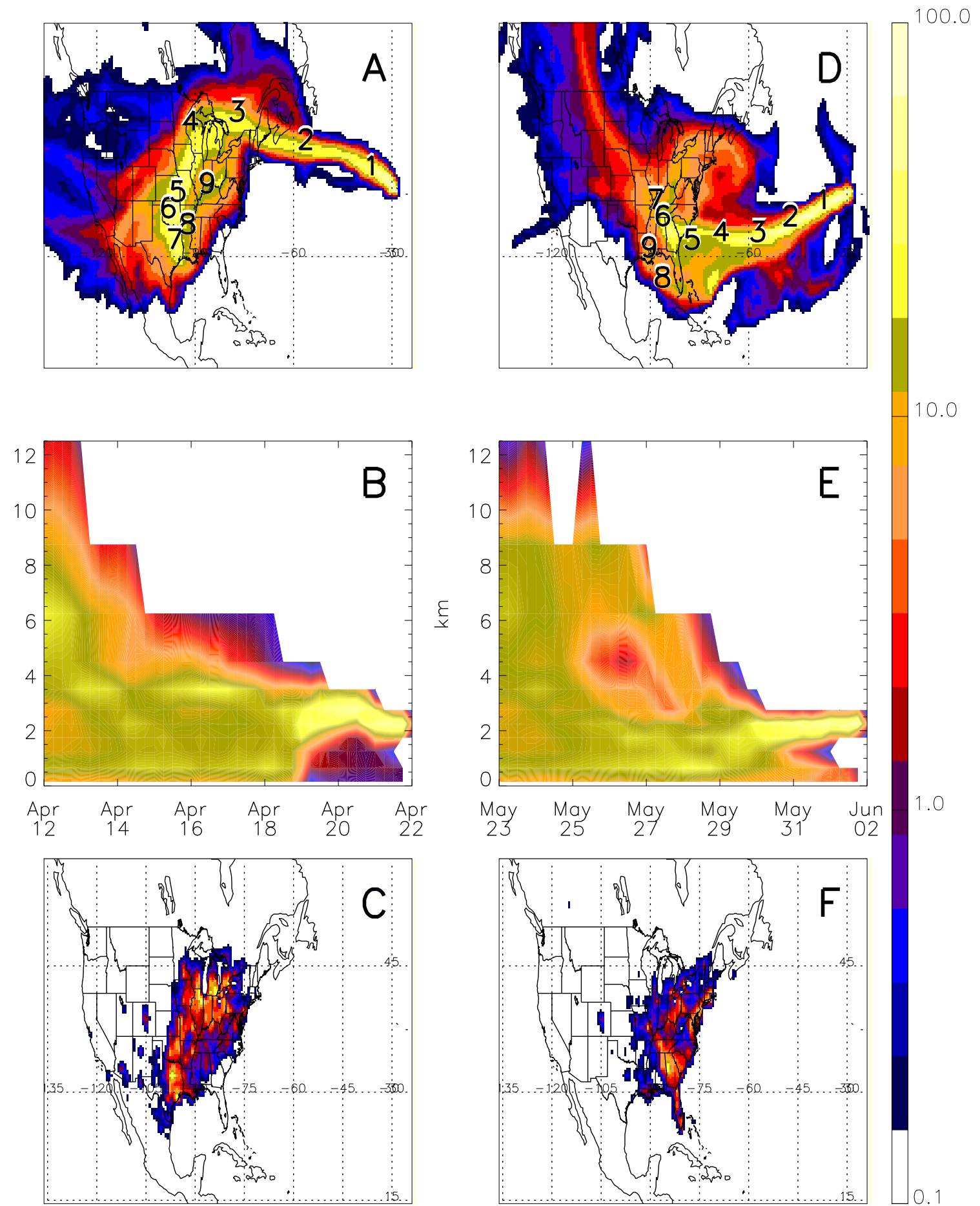

2

Figure 2.8 Results for retroplumes with release times centered on 18 UTC on April 22, 2005 (A, B and C) and 12 UTC on June 2, 2005 (D, E and F). The top row shows the total column (0-15km) SVWRT. Black numerals indicate the location of maximum column-integrated SVWRT at each integral day upwind. The middle row shows the SVWRT height distribution at each time upwind. The bottom row shows the footprint layer $(0-300 \mathrm{~m})$ source contribution. Colors are logarithmically scaled (100-0.1\%) according to a maximum value for each plot type $\left(8 \times 10^{4}\right.$ seconds ${ }^{*} \mathrm{~m}^{3} \mathrm{~kg}^{-1}$ for the column-integrated SVWRT, $2.05 \times 10^{5}$ seconds ${ }^{*} \mathrm{~m}^{3} \mathrm{~kg}^{-1}$ for the SVWRT height distribution, and $4.4 \mathrm{ppbv}$ of $\mathrm{CO}$ for footprint source contributions), as shown by the scale on the right. 
Figure 2.7 a shows the time series of the observations for the episode of April 2024, 2005. This event was the result of emissions from eastern U.S. and Canada as described in detail by Helmig et al., [submitted]. During April 21-24 air from North America impacted the measurement site. As shown in Figure $2.8 \mathrm{a}-\mathrm{b}$ for the retroplume of April 22 18:00 UTC, airmasses spent at least five days over North America (numerals 4-9 in Figure 2.8 a) at altitudes lower than $2 \mathrm{~km}$ and were transported over the ocean for three days (numerals $1-3$ in Figure 2.8 a) at 2-4 km altitudes (April 1922 in Figure 2.8b). Apparently as a consequence of the U.S. emissions, levels of CO, nitrogen oxides and $\mathrm{O}_{3}$ were significantly enhanced during this period, and nitrogen oxides and $\mathrm{O}_{3}$ were well correlated with $\mathrm{CO}$.

Similarly, levels of CO were also considerably elevated during the June 1-3, 2005 episode, as shown in Figure 2.7b. This episode was the result of a sudden switch from airmasses originating at higher latitudes and altitudes to airmasses originating at low altitude over the southeastern U.S.. This episode, however, exhibited generally small enhancements of nitrogen oxides and $\mathrm{O}_{3}$ and no significant correlation with CO. As shown in Figure 2.8d-e for the retroplume of June 2 18:00 UTC, airmasses passed over southeastern U.S. for at least four days (numerals 6-9 in Figure 2.8d) and were transported during two days (numerals $4-5$ in Figure 2.8d) within the marine BL (altitudes below $2 \mathrm{~km}$, May 28-30 in Figure 2.8p) and during three days (numerals 1-3 in Figure 2.8d) at altitudes of about $2 \mathrm{~km}$ (May 30-June 2 in Figure 2.8 ), before reaching the measurement site. Strong removal of nitrogen oxides and $\mathrm{O}_{3}$ destruction in the marine BL may have caused these small enhancements of nitrogen oxides and $\mathrm{O}_{3}$. This conclusion is consistent with previous studies, which indicate rapid removal of $\mathrm{HNO}_{3}$ within the MBL [e.g. Roberts et al., 1996; Peterson and Honrath, 1999; Dibb et al. 2004. 


\subsubsection{Nitrogen Oxides Enhancements in North America Outflow and Estimates of $\mathrm{NO}_{y}$ Transport Efficiency}

Figure 2.9 (left and middle columns) presents the relationship of $\mathrm{NO}_{x}$ and $\mathrm{NO}_{y}$ to $\mathrm{CO}$ in the overall data and in the identified North America outflow periods, on a seasonal basis. It is apparent that transport events from North America occur all year round and they are responsible for part of the high nitrogen oxides observations during all seasons.

To characterize the amount of $\mathrm{NO}_{x}$ remaining or released into these plumes during transport, we determined enhancement ratios of $\mathrm{NO}_{y}$ and $\mathrm{NO}_{x}$ with respect to CO during each U.S. outflow period [e.g. Stohl et al., 2002; Parrish et al., 2004. We first calculated the mean values of $\Delta \mathrm{CO}, \Delta \mathrm{NO}_{y}$ and $\Delta \mathrm{NO}_{x}$ in each event and then used those mean values to estimate the ratio relative to $\mathrm{CO}$ in each anthropogenic event (e.g. $\left.\Delta \mathrm{NO}_{y} / \Delta \mathrm{CO}\right)$. Here $\Delta$ indicates the difference between the concentration of the indicated species and the background concentration (e.g. $\left.[\mathrm{CO}]-[\mathrm{CO}]_{b k g d}\right)$, with background determined as the 20th percentile of all observations for each species, season and year. $\mathrm{CO}$ is commonly used as a tracer for $\mathrm{NO}_{x}$ emissions because it is emitted by combustion sources along with $\mathrm{NO}_{x}$ and has a long lifetime, on the order of one to three months depending on the season Novelli et al., 1992. The resulting seasonally averaged enhancement ratios are presented in Figure 2.9. Table 2.6 summarizes the corresponding enhancement ratios for the individual anthropogenic events shown in Figure 2.9. To indicate the possible influence of local removal of $\mathrm{HNO}_{3}$ on the $\Delta \mathrm{NO}_{y} / \Delta \mathrm{CO}$ ratios (section 2.2.3.1), we show in Table 2.6 the percentage of the event time in which the RH at the measurement site was above $96 \%$.

Figure 2.9 (left column) and Table 2.6 show that $\mathrm{NO}_{y}$ was significantly enhanced in all the North America outflow plumes relative to the background levels, with the exception of one plume (April 26-27, 2005). However, the $\Delta \mathrm{NO}_{y} / \Delta \mathrm{CO}$ ratios were highly variable $\left(0.2-12.0\right.$ pptv $\mathrm{ppbv}^{-1}$; Table 2.6). There are two causes that are 

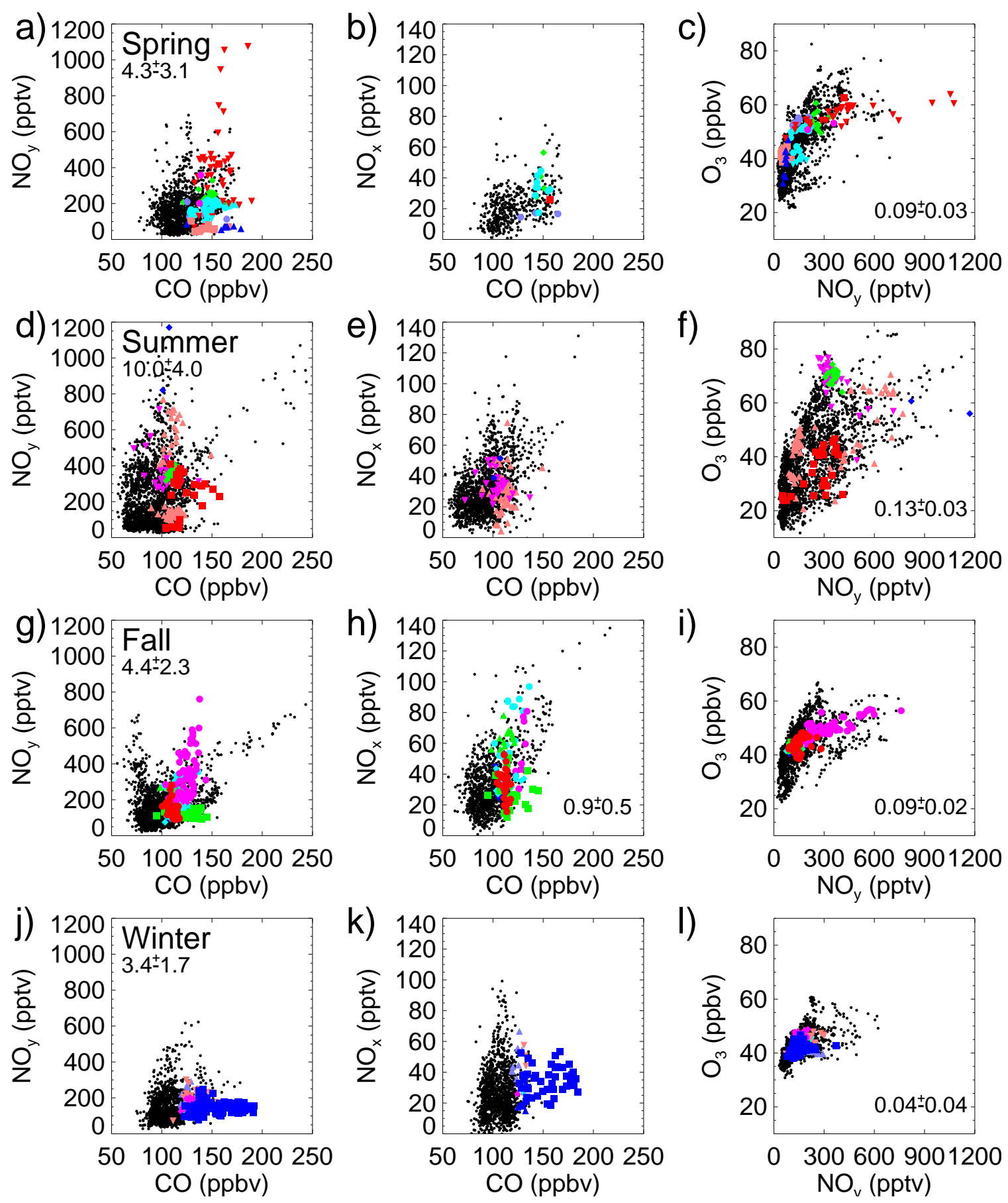

Figure 2.9 Relationship between $\mathrm{CO}$ and $\mathrm{NO}_{y}, \mathrm{CO}$ and $\mathrm{NO}_{x}$ and $\mathrm{NO}_{y}$ and $\mathrm{O}_{3}$ in spring (a-c), summer (d-f), fall $(g-i)$ and winter $(j-1)$ during 2002-2005. North America outflow events are plotted with different symbols and colors. Events with fewer than 5 data points are not indicated. Seasonal average enhancement ratios (mean $\pm 2-\sigma$ ) from the anthropogenic events listed in Table 2.6 are identified in each plot. Units are pptv ppbv ${ }^{-1}$ for $\Delta \mathrm{NO}_{y} \Delta \mathrm{CO}$ and $\Delta \mathrm{NO}_{x} / \Delta \mathrm{CO}$ and ppbv pptv ${ }^{-1}$ for $\Delta \mathrm{O}_{3} / \Delta \mathrm{NO}_{y}$. (Averages with fewer than three events are not shown.) All other other observations in 2002-2005 are plotted with small black dots. 
Table 2.6 Enhancement ratios of nitrogen oxides during the North American outflow events identified in Figure 2.9. Reported enhancement ratios (calculated as described in text), 2- $\sigma$ uncertainty and number (N) of simultaneous 30-min average observations of $\mathrm{NO}_{y}, \mathrm{NO}_{x}, \mathrm{CO}$ and $\mathrm{O}_{3}$. Events with $\mathrm{N}<5$ not shown.

\begin{tabular}{|c|c|c|c|c|c|c|c|c|c|}
\hline \multirow[b]{2}{*}{ Event } & \multirow[b]{2}{*}{ Year } & \multirow[b]{2}{*}{ Period } & \multirow{2}{*}{$\begin{array}{c}\text { Cloud }{ }^{a} \\
(\%)\end{array}$} & \multicolumn{2}{|c|}{$\Delta \mathrm{NO}_{y} / \Delta \mathrm{CO}$} & \multicolumn{2}{|c|}{$\Delta \mathrm{NO}_{x} / \Delta \mathrm{CO}$} & \multicolumn{2}{|c|}{$\Delta \mathrm{O}_{3} / \Delta \mathrm{NO}_{y}$} \\
\hline & & & & pptv ppbv ${ }^{-1}$ & $\mathrm{~N}$ & pptv ppbv ${ }^{-1}$ & $\mathrm{~N}$ & ppbv pptv ${ }^{-1}$ & $\mathrm{~N}$ \\
\hline & & Spring $b$ & & $4.3 \pm 3.1$ & & & & $0.09 \pm 0.03$ & \\
\hline 1 & 2004 & Apr 15 6:15 - Apr 16 11:45 & 0 & $3.4 \pm 0.2$ & 17 & & & $0.14 \pm 0.01$ & 59 \\
\hline 2 & 2004 & Apr 20 12:15 - Apr 21 23:45 & & & & & & $0.07 \pm 0.00$ & 70 \\
\hline 3 & 2004 & Apr 29 0:15 - Apr 30 23:45 c & 100 & $1.3 \pm 0.4$ & 7 & & & $0.36 \pm 0.10$ & 95 \\
\hline 4 & 2005 & Mar 27 18:15 - Mar 28 17:45 & 96 & $3.9 \pm 0.3$ & 29 & $0.6 \pm 0.1$ & 9 & $0.08 \pm 0.01$ & 47 \\
\hline 5 & 2005 & Apr 20 18:15 - Apr 24 11:45 & 47 & $8.7 \pm 1.0$ & 38 & NA & NA & $0.05 \pm 0.01$ & 180 \\
\hline 6 & 2005 & Apr 26 18:15 - Apr 27 5:45d & 100 & $0.2 \pm 0.2$ & 12 & NA & NA & $0.37 \pm 0.27$ & 24 \\
\hline \multirow[t]{2}{*}{7} & 2005 & May 18 6:15 - May $1817: 45^{d}$ & 0 & $0.4 \pm 0.1$ & 10 & NA & NA & $-0.20 \pm-0.10$ & 24 \\
\hline & & Summer $^{b}$ & & $10.0 \pm 4.0$ & & & & $0.13 \pm 0.03$ & \\
\hline 1 & 2004 & Jun 6 0:15- Jun 8 5:45 & 60 & $6.0 \pm 0.7$ & 70 & $0.3 \pm 0.1$ & 53 & $0.10 \pm 0.01$ & 108 \\
\hline 2 & 2004 & Jun 15 18:15 - Jun 16 11:45 & 0 & $12.0 \pm 1.5$ & 28 & $0.7 \pm 0.1$ & 26 & $0.14 \pm 0.01$ & 36 \\
\hline 3 & 2005 & Jun 1 0:15 - Jun 1 11:45 & 0 & $12.0 \pm 0.5$ & 16 & NA & NA & $0.14 \pm 0.01$ & 24 \\
\hline \multirow[t]{2}{*}{4} & 2005 & Jun 1 18:15 - Jun 2 23:45 ${ }^{d}$ & 0 & $3.9 \pm 0.6$ & 27 & NA & NA & $0.03 \pm 0.01$ & 60 \\
\hline & & Fall $^{b}$ & & $4.4 \pm 2.3$ & & $0.9 \pm 0.5$ & & $0.09 \pm 0.02$ & \\
\hline 1 & 2002 & Oct $618: 15$ - Oct $75: 45$ & 0 & $7.6 \pm 0.6$ & 13 & $1.5 \pm 0.2$ & 13 & NA & NA \\
\hline 2 & 2002 & Oct $76: 15$ - Oct $711: 45$ & 0 & $8.3 \pm 0.8$ & 12 & $1.8 \pm 0.2$ & 12 & NA & NA \\
\hline 3 & 2003 & Oct 19 12:15 - Oct 21 11:45 & 54 & $6.6 \pm 0.5$ & 80 & $1.1 \pm 0.2$ & 9 & $0.06 \pm 0.00$ & 96 \\
\hline 4 & 2004 & Nov 11 18:15 - Nov 11 23:45 & 0 & $2.0 \pm 0.3$ & 11 & $0.5 \pm 0.1$ & 11 & $0.11 \pm 0.02$ & 11 \\
\hline 5 & 2004 & Nov 22 18:15 - Nov 23 11:45 & 68 & $2.1 \pm 0.3$ & 19 & $0.5 \pm 0.1$ & 19 & $0.08 \pm 0.01$ & 36 \\
\hline 6 & 2004 & Nov 23 12:15 - Nov 24 11:45 & 14 & $1.3 \pm 0.1$ & 35 & $0.2 \pm 0.1$ & 24 & $0.13 \pm 0.01$ & 48 \\
\hline \multirow[t]{2}{*}{7} & 2004 & Nov 25 6:15 - Nov 27 11:45 & 0 & $2.7 \pm 0.2$ & 56 & $0.5 \pm 0.1$ & 35 & $0.09 \pm 0.01$ & 102 \\
\hline & & Winter ${ }^{b}$ & & $3.4 \pm 1.7$ & & & & $0.04 \pm 0.04$ & \\
\hline 1 & 2004 & Jan 27 12:15 - Jan 27 23:45 & 0 & $1.9 \pm 0.5$ & 11 & & & $0.10 \pm 0.03$ & 24 \\
\hline 2 & 2004 & Dec 11 0:15 - Dec 11 11:45 & 100 & $6.1 \pm 0.8$ & 7 & $1.3 \pm 0.18$ & 7 & $0.00 \pm 0.00$ & 19 \\
\hline 3 & 2005 & Jan 9 6:15 - Jan 9 17:45 & 57 & $4.2 \pm 0.4$ & 21 & & & $0.02 \pm 0.01$ & 24 \\
\hline 4 & 2005 & Jan 10 0:15 - Jan 10 5:45 & 33 & $3.4 \pm 0.3$ & 12 & & & $0.07 \pm 0.01$ & 12 \\
\hline 5 & 2005 & Jan 10 6:15 - Jan 13 17:45 & 96 & $1.4 \pm 0.1$ & 132 & $0.39 \pm 0.03$ & 49 & $0.02 \pm 0.00$ & 168 \\
\hline
\end{tabular}

NA, Not available.

${ }^{a}$ Percentage of the period with RH above $96 \%$.

${ }^{b}$ Average of all events. Average with fewer than 2 events are not shown. Average enhancement ratios do not include events 6 and 7 in spring and event 4 in summer due to transport in the marine $\mathrm{BL}$, and event 3 in spring due to influence of stratospheric transport.

${ }^{c}$ Event with stratospheric transport influence according to FLEXPART Strat- $\mathrm{O}_{3}$ tracer and transport at high altitudes indicated by FLEXPART retroplumes.

${ }^{d}$ Events in the marine BL as indicated by FLEXPART retroplumes. (See text for explanation.) 
likely to contribute to this variation: different $\mathrm{NO}_{x}$ to $\mathrm{CO}$ emission ratios over the continent, which vary as a function of time and type of fuel Neuman et al., 2006, and varying degree of washout processing during transport. On a seasonal basis, the average $\Delta \mathrm{NO}_{y} / \Delta \mathrm{CO}$ was larger in summer $\left(10.0 \pm 4.0 \mathrm{pptv} \mathrm{ppbv}^{-1}\right.$; Figure 2.9d) than in winter $\left(3.4 \pm 1.7\right.$ pptv ppbv $^{-1}$; Figure $\left.2.9 \mathrm{j}\right)$, suggesting a more efficient export of $\mathrm{NO}_{y}$ from eastern North America during summertime.

To quantify the fraction of $\mathrm{NO}_{x}$ originally emitted that was exported as $\mathrm{NO}_{y}$ in North America outflow (f), we compared the $\Delta \mathrm{NO}_{y} / \Delta \mathrm{CO}$ observed at the Pico Mountain station to that from U.S. emissions, using the following approach Parrish et al., 2004; Hudman et al., 2007]:

$$
\mathrm{f}=\frac{\Delta \mathrm{NO}_{y}}{\Delta \mathrm{CO}} \times \mathrm{R}_{\text {emiss }} \times \alpha,
$$

where $\mathrm{R}_{\text {emiss }}$ is the $\mathrm{CO}$ to $\mathrm{NO}_{x}$ emission molar ratio and $\alpha$ is a factor accounting for chemical sources and sinks of CO. We included a correction factor of 0.88 to account for the increase in the CO export from the U.S. due to oxidation of NMHCs to CO (1.2) Chin et al. 1994 and to incorporate a $27 \%$ decline in the CO mixing ratios during the 5 to 6 day transport time from the U.S. BL to the Pico Mountain station (0.73) Honrath et al. 2004. We applied this correction factor only to the summertime observations since biogenic hydrocarbon emissions are reduced during the non-summer seasons and oxidation of $\mathrm{CO}$ is not significant $(\sim 5-10 \%$ in 5 to 6 day transport, based on the $\mathrm{CO}+\mathrm{OH}$ rate constant at $800 \mathrm{hPa}$ Sander et al. 2003] and the estimated zonal average $\mathrm{OH}$ at $35^{\circ} \mathrm{N}$ and $800 \mathrm{hPa}$ Spivakovsky et al. 2000) in these seasons. For the U.S. CO to $\mathrm{NO}_{x}$ emission ratio, we used GEOS-Chem input of $5.9 \mathrm{~mol} \mathrm{~mol}^{-1}$ for eastern U.S. Hudman et al., 2007. This ratio is similar to that obtained by Parrish et al. 2004 (5.1 mol mol $\left.{ }^{-1}\right)$ using the EPA emission inventory adjusted by a decline in vehicle CO emissions estimated based on field measurements.

We applied this approach to the $\Delta \mathrm{NO}_{y} / \Delta \mathrm{CO}$ observed in the North America plumes that traveled above the marine BL. We considered events in the marine BL 
those in which FLEXPART retroplumes spent more than one day at altitudes below $2 \mathrm{~km}$ (e.g., Figure 2.8p) and excluded them from the analysis, i.e., event 6 and 7 in spring and event 4 in summer (Table 2.6). The resulting average $\mathrm{NO}_{y}$ efficiencies for export and transport are: $3 \pm 2 \%$ (mean \pm 2 -standard error of the mean) in spring, $5 \pm 2 \%$ in summer, $3 \pm 1 \%$ in fall and $2 \pm 1 \%$ in winter. The summer season shows an average $\mathrm{NO}_{y}$ transport efficiency about 2 times greater than the other seasons. Although we adjusted the summertime observations by a correction factor, the difference between the summer and non-summer $\mathrm{NO}_{y}$ efficiencies for export and transport is not due to this applied correction as the correction factor changed the summertime values only by about $12 \%$. Table 2.5 on page 46 compares these estimates to previous export efficiencies obtained in U.S. plumes during the NARE and ICARTT campaigns [e.g. Parrish et al., 2004; Li et al., 2004, Hudman et al., 2007]. The Pico Mountain average export efficiencies from spring to fall (3-5\%) are similar to the lower limit of the estimates over the western North Atlantic Ocean lower FT (11 $\pm 6 \%$ in spring, $18 \pm 11 \%$ in summer and $9 \pm 5 \%$ in fall Parrish et al., 2004; Hudman et al., 2007). Consistent with these previous studies, our observations indicate that the majority (95-97\%) of $\mathrm{NO}_{x}$ emitted over eastern U.S. is removed within or during export from the U.S. BL during lofting mechanisms. However, this comparison suggests that about $30 \%$ of the nitrogen oxides emissions that escape the eastern North America BL remain after transport to the lower FT over the Azores region.

Consistent with the expectation that export of $\mathrm{NO}_{y}$ may eventually lead to $\mathrm{NO}_{x}$ released from decomposition of PAN and potentially photolysis of $\mathrm{HNO}_{3}$, Figure 2.9 (middle column) and Table 2.6 show that $\mathrm{NO}_{x}$ was also enhanced in the anthropogenic plumes relative to background during all seasons.

Although $\mathrm{NO}_{x}$ observations in North America outflow were limited, enhancements of $\mathrm{NO}_{x}$ in the North American plumes indicate that North American emissions are a significant source of $\mathrm{NO}_{x}$ to the central North Atlantic lower FT all year round. Larger $\Delta \mathrm{NO}_{x} / \Delta \mathrm{CO}$ ratios during fall suggest that the largest supply of $\mathrm{NO}_{x}$ in the central 
North Atlantic lower FT occurs during this season. This effect is likely the result of the combination of rapid thermal decomposition of PAN to $\mathrm{NO}_{x}$ and slower conversion of $\mathrm{NO}_{x}$ to $\mathrm{HNO}_{3}$ in the plumes during this season (section 2.2.3.2). In addition, direct export of $\mathrm{NO}_{x}$ from North America may have also contributed to the $\mathrm{NO}_{x}$ enhancements since some of the fall events were associated with rapid transport from the U.S. ( $\lesssim 2$ days). Large enhancements of $\mathrm{NO}_{y}$ in spring $\left(4.3 \pm 3.1\right.$ pptv $\mathrm{NO}_{y} / \mathrm{ppbv}$ CO; Figure 2.9 a), mostly in the form of PAN (Figure 2.5), suggest a continuing export of nitrogen oxides, which may eventually release $\mathrm{NO}_{x}$ further downwind.

The average $\mathrm{NO}_{x}$ levels observed during airflow from North America were $31 \pm$ 5 pptv (mean \pm 2 -standard error of the mean; spring), $31 \pm 3$ pptv (summer), $41 \pm 3$ pptv (fall) and $36 \pm 3$ pptv (winter). These mean values correspond to the 75 th percentile of the full distribution each season, with the exception of the summer, which corresponds to the 55th percentile. Lower corresponding percentile during the summer results from the impact of boreal wildfires during this season (section 2.3.2 and Chapter 3). If we exclude the observations impacted by boreal wildfires (section 2.3.2), the $\mathrm{NO}_{x}$ mean in North American outflow corresponds to the 70th percentile of all summertime nonfire impacted observations. Mean levels of daytime NO in these plumes ranged from 8 to 11 pptv, occasionally reaching 20 pptv. Although these levels may be insufficient for a net $\mathrm{O}_{3}$ production Klonecki and Levy, 1997, they may influence the $\mathrm{O}_{3}$ chemical tendency through changes in the $\mathrm{O}_{3}$ production rate Mauzerall et al., 1996].

\subsubsection{Implications for the $\mathrm{O}_{3}$ Production and Budget}

We examined the relationship between $\mathrm{NO}_{y}$ and $\mathrm{O}_{3}$ on a seasonal basis in Figure 2.9 (right column) to investigate the eventual source of $\mathrm{O}_{3}$ from exported nitrogen oxides. Seasonal average enhancement ratios are presented in Figure 2.9 and Table 2.6 summarizes the $\Delta \mathrm{O}_{3} / \Delta \mathrm{NO}_{y}$ ratios for each anthropogenic event.

The seasonal $\Delta \mathrm{O}_{3} / \Delta \mathrm{NO}_{y}$ averages indicate an approximately 90-fold, 130-fold and 40-fold enrichment of $\mathrm{O}_{3}$ relative to $\mathrm{NO}_{y}\left(\mathrm{~mol} \mathrm{~mol}^{-1}\right)$ during spring and fall, 
summer, and winter, respectively. The $\Delta \mathrm{O}_{3} / \Delta \mathrm{NO}_{y}$ of $130 \mathrm{ppbv}^{\mathrm{ppbv}}{ }^{-1}$ is an order of magnitude higher than what was observed in several rural sites in North America during the summer seasons (8.5-10 ppbv ppbv ${ }^{-1}$ Trainer et al., 1993; Olszyna et al., 1994), and is also higher than what was encountered in the FT over North America ( 30-120 ppbv ppbv ${ }^{-1}$ Ridley et al. 1994). The larger summer $\Delta \mathrm{O}_{3} / \Delta \mathrm{NO}_{y}$ observed at the Pico Mountain station is thus consistent with the high efficiency with which $\mathrm{O}_{3}$ is formed in the FT combined with the higher removal rate of $\mathrm{NO}_{y}$ (via $\mathrm{HNO}_{3}$ ) compared to that of $\mathrm{O}_{3}$ during transit to the measurement site. This result contrasts with prior studies over the North Atlantic region, which concluded that the marine BL and lower FT over the North Atlantic are generally on a state of net $\mathrm{O}_{3}$ destruction all year round [e.g., Helmig et al., submitted;Parrish et al., 1998, Reeves et al, 2002]. For example, Parrish et al. [1998] indicated that, in the North Atlantic marine $\mathrm{BL}$ during the winter, $\mathrm{O}_{3}$ is mostly removed by reaction with $\mathrm{NO}_{2}$ and $\mathrm{NO}$ and deposition, with a $\Delta \mathrm{O}_{3} / \Delta \mathrm{NO}_{y}$ ratio of -1.5 to $-1 \mathrm{~mol} \mathrm{~mol}^{-1}$.

To evaluate the ultimate impact of the transport of nitrogen oxides on the $\mathrm{O}_{3}$ budget over the North Atlantic region, we estimated the $\mathrm{O}_{3}$ production upwind of the Pico Mountain station resulting from the long-range transport of nitrogen oxides during the summer season. Estimates of the $\mathrm{O}_{3}$ production can be calculated using the flux of transported $\mathrm{NO}_{y}$ and the flux of transported $\mathrm{PAN}+\mathrm{NO}_{x}$, respectively, based on the measured $\Delta \mathrm{NO}_{y} / \Delta \mathrm{CO}$ and estimated $\mathrm{NO}_{y}$ speciation (i.e., $\mathrm{PAN}+\mathrm{NO}_{x}$ is $\sim 30 \%$ of $\mathrm{NO}_{y}$; section 2.2.3.1). The use of $\mathrm{NO}_{y}$ enhancement ratios gives approximately an upper estimate in the calculation of $\mathrm{O}_{3}$ production as it includes $\mathrm{HNO}_{3}$, which generally does not lead to $\mathrm{NO}_{x}$ generation, while the use of $\mathrm{PAN}+\mathrm{NO}_{x}$ gives a lower estimate, as it neglects the $\mathrm{O}_{3}$ produced upwind of Pico. Both methods are however biased low as the use of our observed $\Delta \mathrm{NO}_{y} / \Delta \mathrm{CO}$ ignores the oxidation of $\mathrm{NO}_{x}$ to $\mathrm{HNO}_{3}$, followed by removal of $\mathrm{HNO}_{3}$ upwind from the Pico Mountain station. We derived the flux of transported $\mathrm{NO}_{y}$ by multiplying the observed summer average $\Delta \mathrm{NO}_{y} / \Delta \mathrm{CO}\left(0.01 \mathrm{ppbv}^{\mathrm{ppbv}^{-1}}\right.$ Table 3.3 ) by the $\mathrm{CO}$ emissions for eastern U.S. 
in 2005. The daily amount of CO emitted in eastern U.S. (estimated as 2/3 of the total national emissions and adjusted for the $8.8 \%$ per year decrease of the onroad CO: $\mathrm{NO}_{x}$ emission ratio Parrish et al. 2004]) corresponds to $4.7 \mathrm{Gmol} \mathrm{day}^{-1}$. Thus, the resulting long-range-transported $\mathrm{NO}_{y}$ is $0.047 \mathrm{Gmol}^{-1}{ }^{-1}$ and, similarly, transported PAN $+\mathrm{NO}_{x}$ is $0.014 \mathrm{Gmol}$ day ${ }^{-1}$. Liang et al. [1998] estimated that 39 and 64 molecules of $\mathrm{O}_{3}$ are produced for each $\mathrm{NO}_{x}$ or PAN molecule advected downwind from North America at altitudes below and above $2.6 \mathrm{~km}$, respectively. Thus, the resulting $\mathrm{O}_{3}$ production can be derived by multiplying these $\mathrm{O}_{3}$ production efficiencies by the amount of $\mathrm{PAN}+\mathrm{NO}_{x}$ and $\mathrm{NO}_{y}$ transported to the central North Atlantic region. The result is approximately $1.8-3 \mathrm{Gmol}$ of $\mathrm{O}_{3}$ produced upwind of the Pico Mountain station per day. The formation of $\mathrm{O}_{3}$ resulting from transport of nitrogen oxides is quite important. For comparison, the amount of $\mathrm{O}_{3}$ produced in eastern U.S. BL and directly exported to the North Atlantic is 1.9-2.4 $\mathrm{Gmol}_{\text {day }}{ }^{-1}$. (This estimate is based on the $\Delta \mathrm{O}_{3} / \Delta \mathrm{CO}$ of $0.4-0.5 \mathrm{ppbv}^{\mathrm{ppbv}}{ }^{-1}$ observed downwind from North America [Hudman et al., North American influence on tropospheric ozone and the effects of recent emission reductions: constraints from ICARTT aircraft observations and the daily eastern U.S. emissions, manuscript in preparation] and the daily eastern U.S. CO emissions). It is important to note that, in these calculations, we did not account for chemical loss of $\mathrm{O}_{3}$ and for chemical sinks and sources of $\mathrm{CO}$, and assume that all PAN decomposes to $\mathrm{NO}_{x}$.

The occurrence of $\mathrm{O}_{3}$ formation in the North American plumes observed at the Pico Mountain station and the significant amount of $\mathrm{O}_{3}$ produced from the long-range transport of nitrogen oxides imply an impact on the regional $\mathrm{O}_{3}$ budget, even during the wintertime. 


\subsubsection{Influence of Boreal Wildfires}

Transport of North American boreal wildfire emissions significantly impacted the nitrogen oxides measured at the Pico Mountain station during summer 2004 Val Martin et al. 2006. On an event-by-event basis, the average levels of nitrogen oxides in boreal wildfire plumes were above levels observed during flow from boreal regions without fire emissions and well above typical summertime background over the central North Atlantic lower FT Val Martin et al., 2006]. We expand here this previous work and investigate the degree to which boreal wildfire emissions modulate the nitrogen oxides background in the central North Atlantic lower FT. For this purpose, we analyzed nitrogen oxides observations made from June 1 to September 15 in 2004 and 2005. Similar to summer 2004, summer 2005 boreal wildfire emissions from Canada and Alaska frequently impacted the Pico Mountain station [Lapina, et al., (in preparation)]. In summer 2002 and 2003, wildfires emissions from Quebec and Siberia, respectively, impacted the measurement site Honrath et al., 2004. However, nitrogen oxides measurements were limited during those summers (Figure 2.1). The time frame of June 1-September 15 was selected since it covers the typical active burning season over northern North America Pfister et al. 2005] and allows for the 1-2 weeks transport time to the measurement site at the end of the season.

We subdivided the data into two categories: one category representing observations significantly influenced by boreal wildfires ("fire") and a second category representing observations with minimal or no fire impact ("non-fire"). Fire and non-fire observations were selected based on the intensity of North American boreal wildfires impact simulated by the FLEXPART Fire-CO. The 25th and 75th percentiles of all FLEXPART Fire-CO values for each summer were used for the "non-fire" and "fire" cutoffs, respectively. These lower and upper cutoff values were selected to allow both categories to contain a similar number of data points. The cutoff values were different for each year, i.e. $1.4 \mathrm{ppbv}$ and $16.4 \mathrm{ppbv}$ for 2004 and $0.9 \mathrm{ppbv}$ and $5.6 \mathrm{ppbv}$ for 

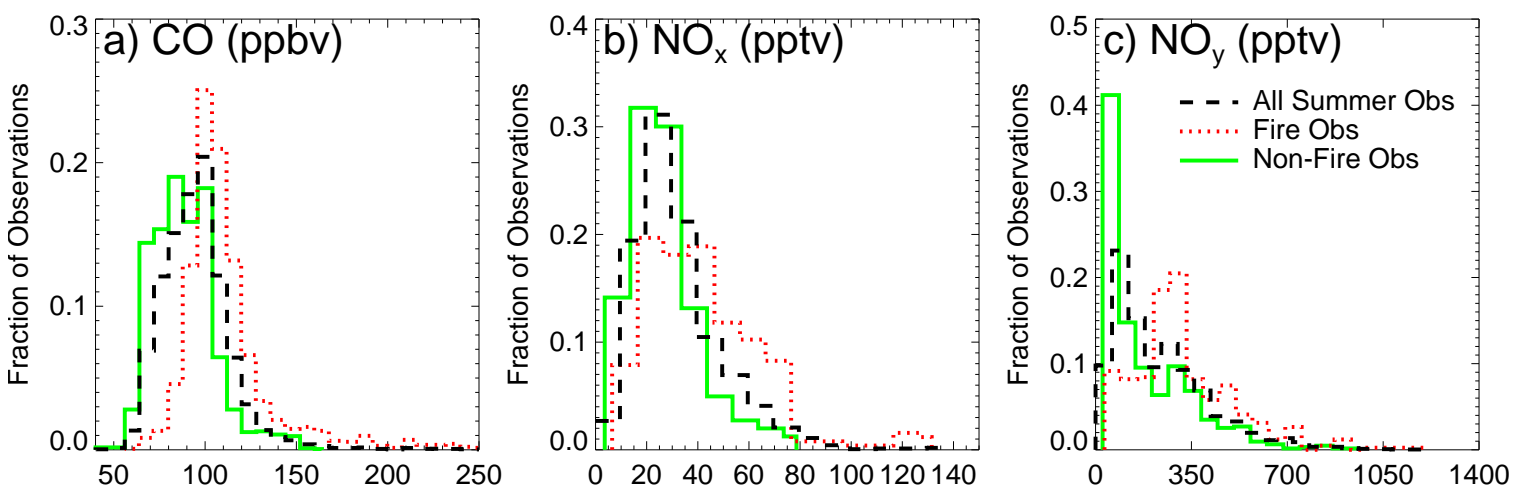

Figure 2.10 Histograms of a) $\mathrm{CO}, \mathrm{b}) \mathrm{NO}_{x}$ and c) $\mathrm{NO}_{y}$ of all summertime observations (black dashed lines), all fire observations (red dotted lines) and all non-fire observations (green solid lines), in 2004 and 2005.

2005, reflecting the different intensity of the boreal wildfires in 2004 and 2005. Figure 2.10 shows the distribution of $\mathrm{NO}_{x}$ and $\mathrm{NO}_{y}$ for the fire and non-fire periods. We also show the distribution for all summer observations. (The distribution of CO is also shown for comparison.) Table 2.7 summarizes the statistical parameters of each distribution for each summer.

Boreal wildfire emissions significantly affected the summertime distribution of nitrogen oxides at the Pico Mountain station. $\mathrm{NO}_{y}$ median values in the fire subset were 175 pptv and 115 pptv larger than those in the non-fire subset in 2004 and 2005, respectively. Similarly, the difference in the $\mathrm{NO}_{x}$ median values were 30 pptv in 2004 and 9 pptv in 2005. As expected, median values for CO were also larger in the fire subset relative to the non-fire subset, with a difference of 40 ppbv in 2004 and 10 ppbv in 2005. A non-parametric Wilcoxon Sum-rank and a student $t$-test indicated that all distributions and the means of distributions were significantly different at a 0.01 level of significance. Larger differences in the median values were observed in 2004 relative to 2005. This is due to the higher fire activity over the North American boreal region in 2004 than in 2005: total CO emissions estimated using the Boreal Wildland-Fire Emissions Model were $37 \mathrm{Tg}$ in summer 2004, whereas they were $24 \mathrm{Tg}$ in 2005 [Lapina et al., (in preparation)].

To verify that the difference in the medians was the result of boreal wildfire emis- 


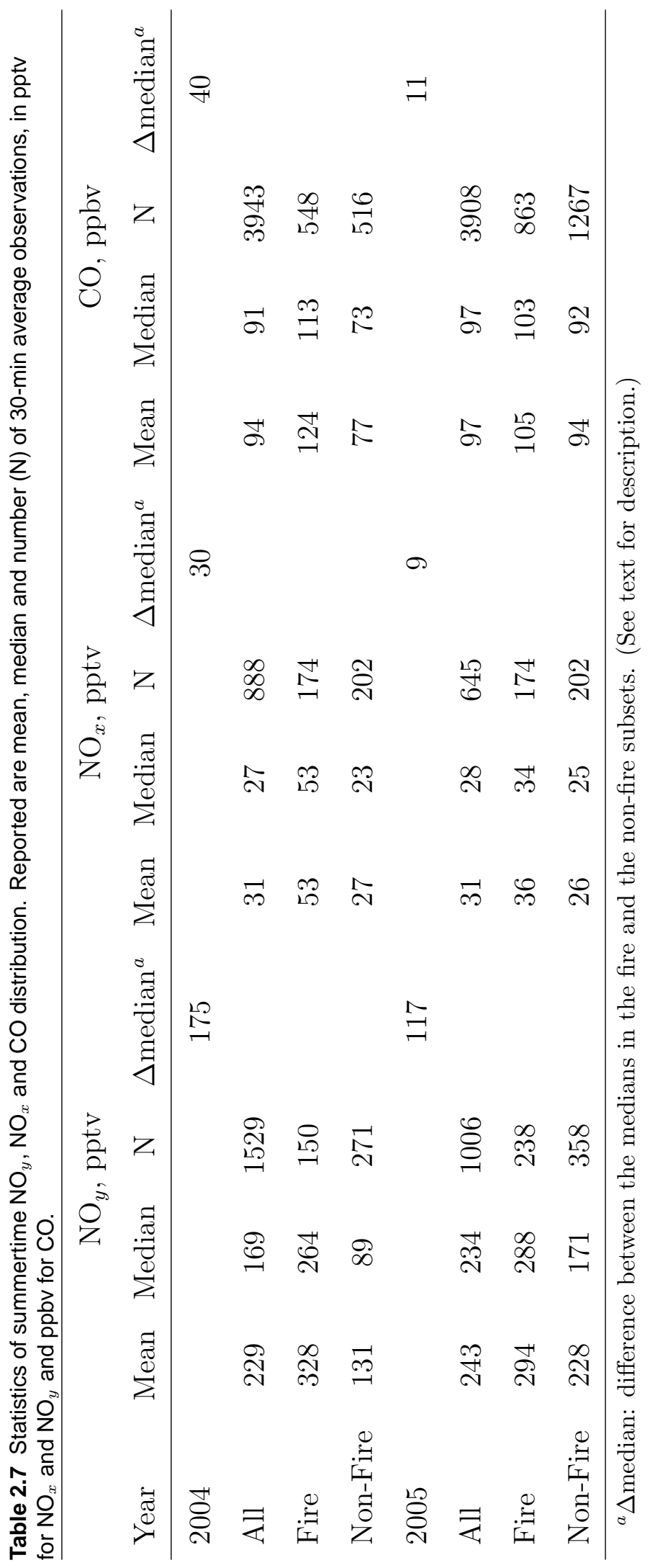


sions, we inspected the periods selected in each category. While the non-fire subset contained observations made in a mixture of both non-boreal and boreal air without wildfire emissions, the fire subset included mainly periods when boreal outflow reached the Pico Mountain station during the active burning season [ Val Martin et al., 2006; Lapina et al., in preparation]. Thus, we conclude that the difference in both subsets may be attributed to the presence of boreal wildfire emissions.

The impact of boreal wildfire emissions on the nitrogen oxides levels may have important implications for the global tropospheric $\mathrm{O}_{3}$ budget [e.g. Val Martin et al., 2006, Pfister et al., 2006; Real et al., 2007. Lapina et al. 2006 showed evidence of the significant impact of boreal wildfire emissions on the $\mathrm{O}_{3}$ background over the North Atlantic region. Consistent with Lapina et al. 2006], the difference between the median values in the non-fire and fire subsets for $\mathrm{O}_{3}$ were 26 ppbv in 2004 and 17 ppbv in 2005 (not shown).

Overall, these analyses indicate that boreal wildfires were responsible for the shift in the nitrogen oxides distributions toward higher mixing ratios. Given the long distance from the boreal region to the Pico Mountain station, this implies very largescale impacts on the background $\mathrm{NO}_{x}$ and $\mathrm{NO}_{y}$ levels in the midlatitude lower $\mathrm{FT}$.

\subsection{Summary and Conclusions}

Measurements of nitrogen oxides made at the Pico Mountain station from July 2002 to August 2005 were used to estimate the magnitude and seasonal variability of nitrogen oxides over the central North Atlantic lower FT and to determine the processes that contribute to this variability.

These measurements reveal the presence of a well-defined seasonal cycle of nitrogen oxides in the background central North Atlantic lower FT, with larger mixing ratios during the summertime. Median $\mathrm{NO}_{x}$ and $\mathrm{NO}_{y}$ of 17-31 pptv and 125-338 pptv observed at the Pico Mountain station were lower than those previously observed 
over the western North Atlantic region and more similar to those observed at the remote marine North Pacific MLO station. The observed $\mathrm{NO}_{x}$ and $\mathrm{NO}_{y}$ levels were consistent with long-range transport of emissions with significant removal upwind of the measurement site.

Observations of $\mathrm{NO}_{x}$ and $\mathrm{NO}_{y}$ and estimates of $\mathrm{PAN}$ and $\mathrm{HNO}_{3}$ indicate that reactive nitrogen over the central North Atlantic lower FT largely exists in the form of $\mathrm{HNO}_{3}$ and PAN, independent of the season. A shift from dominance of PAN in winter-spring to dominance of $\mathrm{HNO}_{3}$ in summer-fall that occurs over this region is attributed to strong decomposition of PAN to $\mathrm{NO}_{x}$ and efficient formation of $\mathrm{HNO}_{3}$ from rapid reaction of $\mathrm{NO}_{x}$ with $\mathrm{OH}$ during the summer and fall seasons.

Nitric acid contributes $53-71 \%$ of $\mathrm{NO}_{y}$ during the summer. Given the significant removal of $\mathrm{NO}_{y}$ during transport, this suggests that the oxidation of $\mathrm{NO}_{x}$ resulting from decomposition of PAN in the airmasses during subsidence, or advection over the ocean with minimal removal, results in a significant source of $\mathrm{HNO}_{3}$ to the central North Atlantic lower FT. The decomposition of PAN in the airmasses has important implications for $\mathrm{O}_{3}$ formation, since released $\mathrm{NO}_{x}$ is available to form $\mathrm{O}_{3}$ before oxidation to $\mathrm{HNO}_{3}$ during transport to the central North Atlantic lower FT.

North American anthropogenic emissions impacted the measurement site all year round. Enhancements of $\mathrm{NO}_{y}$ in North America outflow show that, consistent with previous observations, the majority $(95-97 \%)$ of $\mathrm{NO}_{x}$ emitted over the U.S. is removed before or during export out of the U.S. BL. However, these fractions imply that about $30 \%$ of the emissions that escapes the U.S. BL is efficiently transported as $\mathrm{NO}_{y}$ to the lower FT over the central North Atlantic region. Enhancements of $\mathrm{NO}_{x}$ in these plumes indicate that decomposition of PAN to $\mathrm{NO}_{x}$ and potentially photolysis of $\mathrm{HNO}_{3}$ occurring in the airmasses during subsidence and/or advection westward to the Azores constitute a significant source of $\mathrm{NO}_{x}$ to the central North Atlantic lower FT, in particular during the fall. Observed $\Delta \mathrm{O}_{3} / \Delta \mathrm{NO}_{y}$ and large $\mathrm{NO}_{y}$ levels remaining in the North American plumes suggest a potential for $\mathrm{O}_{3}$ formation well downwind 
from North America. For example, during the summer, $\mathrm{O}_{3}$ formation downwind from North America resulting from the transport of nitrogen oxides may be as important as the direct export of $\mathrm{O}_{3}$ produced within the U.S. BL.

Boreal wildfire emissions were responsible for significant shifts in the nitrogen oxides distributions toward higher levels, when medians $\mathrm{NO}_{x}$ and $\mathrm{NO}_{y}$ were respectively 117-175 pptv and 9-30 pptv, greater with the presence of boreal wildfire emissions. Since our observations were made very far downwind from the boreal region, we conclude that aged boreal fire emissions significantly altered the background $\mathrm{NO}_{x}$ and $\mathrm{NO}_{y}$ levels over a large region of the Northern Hemisphere. During the summer, boreal wildfire emissions appear to cover the impact caused by North American emissions. This highlights the need to understand the impact of boreal wildfires on tropospheric $\mathrm{NO}_{x}$ levels and the resulting implications for $\mathrm{O}_{3}$, in order to evaluate the influence of anthropogenic emissions on the $\mathrm{NO}_{x}$ and $\mathrm{O}_{3}$ budgets during the summer season.

A comparison of nitrogen oxides observations with GEOS-Chem simulations indicates that GEOS-Chem reproduces the seasonal variation of nitrogen oxides over the central North Atlantic lower FT. However, it does not capture the magnitude of the cycles. Important differences were found for PAN, a critical species in the global formation of $\mathrm{O}_{3}$ via dispersal and release of $\mathrm{NO}_{x}$. Over recent decades, there have been significant changes in global fossil-fuel $\mathrm{NO}_{x}$ emission Richter et al., 2005, and even larger emissions are expected in the future. In addition, as a result of climate change, more frequent and severe boreal wildfires are also expected, which will result in an increase in the boreal wildfire emissions Stocks et al., 1998; Flannigan et al., 2000]. Therefore, accurate simulation of the fate and transport of nitrogen oxides is necessary to understand how these emissions have impacted, and will impact, tropospheric $\mathrm{NO}_{x}$ at hemispheric scales and the resulting implications for tropospheric $\mathrm{O}_{3}$. 


\section{Chapter 3}

\section{Impacts of North American Boreal Wildfire Emissions on the North Atlantic Lower Free Troposphere ${ }^{\dagger}$}

Boreal wildfires are large sources of reactive trace gases and aerosols in the atmosphere [e.g., Goode et al., 2000; Andreae and Merlet, 2001]. The large amounts of trace gases and aerosols emitted by boreal forest fires are subject to long-range transport, with the potential to affect air quality from regional to global scales. Boreal wildfire plumes have been detected over continental Wotawa and Trainer, 2000], intercontinental Forster et al., 2001; Honrath et al., 2004, and even hemispheric Damoah et al. 2004 distances. It is recognized that boreal wildfires play an important role in the magnitude and interannual variability of tropospheric background $\mathrm{CO}$ in the Northern Hemisphere [e.g., Novelli et al., 2003; Edwards et al., 2004; Kasischke et al., 2005]. Recent studies have also shown increased mean background summertime $\mathrm{O}_{3}$

†This chapter is based on material previously published as Val Martín M., R. Honrath, R.C. Owen, G. Pfister, P. Fialho and F. Barata (2006), Significant enhancements of nitrogen oxides, ozone and aerosol black carbon in the North Atlantic lower free troposphere resulting from North American boreal wildfires, J. Geosphys. Res., 111, D23S60, doi:10.1029/2006JD007090. 
over northwestern North America JJaffe et al., 2004], the central North Atlantic Lapina et al. 2006 and Europe Simmonds et al., 2005 associated with fire emissions transport. This indicates that boreal wildfires may also impact background $\mathrm{O}_{3}$.

Ozone plays an important role in the chemistry of the atmosphere since it is estimated to be the third most important greenhouse gas [Alley et al. 2007, and is the primary source of tropospheric hydroxyl radical. In addition, $\mathrm{O}_{3}$ has negative impacts on ecosystems and human health. Typically, tropospheric $\mathrm{O}_{3}$ production in the Northern Hemisphere is driven by anthropogenic emissions. However, boreal wildfires are an important source of $\mathrm{CO}, \mathrm{NO}_{x}$ and $\mathrm{NMHCs}$, resulting in the potential for significant formation of $\mathrm{O}_{3}$ during the boreal fire season. Large-scale impacts of boreal fire emissions on tropospheric $\mathrm{O}_{3}$ can occur as a result of dispersion of $\mathrm{O}_{3}$ formed in boreal wildfire plumes. Alternatively, impacts on $\mathrm{CO}, \mathrm{NO}_{x}$ and $\mathrm{NMHCs}$ in the remote atmosphere could also lead to impacts on the $\mathrm{O}_{3}$ budget over a large region.

The magnitude of the resulting impact of boreal wildfire emissions on tropospheric ozone is not yet well quantified. Prior observations in boreal wildfire plumes indicate $\mathrm{O}_{3}$ enhancements that range from very low in fresh plumes [e.g., Goode et al., 2000; Tanimoto et al., 2000] to low in moderately-aged plumes [e.g., Wofsy et al., 1992; Mauzerall et al., 1996] to high in well-aged plumes [e.g., Honrath et al., 2004, Bertschi and Jaffe, 2005. Boreal wildfire emissions have a large degree of variability, and are a function of fuel type (e.g., peat fires versus crown fires) and/or burning conditions (e.g., smoldering versus flaming) Goode et al., 2000, Kasischke et al., 2005. This causes uncertainty and variability in the emissions of $\mathrm{NO}_{x}$, a critical compound that controls $\mathrm{O}_{3}$ production rate.

Measurements of a number of reactive nitrogen species over the North American boreal region were made during the ABLE3A and ABLE3B campaigns. These studies showed that the reactive nitrogen distribution over this region was significantly affected by boreal wildfire emissions [e.g., Sandholm et al., 1992; Singh et al., 1994. 
However, the photochemical $\mathrm{O}_{3}$ production resulting from boreal wildfire $\mathrm{NO}_{x}$ emissions was concluded to be a negligible source of $\mathrm{O}_{3}$ over this region Jacob et al., 1992 ; Mauzerall et al. [1996], due to a combination of low $\mathrm{NO}_{x}$ emissions and low estimated total fire magnitude. However, these studies suggested that dispersion of PAN produced in the fire plumes may provide a major source of $\mathrm{NO}_{x}$, particularly in warmer layers of the troposphere at low altitude Jacob et al., 1992; Singh et al., 1994, and hence could contribute to $\mathrm{O}_{3}$ production far downwind from the fires. Consistent with this expectation, DeBell et al. 2004 reported significant enhancements of $\mathrm{NO}_{y}$ and $\mathrm{O}_{3}$ at several surface sites over the eastern U.S. resulting from a Quebec boreal wildfire plume in July 2002. However, most of these measurements were made in the boundary layer, and loss of $\mathrm{NO}_{y}$ and $\mathrm{O}_{3}$ by surface deposition may have obscured the true magnitude of the fire plume aloft.

In addition to trace gases, boreal wildfires emit large amounts of aerosol black carbon $(\mathrm{BC})$, on average about $10 \%$ of the annual anthropogenic $\mathrm{BC}$ emissions in the Northern Hemisphere Bond et al., 2004]. Recently, it has been shown that BC emissions from boreal wildfires and anthropogenic sources can be efficiently transported to remote regions, such as the Arctic Stohl et al. 2006 and the northwestern Pacific region Park et al. 2005. BC emissions are a significant factor in climate change due to their absorption of light in the atmosphere Hansen et al., 2000, Bond and Sun, 2005. Therefore, the export of BC far downwind from the source emissions may contribute to the radiative forcing of the atmosphere, and thereby affect climate.

During summer 2004, extensive wildfires burned in Alaska - the largest area on record - and western Canada, releasing large amounts of trace gases and aerosols into the atmosphere. For instance, CO emitted from mid-June to August was on the order of the anthropogenic CO emissions for the entire continental U.S. during that same time period [Pfister et al., 2005; Turquety et al., 2007]. Intense plumes of these boreal wildfires were observed over large regions of North America and Europe by research aircraft Flocke et al., 2005; Real et al., 2007; de Gouw et al., 2006 and at 
several sites over the Arctic Stohl et al. 2006] during the International Consortium for Atmospheric Research on Transport and Transformation (ICARTT) study Fehsenfeld et al. 2006.

In this chapter, we present measurements of the composition of highly aged plumes from these fires sampled in the North Atlantic lower free troposphere (FT), using measurements at the Pico Mountain station. Measurements of $\mathrm{CO}, \mathrm{BC}, \mathrm{NO}_{y}, \mathrm{NO}_{x}$ and $\mathrm{O}_{3}$ made from June to early September, 2004, are analyzed to assess the impact of boreal wildfires on levels of aerosol $\mathrm{BC}$ and nitrogen oxides $\left(\mathrm{NO}_{x}\right.$ and $\left.\mathrm{NO}_{y}\right)$ over the central North Atlantic lower FT, to characterize the associated enhancements of $\mathrm{O}_{3}$ in highly aged plumes, and to determine the resulting implications of the North American boreal wildfires for the regional and hemispheric $\mathrm{NO}_{x}$ and $\mathrm{O}_{3}$ budgets.

\subsection{Experimental Methods}

\subsubsection{Pico Mountain Station}

Observations of $\mathrm{CO}, \mathrm{BC}, \mathrm{NO}_{x}, \mathrm{NO}_{y}$ and $\mathrm{O}_{3}$ were made at the Pico Mountain observatory from June to September, 2004. The Pico Mountain station is situated on the summit caldera of the inactive volcano Pico (altitude $2.2 \mathrm{~km}$ ) in the Azores Islands, Portugal $\left(38^{\circ} \mathrm{N}, 28^{\circ} \mathrm{W}\right)$. The Azores are frequently impacted by airflow from high latitudes, which can transport emissions from boreal wildfires in Canada, Alaska and Siberia, and bring them to the Azores 6 to 15 days later. The station is located in the lower FT since marine boundary layer heights in this region are typically less than 1 $\mathrm{km}$ during the summer. Upslope flow can transport air from lower altitudes to the mountaintop, including occasionally from the boundary layer. However, a detailed assessment of the impact of upslope flow to the station found that upslope flow affects the Pico Mountain station much less than it does many other mountain observatories,

and on many summer days tropospheric air is sampled throughout the day Kleissl 
et al., 2007]. From June to September 2004, less than $25 \%$ of the time presented the meteorological conditions necessary for an air mass from below the mountain to reach the summit, i.e., weak synoptic winds and strong insolation for buoyant driven lifting or strong synoptic winds for mechanically driven lifting. Periods potentially affected by upslope flow were identified as described by Kleissl et al. 2007] and removed from the analysis. None of the periods discussed in detail below contain data affected by upslope flow. Further details on the Pico Mountain station and the occurrence of upslope flow to the station are presented elsewhere Honrath et al., 2004; Kleissl et al. 2007.

\subsubsection{Measurements}

\subsubsection{Nitrogen oxides}

$\mathrm{NO}, \mathrm{NO}_{2}$, and $\mathrm{NO}_{y}$ were determined by an automated $\mathrm{NO}_{x, y}$ system developed at Michigan Technological University. This $\mathrm{NO}_{x, y}$ system is an improved version of the instrument previously described by Peterson and Honrath [1999]. NO, $\mathrm{NO}_{2}$, and $\mathrm{NO}_{y}$ were determined using established techniques: $\mathrm{NO}$ detection by $\mathrm{O}_{3}$ chemiluminescence Ridley and Grahek, 1990, $\mathrm{NO}_{2}$ by conversion to $\mathrm{NO}$ via ultraviolet photodissociation Kley and McFarland, 1980, Parrish et al., 1990, and $\mathrm{NO}_{y}$ by Au-catalyzed reduction to NO in the presence of CO Bollinger et al., 1983; Fahey et al., 1985. The $\mathrm{NO}_{x, y}$ system was operated on an automated cycle, which included twice-daily NIST-traceable calibration with $\mathrm{NO}$ and $\mathrm{NO}_{2}$, regular measurements of $\mathrm{NO}$ and $\mathrm{NO}_{2}$ (twice per week) and $\mathrm{NO}_{y}$ (once per week) artifacts in zero air, and determination of the $\mathrm{NO}_{y}$ conversion efficiency in ambient air of two $\mathrm{NO}_{y}$ compounds (i-propyl nitrate and $\left.\mathrm{HNO}_{3}\right)$ and one non- $\mathrm{NO}_{y}$ compound $\left(\mathrm{CH}_{3} \mathrm{CN}\right)$. Measurements were recorded as 30 -s averages ( $\mathrm{NO}$ and $\left.\mathrm{NO}_{2}\right)$ and 20-s averages $\left(\mathrm{NO}_{y}\right)$ every $10 \mathrm{~min}$, and were further averaged to obtain the 30-min averages used in this work. Ambient $\mathrm{NO}_{2}$ was determined by subtracting the signal due to ambient $\mathrm{NO}$ from the $\mathrm{NO}_{2}$ instrument signal, 
and further multiplying this term by the $\mathrm{NO}_{2}$ sensitivity Gao et al. 1994. $\mathrm{NO}_{x}$ was calculated as the sum of the 30-s average measurements of $\mathrm{NO}$ and $\mathrm{NO}_{2}$ during a single measurement cycle.

Total uncertainty of the $\mathrm{NO}, \mathrm{NO}_{2}$ and $\mathrm{NO}_{y}$ measurements at low mixing ratios resulted from measurement precision and uncertainty in the instrument artifact correction, while measurement accuracy was the primary source of uncertainty at higher levels. The precision of individual measurements was mainly attributable to counting noise, which resulted from photon counting statistics. Excluding periods with high ambient variability, the precision $(2-\sigma)$ of the 30-min averages was less than 6 pptv (median 5 pptv) for NO, less than 13 pptv (median 10 pptv) for $\mathrm{NO}_{2}$, less than 14 pptv (median 10 pptv) for $\mathrm{NO}_{x}$, and less than 9 pptv (median 6 pptv) for $\mathrm{NO}_{y}$. Potential bias resulting from uncertainty in the artifact correction was estimated to be less than 2 pptv for $\mathrm{NO}, 4$ pptv for $\mathrm{NO}_{2}, 4$ pptv for $\mathrm{NO}_{x}$ and 2 pptv for $\mathrm{NO}_{y}$. Measurement accuracy was estimated to be $4 \%$ based on total uncertainty of the sample and calibration mass flow controllers and the NO standard calibration gas mixing ratio.

Accuracy of the $\mathrm{NO}_{y}$ measurements also depends on the effective conversion of $\mathrm{NO}_{y}$ compounds and the lack of significant conversion of non- $\mathrm{NO}_{y}$ compounds Fahey et al., 1985; Kliner et al., 1997; Kondo et al., 1997, in addition to the accurate determination of the resulting NO. Based on standard addition tests and regular calibrations, the observed $\mathrm{NO}_{y}$ included $92-100 \%$ of the actual $\mathrm{NO}_{2}$ level (typically 97-100\%), with similar values expected for PAN [Fahey et al., 1985, 70-100\% of the actual $\mathrm{HNO}_{3}$ level, and $80-100 \%$ of the actual i-propyl nitrate. Measurements of $\mathrm{NO}_{y}$ presented in this work were corrected for non-unity $\mathrm{NO}_{y}$ conversion by using the $\mathrm{NO}_{2}$ conversion efficiencies measured at the system. A maximum correction of $8 \%$ was applied, and mainly affected the $\mathrm{NO}_{y}$ observations made from mid-July to mid-August when a degraded $\mathrm{NO}_{y}$ converter lowered the $\mathrm{NO}_{2}$ conversion efficiency to $92-95 \%$. A manual wet cleaning procedure was implemented in mid-August, and 
the $\mathrm{NO}_{2}$ conversion efficiency was restored back to the expected value of $97-100 \%$. In addition to the incomplete conversion of the $\mathrm{NO}_{y}$ species, this type of $\mathrm{NO}_{y}$ converter may overestimate true $\mathrm{NO}_{y}$ levels Fahey et al., 1985; Kliner et al., 1997. However, that was not a problem during this study. Interference from reduced nitrogen species (such as $\mathrm{NH}_{4}, \mathrm{HCN}$, and $\mathrm{CH}_{3} \mathrm{CN}$ ) was found to be always less than $0.3 \%$ during regular (twice-daily) testing using standard addition of $\mathrm{CH}_{3} \mathrm{CN}$, a potential $\mathrm{NO}_{y}$ interferant present in biomass-burning plumes de Gouw et al., 2003. This level of $\mathrm{CH}_{3} \mathrm{CN}$ conversion in our system did not significantly contribute to the observations of $\mathrm{NO}_{y}$ gathered during boreal wildfire plumes: using the maximum enhancement of $\mathrm{CH}_{3} \mathrm{CN}$ relative to $\mathrm{CO}\left(3.52 \mathrm{pptv} \mathrm{CH}_{3} \mathrm{CN} / \mathrm{ppbv} \mathrm{CO}\right)$ in the boreal fire plumes intercepted by the NOAA WP-3 research aircraft during summer 2004 de Gouw et al., 2006], we estimate that the maximum impact of $\mathrm{CH}_{3} \mathrm{CN}$ on the $\mathrm{NO}_{y} / \mathrm{CO}$ enhancement ratios presented below is $0.01 \mathrm{pptv} / \mathrm{ppbv} \mathrm{CO}$, less than $0.2 \%$ of the lowest $\mathrm{NO}_{y} / \mathrm{CO}$ enhancement ratio reported below.

Observations of nitrogen oxides made during periods with near-calm winds and high ambient variability were also excluded from the analysis. This was done for two reasons. First, calm winds may lead to the removal of $\mathrm{HNO}_{3}$ by deposition on the mountain surface. Therefore, observations of $\mathrm{NO}_{y}$ during these periods may not be representative of the actual upwind $\mathrm{NO}_{y}$ levels. Second, unexpected spikes in ambient $\mathrm{NO}_{x}$ and $\mathrm{NO}_{y}$ were sometimes observed during low-wind periods (usually wind speeds less than $3 \mathrm{~m} / \mathrm{s}$ ), suggesting that a local source may have perturbed the measurements. Based on analysis of air sampled directly at several volcano vents (with $\mathrm{NO}_{x}$ reaching 1 to $8 \mathrm{ppbv}$ ), we deduce that volcanic emanations were the cause of the observed spikes. Therefore, to ensure that all the $\mathrm{NO}_{x}$ and $\mathrm{NO}_{y}$ observations were representative of free tropospheric air, we excluded (1) measurements made during low to calm winds (wind speed $<1 \mathrm{~m} / \mathrm{s}$ ), to avoid including $\mathrm{NO}_{y}$ observations with potential $\mathrm{HNO}_{3}$ removed on the mountain surface, and (2) measurements with high ambient variability, to avoid including nitrogen oxides resulting from volcanic 
emissions. For this purpose, periods with high ambient variability were defined as those when the 30-min $\mathrm{NO}_{x}$ standard error was above 10 pptv or the 30-min $\mathrm{NO}_{y}$ standard error exceeded $10 \mathrm{pptv}+0.25\left(\left[\mathrm{NO}_{y}\right]-90\right)$, where the second term was included to allow increased variability during periods of high $\mathrm{NO}_{y}$. The wind speed criterion removed $7 \%$ of the measurements during the study period, and the ambient variability screen removed an additional $23 \%$.

\subsubsection{2 $\mathrm{CO}$ and $\mathrm{O}_{3}$}

CO was measured by a non-dispersive infrared (NDIR) photometer (Thermo Environmental, Inc. (TEI), Model 48C-TL), modified as described by Parrish et al. [1994 and calibrated daily with a CO calibration gas referenced to the NOAA Global Monitoring Division standard. The instrument alternated between two minutes of zero measurement and two minutes of ambient measurement; the first minute of each mode was discarded to ensure equilibration. $\mathrm{O}_{3}$ was measured with a commercial ultraviolet absorption instrument (Thermo Environmental, Inc., Model 49C). The stability of the zero reading and the absence of $\mathrm{O}_{3}$ loss in the inlet and line were confirmed on a daily basis. $\mathrm{CO}$ and $\mathrm{O}_{3}$ data were recorded as one minute averages, and were further averaged to obtain the 30 minute averages used in this work. CO measurement uncertainty $(2-\sigma)$ was estimated to be $7 \%$ based on total uncertainty of the sample and calibration mass flow controllers and the CO calibration standard mixing ratio. The 30-min averages used in this work averaged 7 to 8 one-min average points, and had a precision $(2-\sigma)$ of 9 ppbv from June to mid-July, and 4 ppbv after

mid-July. $\mathrm{O}_{3}$ measurement precision $(2-\sigma)$ was usually less than $1 \mathrm{ppbv}$, based on the standard deviation of the 30 one-min measurements included in each 30-min average. More details on the $\mathrm{CO}$ and $\mathrm{O}_{3}$ instruments are presented by Owen et al. 2006] and Honrath et al. 2004. 


\subsubsection{Aerosol Black Carbon}

Measurements of aerosol light absorption at seven wavelengths $(0.37,0.47,0.52,0.59$, 0.66, 0.88 and $0.95 \mu \mathrm{m}$ ) were conducted using an aethalometer (Magee Scientific, Model AE31). Briefly, this instrument determines the attenuation of light at these wavelengths transmitted through particles accumulated on a quartz filter, relative to a clean spot on the same filter. The change in attenuation as a function of time is used to determined the light absorption coefficient $\left(\sigma_{\text {aerosol }}\right)$. The $\sigma_{\text {aerosol }}$ as a function of wavelength is analyzed to identify the presence of non-BC absorbing compounds Fialho et al., 2005 (none were significant during the period discussed here) and converted to $\mathrm{BC}$ using the calibration constant recommended by the manufacturer (14.6 $\left.\mu \mathrm{m} \mathrm{m}^{2} \mathrm{~g}^{-1}\right)$. The detection limit of the aethalometer depends mainly on the stability of the optics, filter spot area errors, flow rate uncertainties and time error, and was estimated to be $25 \mathrm{ng} \mathrm{m}^{-3}(2-\sigma)$ for the integration period of one hour. More details on the aethalometer used in this study and the approach used to determine the BC concentrations are presented elsewhere Fialho et al., 2005.

\subsubsection{Model Simulations and Transport Analysis}

To identify periods apparently impacted by upwind boreal wildfire emissions, we examined CO mixing ratios simulated at the Pico Mountain station by the Model for OZone and Related Chemical Tracers (MOZART) global chemical transport model Horowitz et al., 2003]. MOZART simulations were driven by 6-hourly meteorological fields from the National Centers for Environmental Predictions (NCEP) National Center for Atmospheric Research re-analysis. The spatial resolution of the model is $\sim 2.8^{\circ} \times 2.8^{\circ}$ with 28 levels between the surface to $2 \mathrm{hPa}$. The chemical time step of the model is 20 minutes. Emissions of CO from the 2004 North American boreal wildfires were optimized to match MOPITT CO observations using an inverse modelling technique Pfister et al. 2005. Boreal wildfire CO emissions were injected 
uniformly from 0 to $9 \mathrm{~km}$. MOZART simulations used in this work are mixing ratios averaged over 2-hr intervals and interpolated to the pressure and location of the Pico Mountain observatory Pfister et al. 2006. To assess the magnitude of fire impact at the Pico Mountain station, we used the MOZART-simulated ratio of CO fire tracer (CO emitted from North American boreal wildfires) to total CO mixing ratio (i.e., $[\mathrm{CO}]_{\text {fire }} /[\mathrm{CO}]_{\text {total }}$ ) interpolated to the measurement times (hereinafter termed the "MOZART fire-CO fraction").

A second MOZART tracer was used for U.S. anthropogenic CO emissions to evaluate the contribution of anthropogenic emissions during the fire-impacted observations. For this purpose, we used the MOZART-simulated ratio of U.S. anthropogenic CO tracer to total CO mixing ratio at the Pico Mountain station (i.e., $[\mathrm{CO}]_{\text {anthro }} /[\mathrm{CO}]_{\text {total }}$ ) interpolated to the 30-min average field observations (hereinafter termed the "MOZART anthro-CO fraction").

To complement field observations and MOZART simulations, we used backward trajectories analysis. We calculated backward trajectories with the Hybrid SingleParticle Lagrangian Integrated Trajectories (HYSPLIT-4) model Draxler and Rolph, 2003. This model uses 6-hourly data from the NCEP global FNL meteorological dataset. Ten-day backward trajectories were calculated every hour. At each hourly arrival time, six backward trajectories ending at six different locations near the Pico Mountain station were calculated: one centered at the station, four separated from the first by $1^{\circ}$ latitude and longitude, and one below the station, at $2000 \mathrm{~m}$.

\subsection{Results and Discussion}

Time series of $\mathrm{CO}, \mathrm{BC}, \mathrm{NO}_{y}, \mathrm{NO}_{x}$ and $\mathrm{O}_{3}$ measurements and MOZART fire-CO fraction at the Pico Mountain station from July to September 5, 2004 are shown in Figure 3.1. Frequent periods with elevated CO levels coinciding with maxima of MOZART fire-CO fraction are evident. 

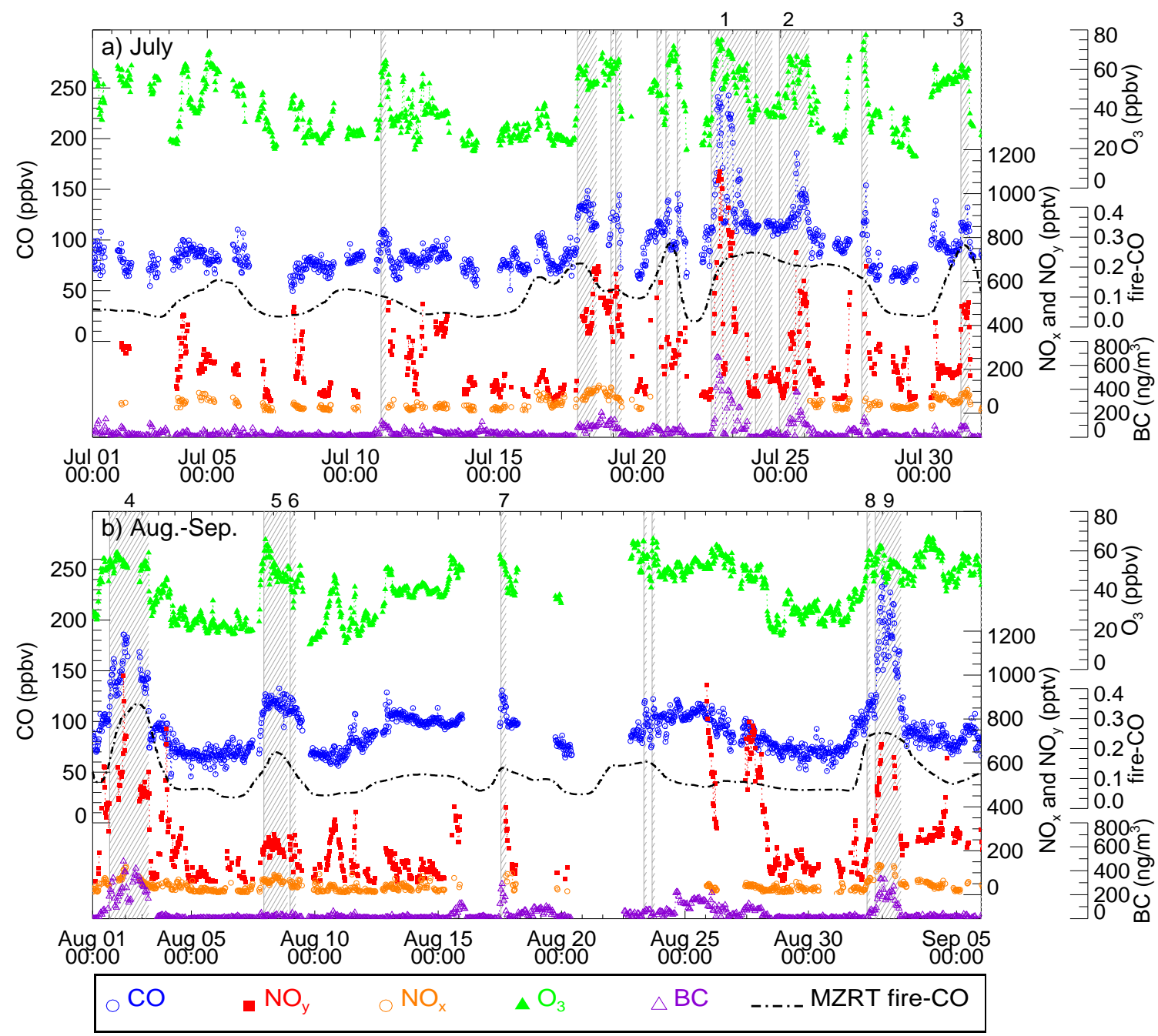

Figure 3.1 Summer 2004 time series of $\mathrm{CO}, \mathrm{BC}, \mathrm{NO}_{y}, \mathrm{NO}_{x}, \mathrm{O}_{3}$ measurements, and MOZART fire-CO fraction at the Pico Mountain station. $\mathrm{CO}$ is plotted with open blue circles, $\mathrm{NO}_{y}$ with red squares, $\mathrm{NO}_{x}$ with open orange circles, $\mathrm{BC}$ with open purple triangles, $\mathrm{O}_{3}$ with green triangles and MOZART fire-CO fraction with a dash-dotted line. Events identified as potentially boreal fire-impacted periods are identified with hatched areas; events further discussed in the text are numbered above the plot. 


\subsubsection{Identification of Fire-Impacted Periods}

Periods when the hourly average of CO was above 110 ppbv and the MOZART fireCO fraction was above 0.1 were identified as potentially impacted by upwind boreal wildfire emissions. The $\mathrm{CO}$ value of $110 \mathrm{ppbv}$ is well above typical background $\mathrm{CO}$ levels at the station and is approximately the maximum value observed in boreal region outflow in the absence of fires, as discussed in section 3.2.3.1 below. (Although we use 30-min averages of $\mathrm{CO}$ throughout the remainder of this work, for the purpose of identifying fire-impacted periods we used hourly averages of CO to smooth the CO measurements and compare them with the CO cutoff value.) The MOZART fire-CO fraction cutoff of 0.1 corresponds to approximately the 70th percentile of all model simulated values at the Pico Mountain station for summer 2004. Both of these cutoff values were designed to be conservative and, as a result, may omit some additional periods influenced by boreal wildfire emissions. For example, on August 12 12:00-August 15 23:00, an enhancement of MOZART fire-CO fraction above 0.1 was correlated with an increase in CO, but CO did not exceed the 110 ppbv cutoff value. Conversely, on July 30 7:00-11:00, the hourly average CO increased to 135 ppbv while backward trajectories indicated transport from active fires, but the MOZART fireCO fraction was lower than 0.07 , likely as a result of the model spatial resolution. Although both of these cutoff values are somewhat arbitrarily selected, we find that the use of slightly larger or smaller cutoffs would not significantly affect the results presented below.

In addition to outflow directly from the boreal regions, flow patterns that bring air to the Azores from higher latitudes can travel over the eastern U.S. Owen et al., 2006]. Therefore transport of boreal wildfire emissions over the Azores may be mixed with air potentially containing North American anthropogenic emissions, which can also be characterized by significant enhancements of $\mathrm{CO}$ and $\mathrm{O}_{3}$ Honrath et al. 2004]. To determine the magnitude of the impact of anthropogenic emissions during 
the boreal wildfire periods, we use the MOZART anthro-CO fraction (not shown in Figure 1). According to the MOZART simulations, anthropogenic emissions may explain some of the enhancements of CO at the station during summer 2004 either alone (e.g. August, 25 8:00-19:00) or in combination with boreal wildfire emissions (e.g. July 19, 2:00-9:00). To avoid inclusion of observations significantly affected by upwind anthropogenic emissions, we exclude from further analysis all observations with MOZART anthro-CO fraction values above 0.1. This MOZART anthro-CO fraction cutoff corresponded to approximately the 70th percentile of all model values simulated at the site.

To better understand transport patterns during the periods identified as fireimpacted, we examined backward trajectories arriving at the Pico Mountain station altitude. Consistent with MOZART simulations, backward trajectories indicate transport of air that originated from the boreal regions in Alaska and/or Canada as shown in Figures $3.2 \mathrm{a}$ and $3.2 \mathrm{~b}$. However, the backward trajectories during a few periods indicated intermixing of subtropical and/or tropical air (hereinafter termed tropical air) with the boreal region outflow. Figure 3.2 s shows an example of tropical backward trajectories intermixed with boreal region outflow. Observations made during these periods may be affected by clean tropical air and, thus, may not be representative of boreal region outflow. We identified periods potentially affected by tropical air when one or more backward trajectories originated over the Atlantic Ocean south of Pico Island $\left(<35^{\circ} \mathrm{N}\right)$ and spent more than $90 \%$ of the time over the Atlantic Ocean before arriving at the site. We therefore omit all observations associated with tropical air intermixing from the analysis, with the following exception: during July 23 2:00-18:00, although tropical air masses intermixed with boreal region outflow upwind the station, very large mixing ratios of $\mathrm{CO}$ recorded during most of the period ([CO]>180 ppbv) indicate a lack of significant tropical air impact.

Periods identified as potentially affected by boreal wildfire emissions based on $\mathrm{CO}$ enhancements and MOZART fire-CO fraction criteria are identified with hatched 
07/22/2004 20:00
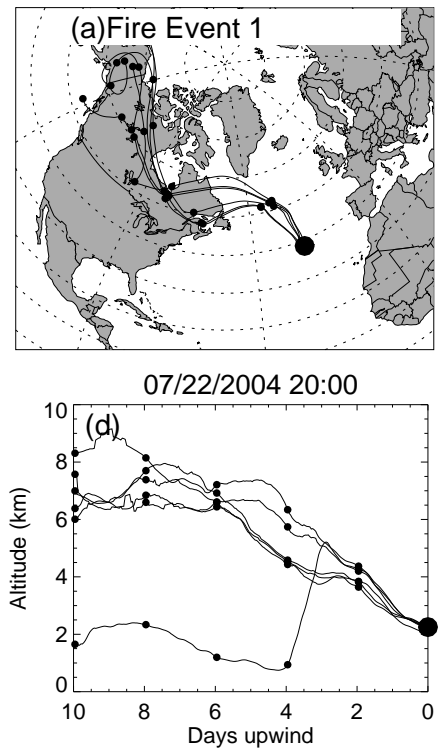

07/22/2004 15:00

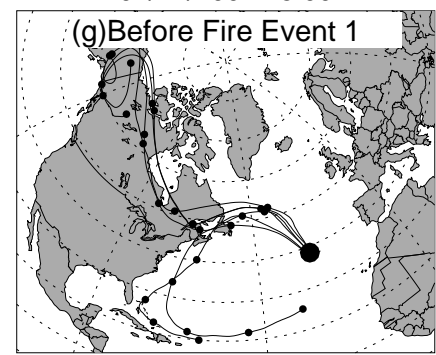

07/22/2004 15:00

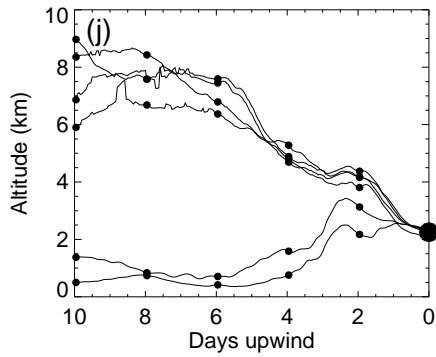

09/01/2004 21:00

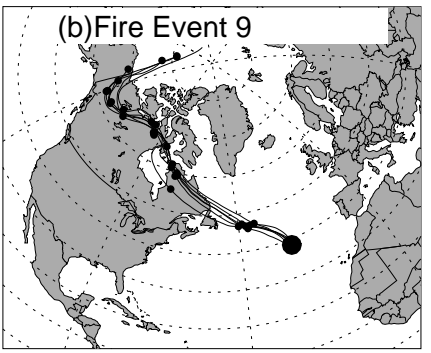

09/01/2004 21:00

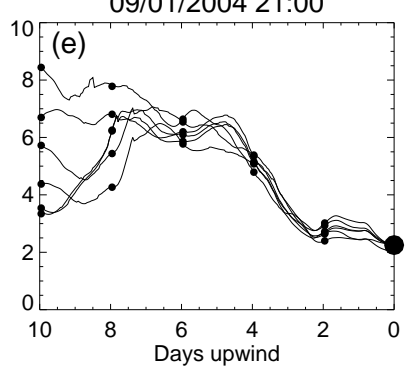

09/01/2004 02:00

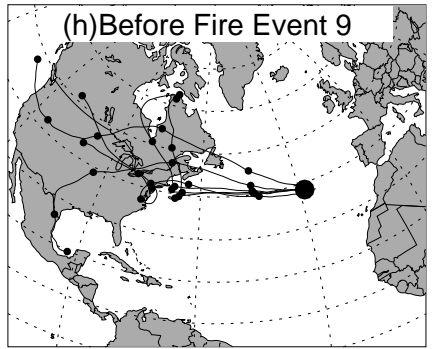

09/01/2004 02:00

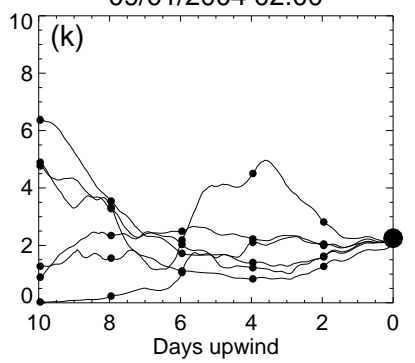

06/19/2004 13:00

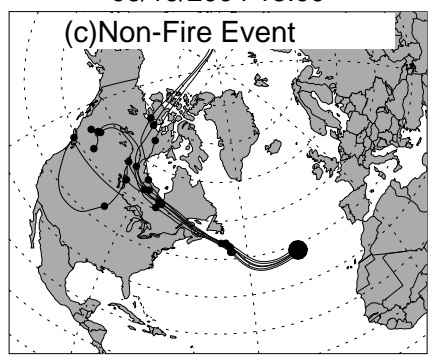

06/19/2004 13:00

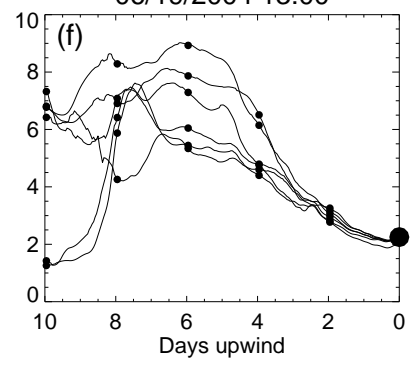

06/18/2004 22:00

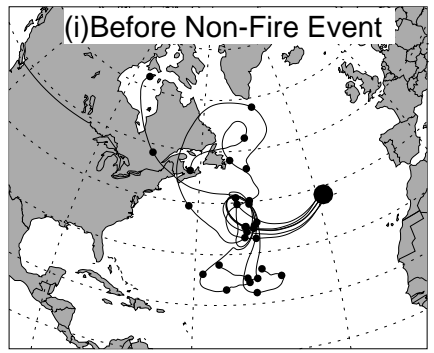

06/18/2004 22:00

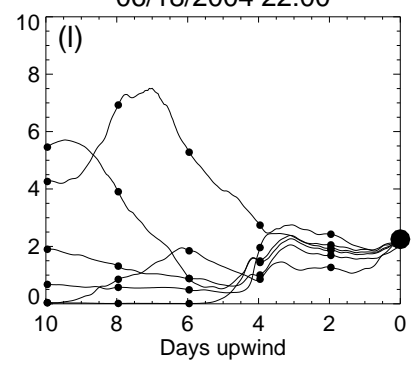

Figure 3.2 Backward trajectories arriving at the measurement site during boreal region outflow: (a, e) boreal region with upwind fire emissions, and (i) boreal region without upwind fire emissions. Backward trajectories before the passage of the boreal region air masses are also shown (c, g, k). Solid lines show the paths of the six trajectories ending on a grid around and below the station; trajectory arrival times are displayed above each pair of plots $(a, e, i)$ and $(c, g, k)$. Plots on the top show the horizontal path of the trajectories [(a, e, i) and $(\mathrm{c}, \mathrm{g}, \mathrm{k})]$, while plots on the bottom show the altitude profile $[(b, \mathrm{~d}, \mathrm{f})$ and $(\mathrm{d}, \mathrm{h}, \mathrm{I})]$; small dots indicate each 2 days travel time. The location of the Pico Mountain station is marked with a large dot. 
areas in Figure 3.1 periods identified with the same criteria, but excluding periods of anthropogenic or tropical influence are also enumerated in Figure 3.1. Table 3.1 provides the statistics of the observations of $\mathrm{CO}, \mathrm{BC}, \mathrm{NO}_{y}, \mathrm{NO}_{x}$ and $\mathrm{O}_{3}$ for both criteria, i.e. all fire-impacted observations and those excluding anthropogenic or tropical influence.

\subsubsection{Overview of Summer 2004 Boreal Wildfire Observa- tions}

The impact of boreal wildfire emissions at the Pico Mountain station was very frequent during summer 2004, as shown in Figure 3.1. A total of 21 events with apparent fire impact were identified during the period of study, accounting for $16 \%$ of the measurement time from July 1 to September 5. Of these, 9 were unaffected by potential tropical or anthropogenic impacts. We focus only on these fire-impacted periods without anthropogenic or tropical influence, and refer to these periods as boreal wildfire events in the remainder of this paper. These 9 events are numbered in Figure 3.1. During these events, $\mathrm{BC}, \mathrm{NO}_{y}, \mathrm{NO}_{x}$ and $\mathrm{O}_{3}$ levels were also elevated and significantly correlated with $\mathrm{CO}$ in most of the cases. MOZART daily $\mathrm{CO}$ fire tracer distributions during the ICARTT study (July 10-August 8) indicated the impact of North American fire emissions emitted 6 to 15 days earlier during the events identified during this period (i.e. events $1-5$ ).

Figures $3.3 \mathrm{~b}$ and $3.3 \mathrm{~b}$ show the time series of 30-min average observations of $\mathrm{CO}, \mathrm{NO}_{y}, \mathrm{NO}_{x}$ and $\mathrm{O}_{3}$, and 1-hr average observations of BC during July 22-24 and September 1-2. These events, labelled respectively event 1 and event 9 in Figure 3.1 , represent two of the most intense fire emission episodes observed during the study. Levels of $\mathrm{CO}, \mathrm{BC}, \mathrm{NO}_{y}$ and $\mathrm{O}_{3}$ during July 22-24 were extremely enhanced for more than a day, peaking at $249 \mathrm{ppbv}, 665 \mathrm{ng} \mathrm{m}^{-3}, 1100 \mathrm{pptv}$ and $75 \mathrm{ppbv}$, respectively. $\left(\mathrm{NO}_{x}\right.$ measurements were not available during this event.) This period had the highest 


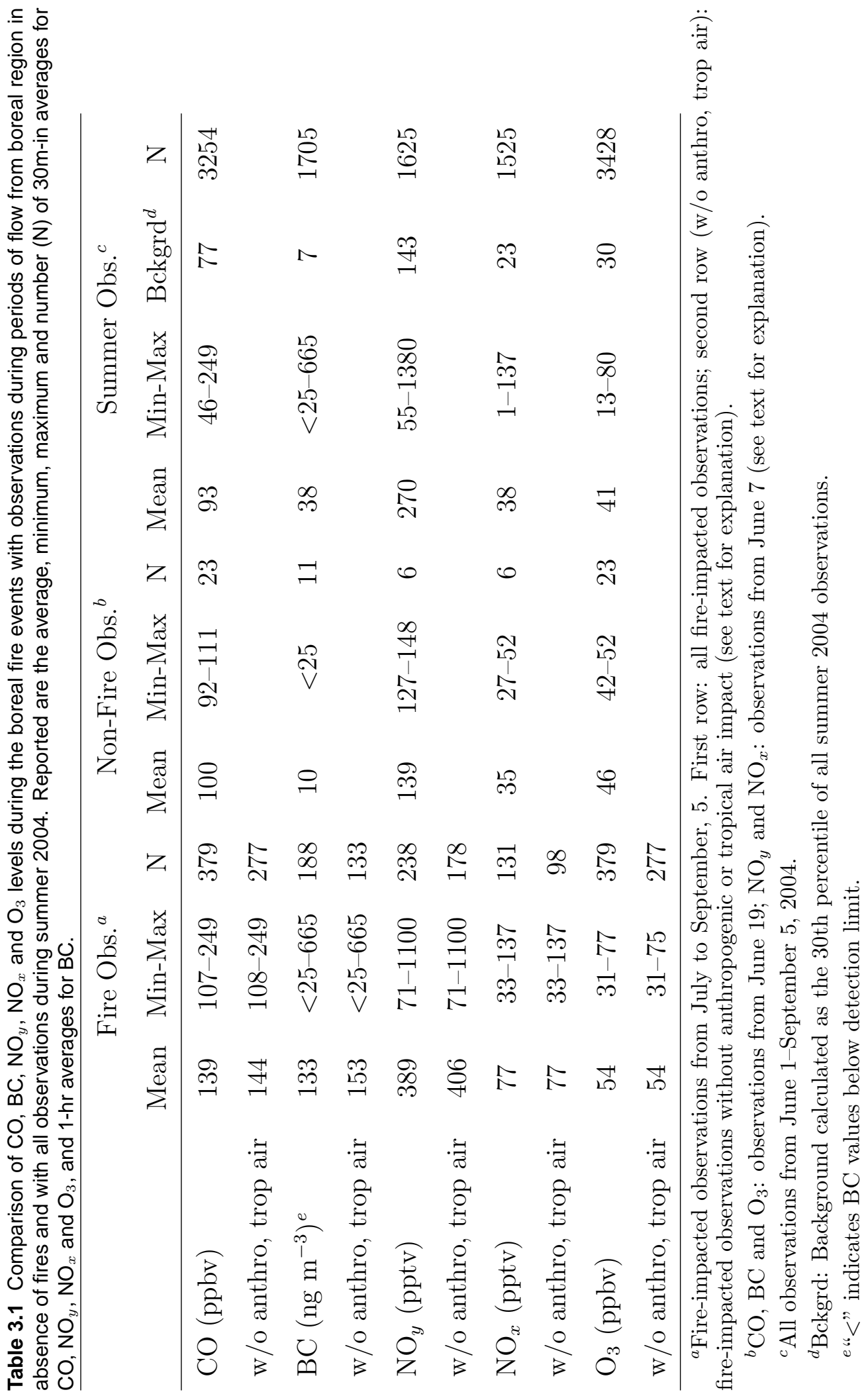


level of $\mathrm{CO}$ yet recorded at the Pico Mountain station. Similarly, $\mathrm{CO}, \mathrm{BC}, \mathrm{NO}_{y}, \mathrm{NO}_{x}$ and $\mathrm{O}_{3}$ levels were also strongly elevated for more than a day during September 1-2, with peaks of $243 \mathrm{ppbv}, 329 \mathrm{ng} \mathrm{m}^{-3}, 685 \mathrm{pptv}, 134 \mathrm{pptv}$ and $62 \mathrm{ppbv}$, respectively. The MOZART fire-CO fraction was also particularly high during these two events, as shown in Figure 3.1 .

Analyses of backward trajectories during events 1 and 9 confirm that the enhancements of these species occurred when airflow from Alaska and/or Canada arrived at the station. Examples of backward trajectories associated with the passage of the boreal fire plumes for these events are shown in Figures $3.2 \mathrm{a}$ and $3.2 \mathrm{~b}$. For comparison, Figures $3.2 \mathrm{~b}$ and $3.2 \mathrm{~h}$, show the airflow before the passage of each boreal fire plume. An important feature of these events is that the levels of these species remained constantly high for more than 24 hours, suggesting the impact of two very large highly aged plumes.

\subsubsection{Impacts of Boreal Wildfire Emissions}

In this section, we assess the impacts of boreal wildfire emissions by comparing enhancements of $\mathrm{CO}, \mathrm{BC}, \mathrm{NO}_{y}, \mathrm{NO}_{x}$ and $\mathrm{O}_{3}$ in fire-impacted boreal outflow to levels under similar conditions but in the absence of fires. First, however, we discuss the estimation of levels during periods of boreal outflow in the absence of fire emissions.

\subsubsection{Estimation of Levels in Absence of Fires}

To estimate the background concentration at the Pico Mountain station in air from the fire source region, but in the absence of fire emissions, we identified two periods when boreal region outflow reached the station prior to the occurrence of the large fires: June 7 5:00-9:00 and June 19 8:00-19:00. Early June was a period with low area burned over northern North America, and as a result, with low boreal wildfire emissions Turquety et al. 2007]. Therefore, we expect that the contribution of boreal 

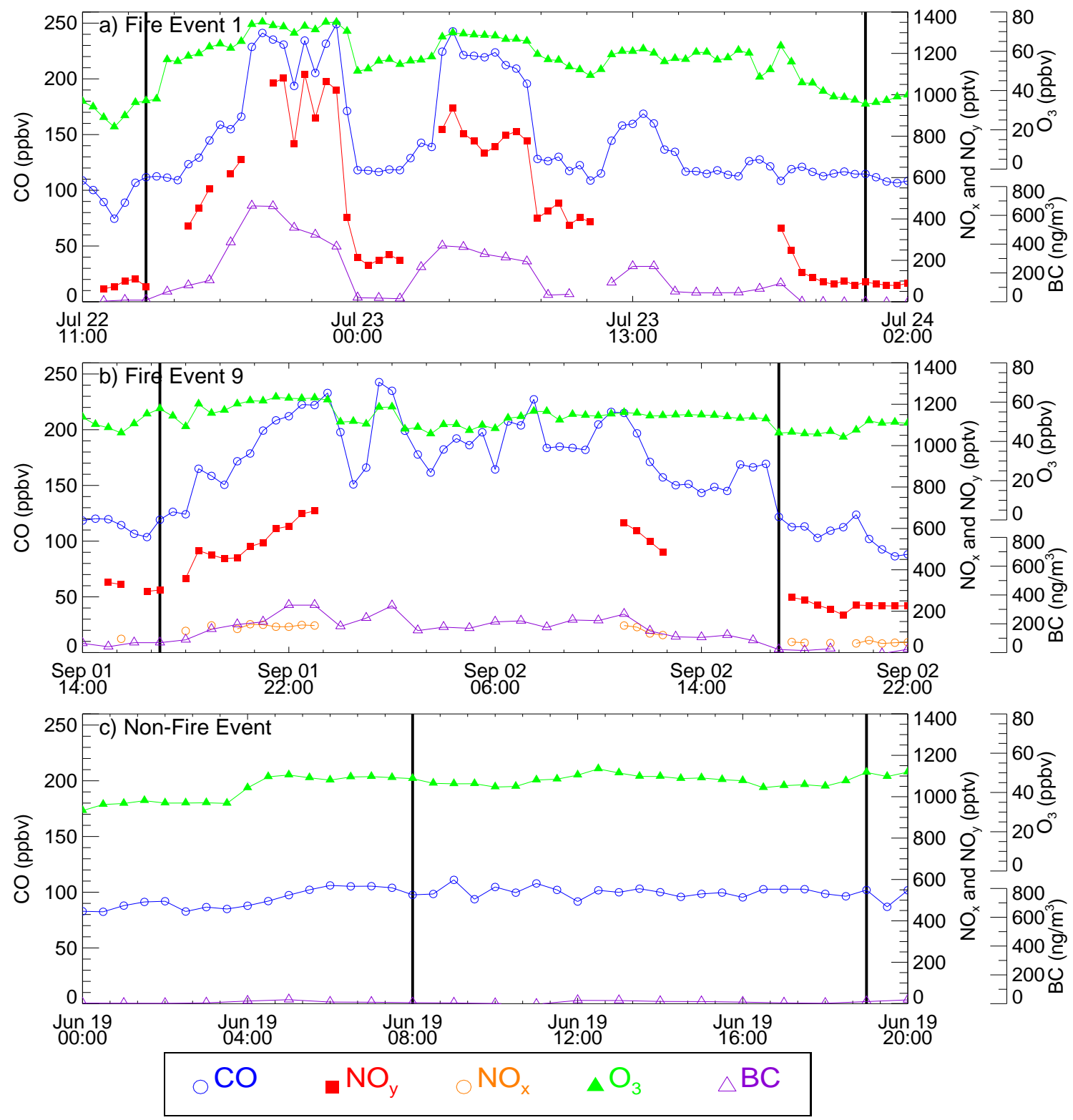

Figure 3.3 Time series of 30-min average $\mathrm{CO}, \mathrm{NO}_{x}, \mathrm{NO}_{y}$ and $\mathrm{O}_{3}$, and 1-hr average $\mathrm{BC}$ observations during two boreal wildfire events and one boreal outflow period without upwind fire emissions: a) Fire event 1: July 22 1800-July 23 21:00 ( $\mathrm{NO}_{x}$ measurements are not available), b) Fire event 9: September 1 16:30-September 2 16:00 and c) Non-fire event: June 19 8:00-19:00 $\left(\mathrm{NO}_{x}\right.$ and $\mathrm{NO}_{y}$ measurements are not available). CO is plotted with open blue circles, $\mathrm{NO}_{y}$ with red squares, $\mathrm{NO}_{x}$ with open orange circles, $\mathrm{BC}$ with open purple triangles and $\mathrm{O}_{3}$ with green triangles. Vertical solid lines indicate the start and end time of the event; remaining data are plotted to make the events more apparent. 
wildfire emissions to our site was small during these two periods. This is consistent with MOZART simulations, which indicate a maximum fire-CO fraction of 0.05 during these periods.

Figure 3.3. shows the time series of 30-min average observations of $\mathrm{CO}$ and $\mathrm{O}_{3}$ and 1-hr average observations of BC during the longer of these events, June 19 8:0019:00. ( $\mathrm{NO}_{x}$ and $\mathrm{NO}_{y}$ measurements were not available at this time.) Example of the backward trajectories associated with the passage of the air masses during and before this period are shown in Figures 3.2 and 3.2 , respectively. Average levels of $\mathrm{CO}, \mathrm{BC}$ and $\mathrm{O}_{3}$ during this period are used as background levels of these species for comparison with fire-impacted periods below. In addition, the maximum level of CO during this event (111 ppbv) was the basis for the $110 \mathrm{ppbv}$ cutoff to select the boreal fire-impacted periods, as discussed in section 3.2.1. (The $\mathrm{CO}$ and $\mathrm{O}_{3}$ background values used in this work are somewhat larger than the levels in non-fire air presented for the same dataset by Lapina et al. [2006, because that analysis included periods with a mixture of boreal and non-boreal air).

MOZART simulations during the other non-fire boreal outflow period indicate that anthropogenic emissions may have contributed to these observations (i.e., the MOZART anthro-CO fraction was above 0.1). However, nitrogen oxides measurements in non-fire-impacted boreal outflow were available only during the June 7 event. (Few measurements were available in June 2004 due to testing of the instruments prior the ICARTT campaign.) Average mixing ratios of $\mathrm{NO}_{y}$ and $\mathrm{NO}_{x}$ during this period were used as upper-limit estimates of the background of these species in boreal region outflow in the absence of fires.

The background levels of $\mathrm{CO}, \mathrm{BC}, \mathrm{NO}_{y}, \mathrm{NO}_{x}$ and $\mathrm{O}_{3}$ used for boreal region outflow in the study are compared to background levels reported within the North American boreal region in Table 3.2. A wide range of background levels have been reported over the North American boreal region, reflecting differences in the latitude and altitude regions sampled, and the years of study. The values used here are 
similar to the background levels reported over the North American boreal region. The enhancement ratios calculated below are dependent on the background values used. This is discussed further in section 3.2.4.

\subsubsection{Comparison of Levels in Boreal Region Outflow with and without Fire Emissions}

Levels of $\mathrm{CO}, \mathrm{BC}, \mathrm{NO}_{y}, \mathrm{NO}_{x}$ and $\mathrm{O}_{3}$ during boreal region outflow with fire emissions are summarized and compared to levels observed during boreal region outflow without fire emissions in Table 3.1, Statistics for all summertime observations are also shown. Average CO mixing ratios during the boreal wildfire events (144 ppbv) were above levels observed during flow from boreal region without fire emissions (100 ppbv), and were nearly double the summertime background (estimated as equal to the 30th percentile of all summertime measurements, $77 \mathrm{ppbv})$. This significant impact is consistent to what it has previously been observed at the Pico Mountain station Honrath et al., 2004, Lapina et al., 2006, and for the entire Northern Hemisphere in years of high fire activity [e.g., Novelli et al., 2003; Edwards et al., 2004; Kasischke et al. 2005.

Levels of $\mathrm{BC}, \mathrm{NO}_{y}, \mathrm{NO}_{x}$ and $\mathrm{O}_{3}$ were also increased during the fire-impacted events, with levels of these species above those observed in boreal outflow in the absence of fires, and well above the typical summertime background at the site. For example, average $\mathrm{NO}_{x}$ mixing ratios during the boreal wildfire events (77 pptv) were double those observed in boreal outflow without fire emissions (35 pptv) and triple the summertime background at the site (23 pptv).

Figures 3.4 a $3.4 \mathrm{~d}$ show the relationships between $\mathrm{CO}$ (used as a tracer of fire emissions) and $\mathrm{BC}, \mathrm{NO}_{y}, \mathrm{NO}_{x}$ and $\mathrm{O}_{3}$. Solid color-coded symbols represent observations obtained during each boreal wildfire event, with one exception: grey circles represent the early June observations made in non-fire boreal outflow discussed in section 3.2.3.1. Most of the fire-impacted observations were above the background 


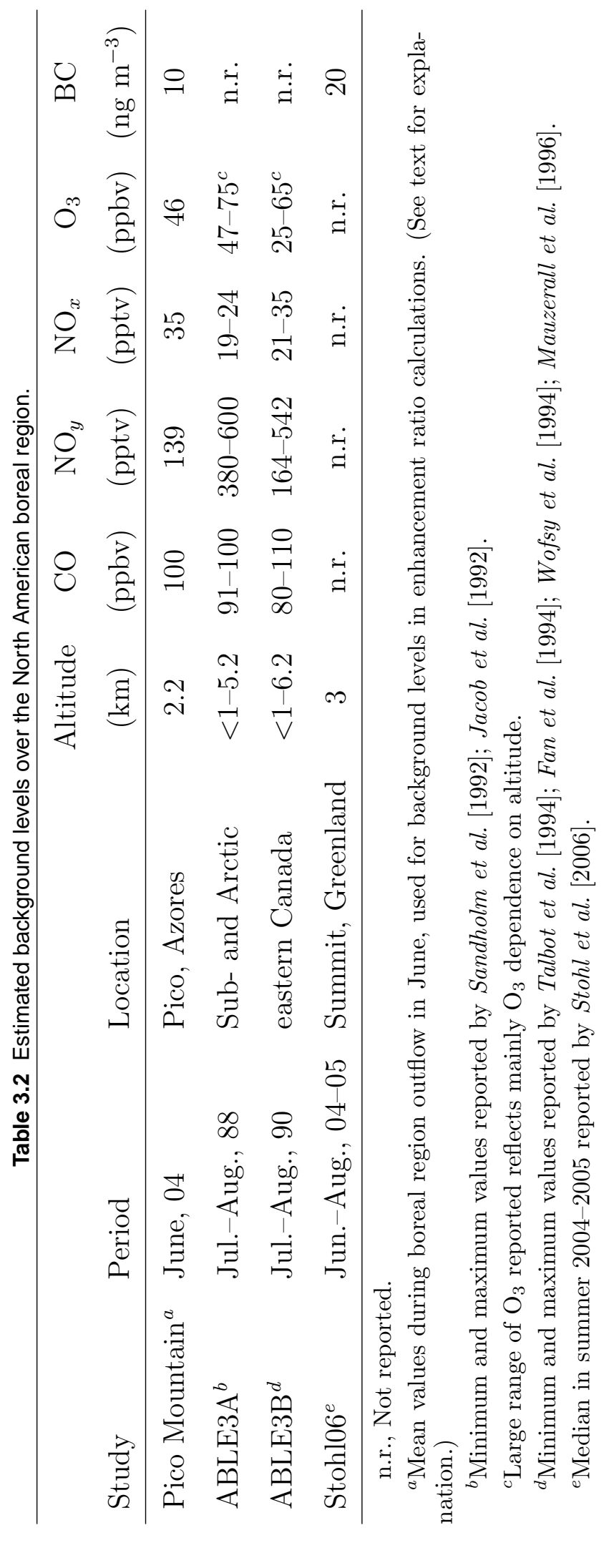


from the boreal regions in the absence of fires, consistent with the average difference noted above. In almost all events, these species were well correlated with $\mathrm{CO}$, although distinct behaviors were observed depending on the levels of $\mathrm{CO}$, in particular for $\mathrm{O}_{3}$, as discussed further below.

As discussed in section 3.2.1, a number of fire-impacted observations were excluded from the boreal wildfire events due to probable mixing of tropical air or MOZARTsimulated anthropogenic emission transport. These observations are also shown in Figure 3.4: observations omitted due to tropical air mixing are represented with open cyan circles and those omitted due to anthropogenic emissions impact are represented with open black squares. Observations omitted due to tropical air mixing fall into two distinct groups of points, suggesting differing degrees of mixing. Of the observations excluded because of anthropogenic impact, some had exceptionally large $\mathrm{NO}_{y}, \mathrm{NO}_{x}$ and $\mathrm{O}_{3}$ levels, suggesting significant anthropogenic impacts on those species as well. This impact is expect to be small in the events that were not excluded however. During those boreal wildfire events, MOZART-simulated anthropogenic CO was always below 7 ppbv, and usually (60\% of the observations) below 3 ppbv.

\subsubsection{Analysis of Enhancement Ratios in the Boreal Wildfire Plumes}

To characterize the amount of emitted $\mathrm{BC}$ and $\mathrm{NO}_{x}$ that still remains in the plumes and the net $\mathrm{O}_{3}$ production occurring in these plumes during transport to the station, we determined the enhancement ratio of $\mathrm{BC}, \mathrm{NO}_{y}, \mathrm{NO}_{x}$ and $\mathrm{O}_{3}$ with respect to $\mathrm{CO}$ during each boreal wildfire event [e.g., Wofsy et al., 1992; Stohl et al., 2002. CO is commonly used as a tracer because it is emitted from combustion processes in large quantities and has relatively a long lifetime Novelli et al., 1992. We consider CO as an inert tracer in this approach. de Gouw et al. 2006, based on analysis of VOC measurements, indicated that $\mathrm{OH}$ concentrations in the boreal wildfire plumes 

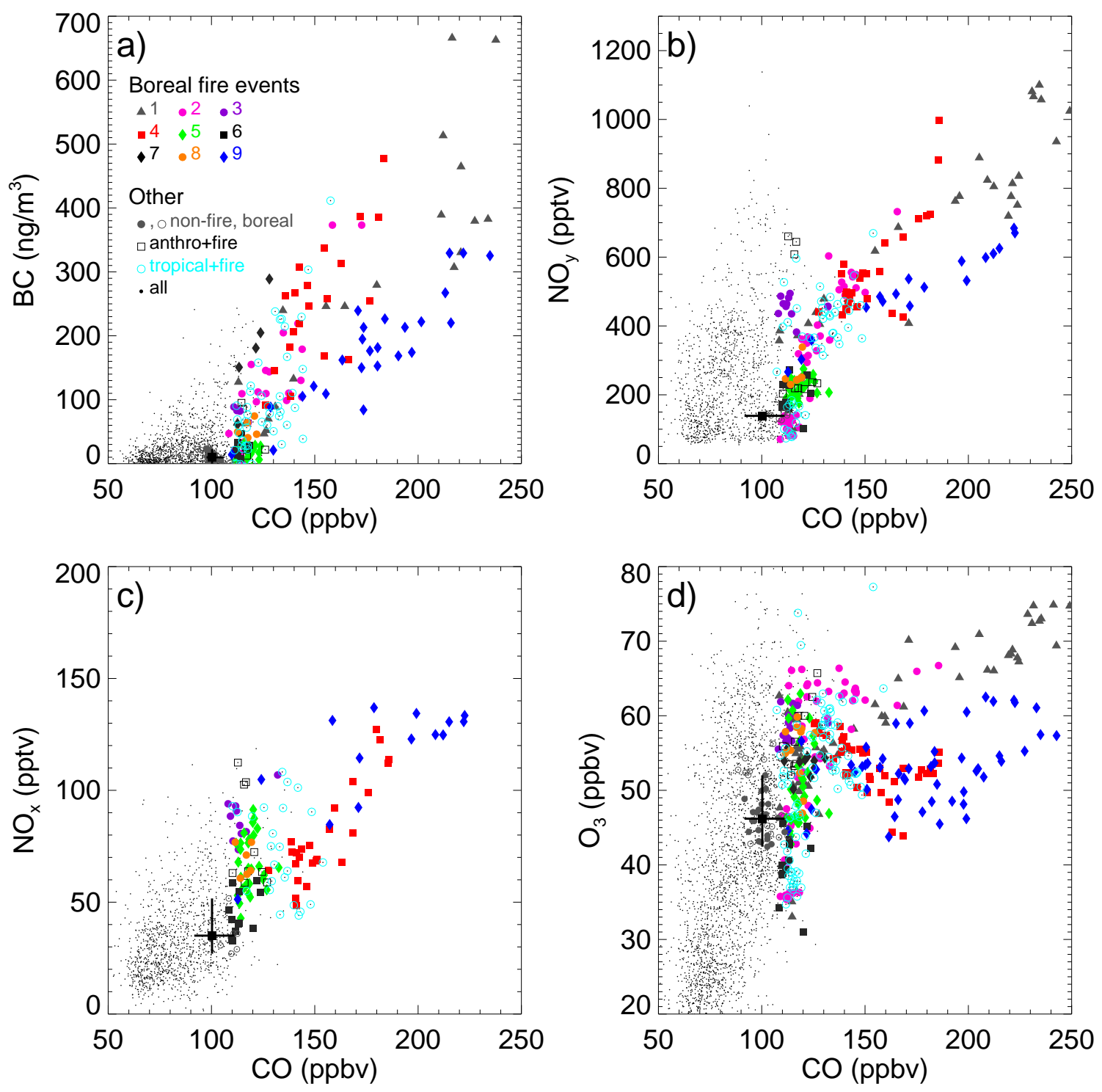

Figure 3.4 Relationship between $\mathrm{CO}$ and the indicated species during summer 2004: a) $\mathrm{BC}$ versus $\mathrm{CO}, \mathrm{b}) \mathrm{NO}_{y}$ versus $\mathrm{CO}$, c) $\mathrm{NO}_{y}$ versus $\mathrm{CO}$ and d) $\mathrm{O}_{3}$ versus $\mathrm{CO}$. Boreal wildfire events listed in Table 3.3 and identified in Figure 1 are coded as follows: Event 1 (dark grey triangles), event 2 (magenta circles), event 3 (purple circles), event 4 (red squares), event 5 (green diamonds), event 6 (black squares), event 7 (black diamonds), event 8 (orange circles) and event 9 (blue diamonds). Event 7 is not plotted for $\mathrm{NO}_{y}$ and $\mathrm{NO}_{x}$ because it contained fewer than 5 data points. Fire-impacted observations apparently impacted with tropical air are plotted with open cyan circles; fire-impacted observations apparently impacted with anthropogenic emissions are plotted with open black squares. Observations made during non-fire-impacted boreal outflow are plotted with small solid grey circles; non-fire-impacted boreal outflow observations with anthropogenic impact are plotted with open grey circles. The black square represents the average of non-fire-impacted boreal outflow observations, and black error bars connect minimum and maximum values observed. All other measurements during summer 2004 are plotted with small black dots. 
intercepted by the NOAA WP-3 were four times smaller than typical values in the North Atlantic troposphere. Hence, CO reaction with $\mathrm{OH}$ is expected to be limited in the boreal fire plumes during the 6-15 days travel time to the station. We calculated mean values of $\Delta \mathrm{CO}, \Delta \mathrm{BC}, \Delta \mathrm{NO}_{y}, \Delta \mathrm{NO}_{x}$ and $\Delta \mathrm{O}_{3}$ during each boreal wildfire event, and calculated enhancement ratios relative to $\mathrm{CO}$ for each event using these mean values. Here $\Delta$ indicates the difference between the concentration of the indicated species and the background concentration $\left(e . g . \Delta \mathrm{CO}=[\mathrm{CO}]-[\mathrm{CO}]_{b k g d}\right)$. Enhancement ratios are critically dependent on the background levels used Mauzerall et al., 1998. Our background levels were derived using observations during transport events in June, as discussed in section 3.2.3.1. This results in background levels higher than those that would be estimated using clean marine levels or using the 30th percentile of all summertime measurements. This leads to reduced calculated enhancement ratios for all the species.

Table 3.3 presents the resulting enhancement ratios. A large variability of enhancement ratios was observed. There are two causes that probably contributed to the varying enhancement ratios: different emission rates, which vary as a function of fuel type and burning conditions Goode et al., 2000; Reid et al., 2005, and varying degrees of removal during transport. We examine both processes in the following sections.

\subsubsection{Aerosol Black Carbon}

The relationships between $\mathrm{BC}$ and $\mathrm{CO}$ in boreal fire plumes and in background air from boreal regions are shown in Figure 3.4 . Estimated $\Delta \mathrm{BC} / \Delta \mathrm{CO}$ ratios for each boreal fire event are shown in Table 3.3. Black carbon was significantly enhanced in all events relative to background from boreal outflow without upwind fire emissions, with the exception of events 5 and 6 (green diamonds and black squares in Figure 3.4 , respectively).

A broad range of $\mathrm{BC}$ enhancement ratios (0.5-8.4 $\mathrm{ng} \mathrm{m}^{-3} / \mathrm{ppbv}$; Table 3.3) were 


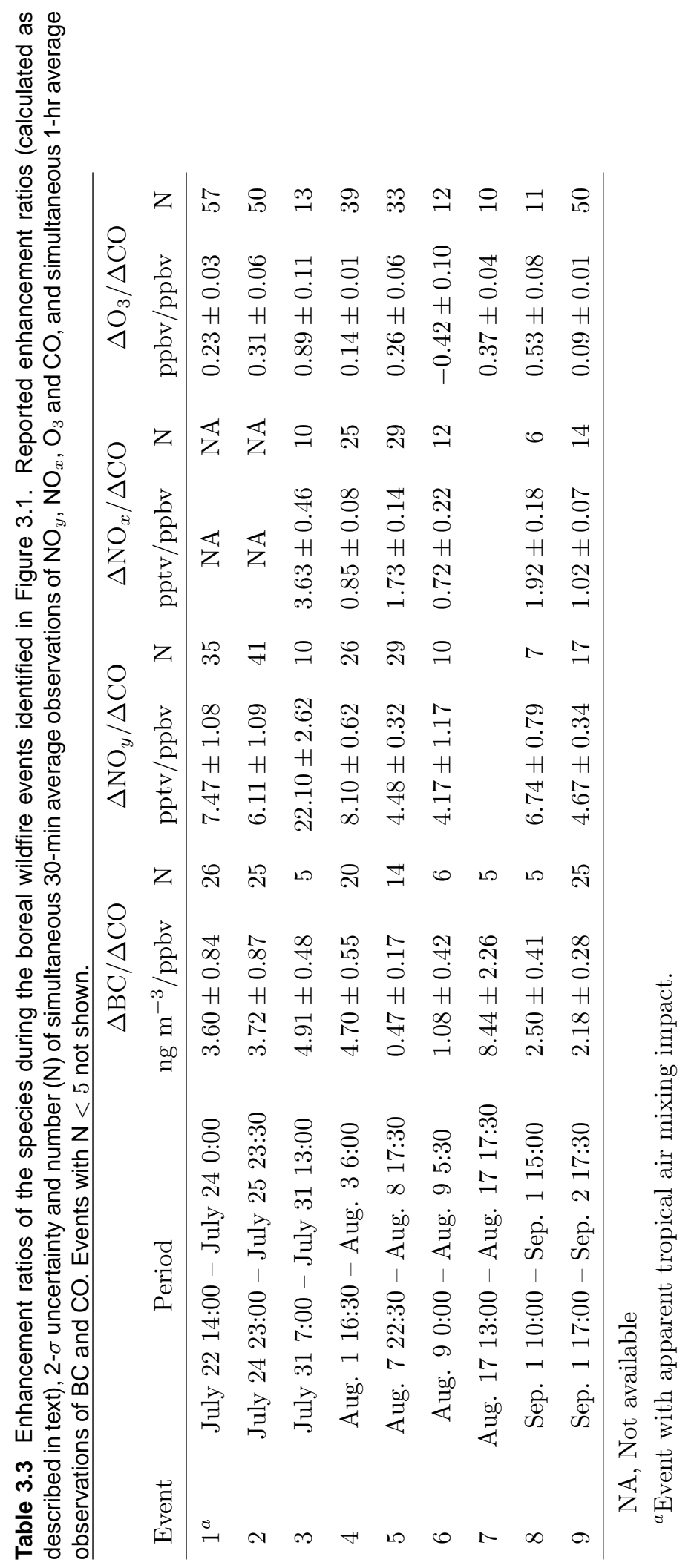


observed in the boreal fire plumes. Large variability in $\mathrm{BC}$ emissions from boreal wildfires has been reported previously. For example, BC concentrations during smoldering combustion are low, with $\mathrm{BC}$ mass fractions typically $2-5 \%$ of all carbon particles emitted, while BC mass fractions from flaming combustion are 4 to $28 \%$ of all carbon particles emitted Reid et al., 2005, and references therein].

However, washout processes during transport to the station may also have contributed to this variability. To evaluate this possibility, we examined precipitation during transport and meteorological conditions at Pico during each event. For this purpose, we extracted rainfall rates from the HYSPLIT model output for the backward trajectories during each event and analyzed relative humidity measurements and archived photos of conditions at the station. Average rainfall rates were low (less than $0.05 \mathrm{~mm} / \mathrm{hr}$ ) in all backward trajectories travelling from the boreal region to the station, with the exception of events 5, 6 and 9, which showed average rainfall rates of $0.09,0.06$ and $0.08 \mathrm{~mm} / \mathrm{hr}$, respectively. (These events are represented by green diamonds, black squares and blue diamonds in Figure 3.4a, respectively.) Conditions at the station were dry and sunny during all events, with the exception of event 6 , when heavy fog, and most likely rain, was present. Therefore, the lower $\Delta \mathrm{BC} / \Delta \mathrm{CO}$ ratios during events 5, 6 and 9 compared to those during the other events are consistent with the wet scavenging of a greater fraction of $\mathrm{BC}$ during transport and/or at the station location during those events. This is consistent with previous observations of light absorbing aerosols (e.g., $\mathrm{BC}$ ) in boreal fire plumes, which indicate that a large fraction of aerosols may be removed in the presence of rain and/or clouds Bertschi and Jaffe, 2005; Stohl et al., 2006.

The BC enhancement ratios we report are 8-141\% (average $59 \%$, or $78 \%$ excluding events 5,6 and 9) of the $\mathrm{BC} / \mathrm{CO}$ emission ratio from extra-tropical forest fires (6 $\pm 3 \mathrm{ng} \mathrm{m}^{-3} / \mathrm{ppbv}$ ) recommended by Andreae and Merlet [2001]. (The value of $141 \%$ is not significantly different from $100 \%$, considering the uncertainties of the measurements and the recommended value.) These observations indicate that an im- 
portant fraction of the total $\mathrm{BC}$ emitted into the plumes we sampled was efficiently exported to the Azores, very far downwind from the fires. This underscores other recent work that has documented long-range impacts of the North American wildfire BC emissions [Stohl et al., 2006; Duck et al., 2007]. Since BC effectively absorbs light in the atmosphere Hansen et al., 2000; Bond and Sun, 2005, this implies a potentially significant large-scale impact of boreal wildfire emissions on the direct radiative forcing over the Northern Hemisphere troposphere.

\subsubsection{2 $\mathrm{NO}_{y}$}

Figure $3.4 \mathrm{~b}$ shows the relationship between $\mathrm{NO}_{y}$ and $\mathrm{CO}$ in the boreal wildfire plumes and in background air from boreal regions without fire emissions. Table 3.3 provides the $\Delta \mathrm{NO}_{y} / \Delta \mathrm{CO}$ ratios estimated for each boreal fire event. Nitrogen oxides were significantly enhanced in all the boreal fire plumes, relative to background levels.

The $\mathrm{NO}_{y}$ enhancement ratios were highly variable, however (4.2-22.1 pptv/ppbv; Table 3.3. In the previous section, we concluded that the variation in BC enhancement ratios could be the result of a combination of emission variation among fires and wet removal during transit to the station. Since $\mathrm{NO}_{x}$ emissions also vary as a function of type of combustion [e.g. Yokelson et al., 1996; Goode et al., 2000] and a part of $\mathrm{NO}_{y}$ (i.e. $\mathrm{HNO}_{3}$ ) is susceptible to wet deposition, the same processes are expected to contribute to the variation of $\mathrm{NO}_{y}$ enhancement ratios. Consistent with this expectation, the events with the lowest $\Delta \mathrm{BC} / \Delta \mathrm{CO}$ ratios are also those with the lowest $\Delta \mathrm{NO}_{y} / \Delta \mathrm{CO}$ ratios (i.e., events 5, 6 and 9). As a result, a plot of $\mathrm{NO}_{y}$ versus $\mathrm{BC}$ is less scattered than the plot of $\mathrm{NO}_{y}$ versus $\mathrm{CO}$, as shown in Figure 3.5. and the correlation of $\mathrm{NO}_{y}$ with $\mathrm{BC}\left(r^{2}=0.82\right)$ is slightly better than that with $\mathrm{CO}$ $\left(r^{2}=0.75\right)$. Additional evidence for efficient $\mathrm{HNO}_{3}$ removal in some plumes is provided by aircraft measurements over the northwestern Atlantic Ocean, which found very low $\mathrm{HNO}_{3}$ to $\mathrm{NO}_{y}$ ratios in several 2004 North American fire plumes Flocke et al. 2005. 


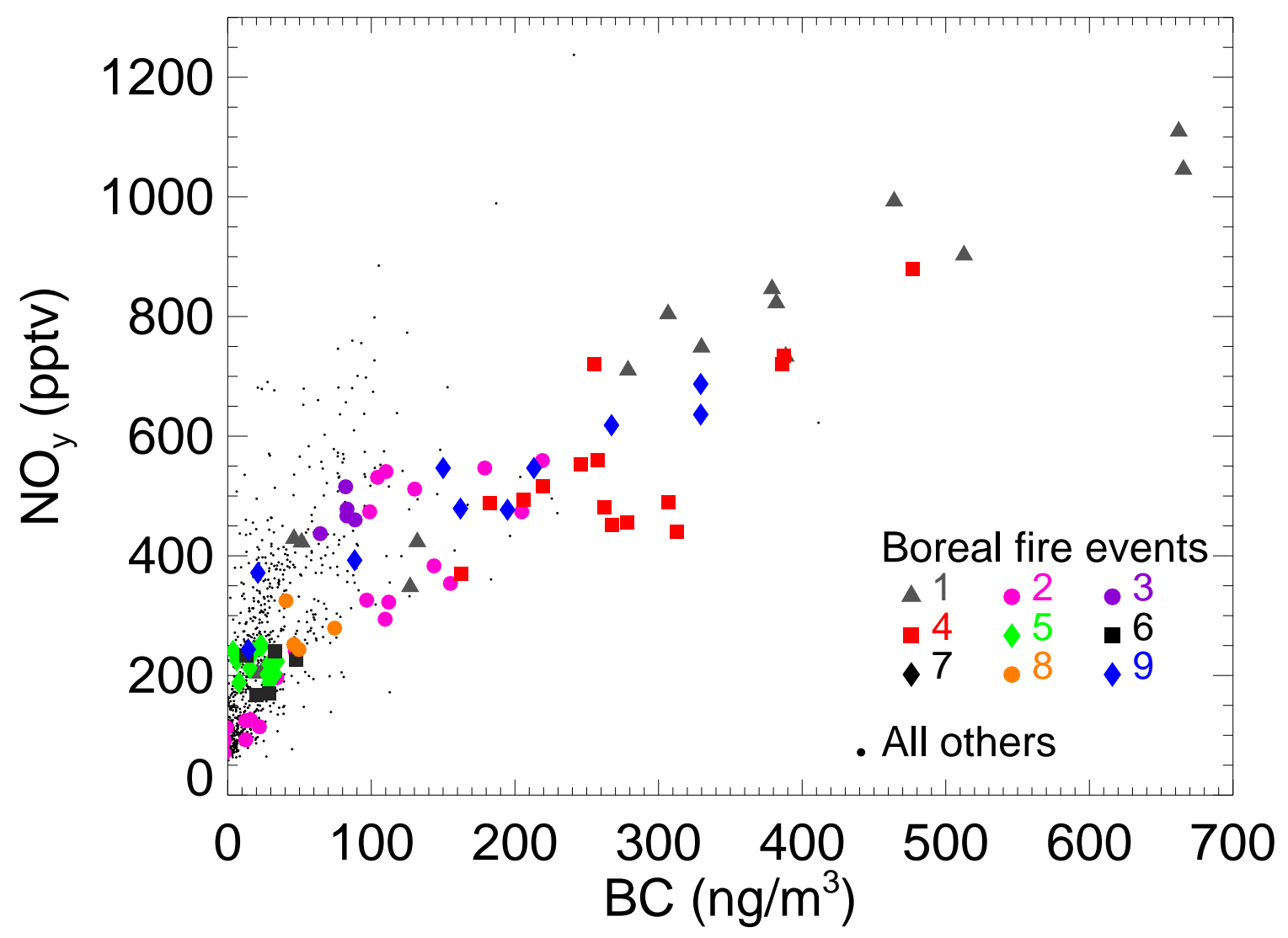

Figure 3.5 Relationship between $\mathrm{BC}$ and $\mathrm{NO}_{y}$ during summer 2004. Boreal wildfire events are coded as follows: event 1 (dark grey triangles), event 2 (magenta circles), event 3 (purple circles), event 4 (red squares), event 5 (green diamonds), event 6 (black squares), event 8 (orange circles), event 9 (blue diamonds). Event 7 contained $<5$ simultaneous data points and is not plotted. All other measurements during summer 2004 are plotted with small black dots. 
Table 3.4 compares these $\Delta \mathrm{NO}_{y} / \Delta \mathrm{CO}$ ratios to previous $\Delta \mathrm{NO}_{y} / \Delta \mathrm{CO}$ ratios obtained from previous studies of boreal wildfire plumes. The mean enhancement ratio we observed ( $8 \mathrm{pptv} / \mathrm{ppbv}$ ) is within the large range of mean values observed in plumes sampled over North America (5.6-14.1 pptv/ppbv; Table 3.4). The Pico Mountain mean enhancement ratio is also a significant fraction of the available (but poorly constrained) estimates of North American boreal fires $\mathrm{NO}_{x} / \mathrm{CO}$ emission ratios, e.g. $12 \mathrm{pptv} / \mathrm{ppbv}$ Jain et al. 2006 or 26士15 pptv/ppbv Andreae and Merlet, 2001. These comparisons indicate that a significant fraction of the $\mathrm{NO}_{x}$ emitted into the sampled plumes was exported as $\mathrm{NO}_{y}$ to the lower FT over the Azores region.

This conclusion contrasts with some prior studies of the export of anthropogenic $\mathrm{NO}_{y}$ to the FT, which conclude that a large majority of surface $\mathrm{NO}_{x}$ emissions $(>70 \%)$ is removed before or during export from the boundary layer during lofting mechanisms [e.g., Liang et al., 1998; Stohl et al., 2002; Parrish et al., 2004; Li et al., 2004.

However, the boreal fire plumes sampled here differ from typical anthropogenic export in two key ways. First, in boreal wildfires PAN is expected to account for a significant fraction of $\mathrm{NO}_{y}$ Jacob et al., 1992; Singh et al., 1994 as a result of lower $\mathrm{NO}_{x} /$ hydrocarbon emission ratios Jacob et al. 1992. Second, boreal wildfires can often be very energetic, releasing enough thermal energy to create smoke and convection columns that extend rapidly into the troposphere and even into the stratosphere [e.g. Fromm et al., 2005; Damoah et al., 2006]. The rapid vertical transport of emissions in fire-induced convection plumes soon after emission may contribute to the inefficient removal of $\mathrm{NO}_{y}$ during the lofting mechanism, as has been suggested for BC Stohl et al. 2006. In addition, as described above, most boreal fire plumes sampled at Pico were associated with low precipitation during transport as well as dry and sunny conditions at the site. Thus, these conditions may have contributed to a more efficient export of $\mathrm{NO}_{y}$. 


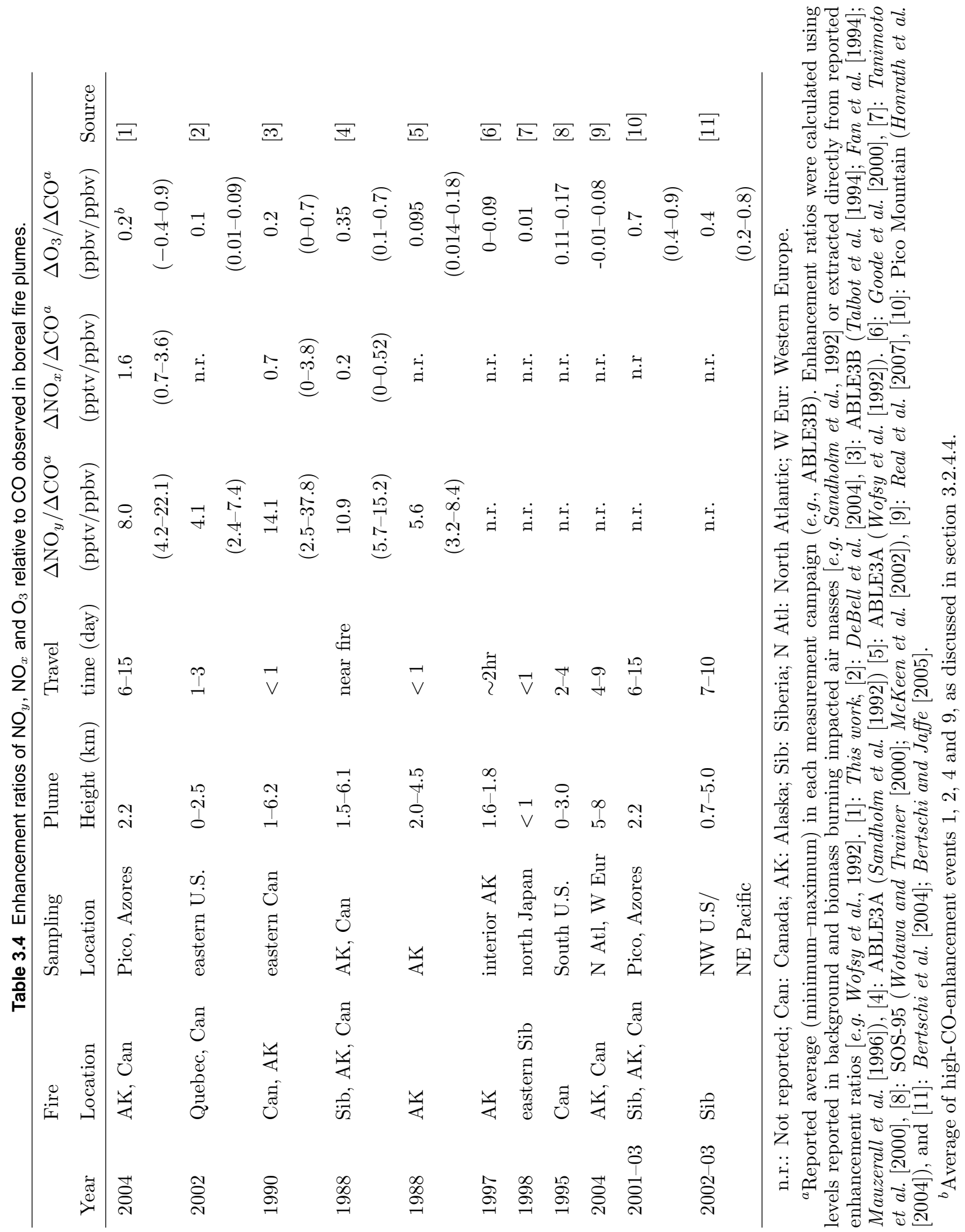




\subsubsection{3 $\mathrm{NO}_{x}$}

Given the presumption of significant PAN content, the export of $\mathrm{NO}_{y}$ is expected to lead to $\mathrm{NO}_{x}$ release downwind from the fires. $\mathrm{NO}_{x}$ mixing ratios were indeed significantly enhanced in these plumes relative to background. Figure 3.4c shows the relationship between $\mathrm{NO}_{x}$ and $\mathrm{CO}$ in the boreal wildfire plumes and in background air from boreal regions in absence of fire emissions; $\Delta \mathrm{NO}_{x} / \Delta \mathrm{CO}$ ratios for the boreal wildfire events are listed in Table 3.3 .

The average of these $\mathrm{NO}_{x}$ enhancement ratios (1.6 pptv/ppbv; Table 3.4) is significantly larger than those reported previously in moderately aged boreal fire plumes (0.2-0.7 pptv/ppbv; Table 3.4 [e.g., Sandholm et al., 1992; Mauzerall et al., 1996). The occurrence of large enhancements of $\mathrm{NO}_{x}$ and large $\Delta \mathrm{NO}_{x} / \Delta \mathrm{CO}$ ratios in these plumes implies that decomposition of PAN to $\mathrm{NO}_{x}$, occurring as the plumes subside southward to the latitude of the Azores, may be an important source of $\mathrm{NO}_{x}$ to the lower troposphere. This is consistent with the large enhancements of $\mathrm{NO}_{y}$ observed at Pico as well as the large enhancements of $\mathrm{NO}_{y}$ and PAN detected in plumes at higher altitudes than Pico over eastern North America [Flocke et al., 2005] and over western Europe [H. Schlager, Deutsches Zentrum für Luft- und Raumfahrt (DLR), Germany, personal communication, 2006] during the ICARTT campaign.

The overall impact of fire plumes on $\mathrm{NO}_{x}$ levels during summer 2004 was significant. Fire emissions were responsible for $36 \%$ of all observations of $\mathrm{NO}_{x}$ above 50 pptv (and $90 \%$ of all observations above 100 pptv). Fire plumes also led to a significant impact on NO levels. The 9 boreal wildfire events were responsible for $29 \%$ of all observations of NO above $20 \mathrm{pptv}$, and the average daytime fire-impacted NO was significantly larger $(17 \pm 2 ;$ mean $\pm 2-\sigma)$ than the average daytime NO for all summer observations $(11 \pm 1)$. The large $\mathrm{NO}$ and $\mathrm{NO}_{x}$ mixing ratios present in these well-aged boreal wildfire plumes indicate a significant impact on the regional $\mathrm{O}_{3}$ budget. 


\subsubsection{Ozone}

Figure $3.4 \mathrm{~d}$ shows the relationship between $\mathrm{O}_{3}$ and $\mathrm{CO}$ in the boreal wildfire plumes and in background air from boreal regions without fire emissions. The estimated $\mathrm{O}_{3}$ enhancement ratio of each boreal fire event is provided in Table 3.3 .

The behaviors of $\mathrm{O}_{3}$ in the fire plumes varied from significant $\mathrm{O}_{3}$ enhancement in some plumes (e.g. event 1; grey triangles in Figure 3.4 d) to $\mathrm{O}_{3}$ enhancement relative to background, with a negative $\mathrm{CO}-\mathrm{O}_{3}$ slope (e.g. event 4; red squares) to a smaller $\mathrm{O}_{3}$ enhancement (e.g. event 9; blue diamonds). Furthermore, several fire plumes presented relatively large $\Delta \mathrm{O}_{3} / \Delta \mathrm{CO}$ ratio associated with only moderate $\mathrm{CO}$ enhancements (e.g. event 3; purple circles in Figure 3.4d; also events 5-8). The moderate $\mathrm{CO}$ enhancements during those periods make these events difficult to interpret, and therefore we focus here on the $\mathrm{O}_{3}$ enhancement ratios in the high-CO-enhancement events.

The significant enhancements of $\mathrm{O}_{3}$ and large $\Delta \mathrm{O}_{3} / \Delta \mathrm{CO}$ ratios (mean $0.2 \mathrm{ppbv} / \mathrm{ppbv}$ ) in these plumes are consistent with other studies that suggest that significant ozone production occurred downwind from boreal wildfires. For example, ozone enhancements of 20-30 ppbv were observed in boreal wildfire plumes after 5-7 days travel time to southern U.S. Wotawa and Trainer, 2000, Morris et al., 2006 and to Europe Forster et al., 2001, Real et al., 2007. Model simulations of the $\mathrm{O}_{3}$ formation in biomass burning plumes indicate that the slow recycling of PAN, and to a lesser extend $\mathrm{HNO}_{3}$ and organic nitrates, increases the effective lifetime of $\mathrm{NO}_{x}$ stimulating the continued formation of $\mathrm{O}_{3}$ in these plumes beyond the typical 1-day $\mathrm{NO}_{2}$ lifetime Chatfield and Delany, 1990; Real et al., 2007.

However, this mean $\Delta \mathrm{O}_{3} / \Delta \mathrm{CO}$ ratio is smaller than some reported previously and listed in Table 3.4 (e.g., 0.4-0.7 ppbv/ppbv Honrath et al. 2004, Bertschi and Jaffe, 2005, Lapina et al. 2006]). This is mainly a result of the background value used here, as discussed in section 3.2.4. The average $\mathrm{O}_{3}$ enhancement ratio we calculate 
increases to $0.3 \mathrm{ppbv} / \mathrm{ppbv}$ if the 2004 summertime background (Table 3.1) is used. If, in addition, all boreal wildfire events are considered, i.e., moderate- and high-COenhancement events, the average $\Delta \mathrm{O}_{3} / \Delta \mathrm{CO}$ ratio increases to $0.5 \mathrm{ppbv} / \mathrm{ppbv}$ (range $0.2-0.8 \mathrm{ppbv} / \mathrm{ppbv})$.

The significant $\mathrm{O}_{3}$ enhancements observed during all but one event indicate $\mathrm{O}_{3}$ production in most of the sampled boreal wildfire plumes. However, although $\mathrm{O}_{3}$ levels were above background on average in all these events, the negative $\mathrm{O}_{3}-\mathrm{CO}$ slope observed in event 4 , and in parts of events 2 and 9 , and the very low $\Delta \mathrm{O}_{3} / \Delta \mathrm{CO}$ ratio in parts of event 9 imply the removal of $\mathrm{O}_{3}$ or the suppression of $\mathrm{O}_{3}$ production as well. This behavior is not fully understood, but may be due to one or a combination of the following causes.

First, a reduction of the $\mathrm{O}_{3}$ production rates in the plumes would cause a low $\Delta \mathrm{O}_{3} / \Delta \mathrm{CO}$, but positive $\mathrm{O}_{3}-\mathrm{CO}$ slope. A flat relationship between $\mathrm{O}_{3}$ and $\mathrm{CO}$, in combination with large enhancements of PAN and little $\mathrm{NO}_{x}$ Flocke et al. 2005 and large enhancements of VOCs [de Gouw et al., 2006], was observed in some of the boreal fire plumes intercepted by the NOAA W-P3 at higher altitudes than Pico. de Gouw et al. 2006] based on the VOCs measurements deduced that $\mathrm{OH}$ levels were depressed in these plumes. Similar conditions (i.e. large enhancements of PAN and VOCs) were observed at the BAe146 Real et al., 2007. As a consequence of low $\mathrm{OH}$ concentrations and limited $\mathrm{NO}_{x}$ availability, $\mathrm{O}_{3}$ production rates may have been reduced. Similarly, Pfister et al. 2006] indicated that near the fire regions and, to a lesser extent downwind from the fires, $\mathrm{O}_{3}$ production may also be reduced due to the combination of a reduction in the production rate and an increase in the loss rate of background $\mathrm{O}_{3}$, as a result of a decrease in $\mathrm{HO}_{x}\left(\mathrm{OH}+\mathrm{HO}_{2}\right)$ concentrations.

Second, several studies have demonstrated the loss of $\mathrm{O}_{3}$ by reaction with organic compounds present in aerosols [e.g., de Gouw and Lovejoy, 1998; Griffin et al., 1999. Biomass burning is a large source of smoke particles composed typically of organic carbon $(\mathrm{OC}) \sim 50-60 \%$ and $\mathrm{BC} \sim 5-10 \%$ Reid et al., 2005. Given the significant 
levels of $\mathrm{BC}$ observed in the boreal fire plumes and the large ratio of $\mathrm{OC}$ to $\mathrm{BC}$ in biomass burning Reid et al., 2005], $\mathrm{O}_{3}$ destruction on organic aerosols may have contributed to the reduced $\mathrm{O}_{3}$ enhancement ratio or the negative $\mathrm{O}_{3}-\mathrm{CO}$ relationship observed in some events.

Finally, nighttime chemistry processes may also result in destruction of $\mathrm{O}_{3}$. At night, chemical processing of $\mathrm{NO}_{x}$ oxidizes $\mathrm{NO}_{x}$ to $\mathrm{HNO}_{3}$ via rapid heterogeneous hydrolysis of $\mathrm{N}_{2} \mathrm{O}_{5}$ in aerosols and initiates nocturnal oxidation of VOCs, with the concurrent destruction of $\mathrm{O}_{3}$ Parrish et al., 1998; Brown et al., 2006. Thus, nocturnal $\mathrm{NO}_{x}$ emissions from boreal wildfires may result in a reduction of $\mathrm{O}_{3}$ and $\mathrm{NO}_{y}$, and result in reduced $\Delta \mathrm{O}_{3} / \Delta \mathrm{CO}$ ratio or negative $\mathrm{O}_{3}-\mathrm{CO}$ relationships.

To further investigate the photochemical properties of the plumes, we present the relationship between $\mathrm{O}_{3}$ and $\mathrm{NO}_{y}$ in Figure 3.6. With the exception of event $4, \mathrm{O}_{3}$ and $\mathrm{NO}_{y}$ showed positive correlations in all plumes $\left(r^{2}=0.5-0.8\right)$. Positive $\mathrm{O}_{3}-\mathrm{NO}_{y}$ correlations are consistent with our expectation of photochemical $\mathrm{O}_{3}$ production in the plumes, as a result of decomposition of PAN to $\mathrm{NO}_{x}$ occurring in the air masses during subsidence to the station. The sole exception, event 4 (red squares) exhibits no correlation between $\mathrm{O}_{3}$ and $\mathrm{NO}_{y}$ (Figure 3.6) and a negative $\mathrm{O}_{3}-\mathrm{CO}$ relationship (Figure $3.4 \mathrm{~d}$ ) and a larger $\mathrm{BC}^{-\mathrm{NO}_{y}}$ relationship than the general trend (Figure 3.5). This situation suggests $\mathrm{O}_{3}$ destruction from organic aerosols during transport towards the station. However, the data available here are insufficient to test this hypothesis.

Finally, we have evaluated the possibility that stratospheric $\mathrm{O}_{3}$ contributed to the $\mathrm{O}_{3}$ enhancements observed during some of these events. Stratospheric $\mathrm{O}_{3}$ frequently impacted the FT over eastern North America during summer 2004 Thompson et al., 2007]. Boreal fire plumes that impacted Pico were often associated with subsidence from altitudes of approximately $6-8 \mathrm{~km}$, suggesting a potential stratospheric impact. To assess this, we used FLEXPART stratospheric $\mathrm{O}_{3}$ tracer values simulated at the station location and altitude during July 1-August 16 [A. Stohl, Norwegian Institute for Air Research (NILU), personal communication, 2006]. Detailed information about 


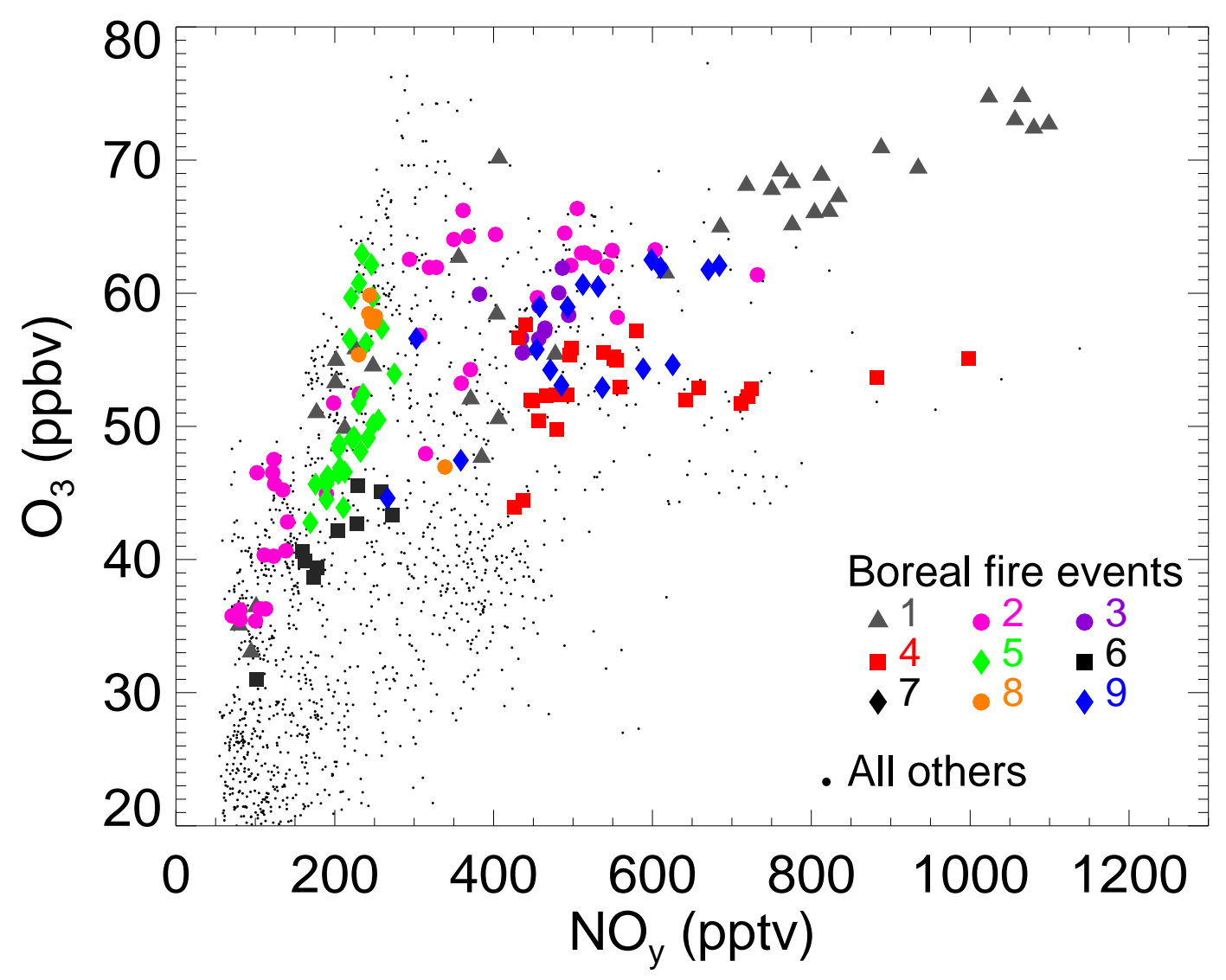

Figure 3.6 As Figure 3.5, but for the relationship between $\mathrm{O}_{3}$ and $\mathrm{NO}_{y}$.

the FLEXPART model is present elsewhere [Stohl et al., 2005]. This analysis indicated that stratospheric $\mathrm{O}_{3}$ occasionally impacted the station during the ICARTT period, but that the overall impact of stratospheric $\mathrm{O}_{3}$ was rather small: the average $( \pm$ standard deviation) of all stratospheric $\mathrm{O}_{3}$ tracer values was $8.4 \pm 5.2 \mathrm{ppbv}$. During the fire-impacted events, stratospheric $\mathrm{O}_{3}$ tracer values were usually reduced, rather than increased, with an average ( \pm standard deviation) of $5.8 \pm 4.2$ ppbv. We found only one episode during the boreal fire events (August 07 23:00-August 08 21:00) when the stratospheric $\mathrm{O}_{3}$ tracer was large (10 to $18 \mathrm{ppbv}$ ). This episode occurred during event 5 (green diamonds in Figure 3.4 d). Even during this episode, the $\mathrm{O}_{3}$ 
enhancement during the event did not appear to be due to stratospheric $\mathrm{O}_{3}$, as FLEXPART stratospheric $\mathrm{O}_{3}$ tracer values did not increase relative to values before or after the event. Therefore, we conclude that stratospheric $\mathrm{O}_{3}$ was not the cause of the enhancements of $\mathrm{O}_{3}$ observed during event 5, and that the overall impact of stratospheric $\mathrm{O}_{3}$ was not significant during the boreal fire plumes analyzed in the study.

\subsubsection{Implications of Boreal Wildfires for the $\mathrm{NO}_{x}$ and $\mathrm{O}_{3}$ Budgets}

The $\mathrm{NO}_{y}$ enhancement ratios observed at Pico may be used to estimate the total amount of $\mathrm{NO}_{x}$ emitted from the fires and exported in the plumes by multiplying the observed $\mathrm{NO}_{y} / \mathrm{CO}$ enhancement ratio by the fire $\mathrm{CO}$ emissions Stohl et al., 2002;

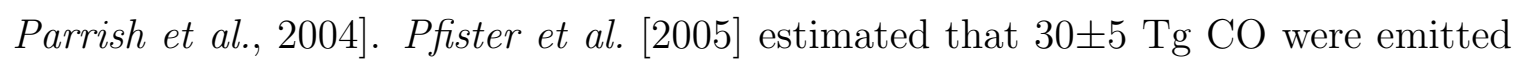
over the North American boreal region from mid-June to August, 2004, consistent with the estimate of Turquety et al., 2007. Using the $\Delta \mathrm{NO}_{y} / \Delta \mathrm{CO}$ ratio at the Pico Mountain station (8.0 pptv/ppbv CO; Table 3.4) as an approximation of the impact of long-range-transported fire emissions, this $\mathrm{CO}$ emission implies that the fires contributed $0.12 \mathrm{Tg} \mathrm{NO}_{y}$ (as N). If, instead, we use total boreal fire $\mathrm{CO}$ emissions in a typical year $(\sim 61 \mathrm{Tg}$ CO; Kasischke et al. 2005]), i.e., including Siberian emissions as well as North American, the total contribution to long-range-transported $\mathrm{NO}_{y}$ is estimated as $0.24 \mathrm{Tg}$. These values are quite large. For comparison, the amount of eastern North American $\mathrm{NO}_{x}$ emissions exported to the FT during mid-June through August 2004 was approximately $0.30 \mathrm{Tg} \mathrm{NO}_{y}$ (as N). (This estimate is based on eastern U.S. $\mathrm{NO}_{x}$ emissions equal to two-thirds of the U.S. national emissions during that period, using total $\mathrm{NO}_{x}$ U.S. emissions in 1999 reported by Parrish et al. 2004, adjusted for the $8.8 \%$ per year decrease of the on-road CO: $\mathrm{NO}_{y}$ emission ratio, and estimated efficiency of export to the FT equal to approximately $25 \%$ during sum- 
mertime [e.g., Liang et al., 1998, Stohl et al., 2002, Parrish et al., 2004, Li et al., 2004.) These observations imply significant impacts of the boreal wildfires on the $\mathrm{NO}_{y}$ budget over downwind regions distant from the fires.

If the $\mathrm{O}_{3}$ enhancement ratio at the Pico Mountain station applies to all fire emissions, the average $\Delta \mathrm{O}_{3} / \Delta \mathrm{CO}$ ratio $(0.2 \mathrm{ppbv} / \mathrm{ppbv})$, combined with the total $\mathrm{CO}$ emitted from the North American wildfires (30 Tg) or with the typical CO emitted from boreal wildfires $(61 \mathrm{Tg})$, indicates that the boreal wildfires may have resulted in a source of $10-21 \mathrm{Tg}$ of $\mathrm{O}_{3}$ during summer 2004. This method is generally consistent with the MOZART analysis of fire-induced $\mathrm{O}_{3}$ production discussed by Pfister et al. [2006. The monthly mean of our estimate (4-8 $\mathrm{Tg} \mathrm{O}_{3} /$ month from mid-June to August) is $10-20 \%$ of the July net photochemical $\mathrm{O}_{3}$ production in the northern middle and high latitudes $\left(30-90^{\circ} \mathrm{N}\right.$; surface to $350 \mathrm{hPa}$ ) estimated by Emmons et al. 2003. The ultimate impact could be even larger, since additional $\mathrm{O}_{3}$ is expected to form as a result of the $\mathrm{NO}_{x}$ and PAN still remaining in the transported plumes. Therefore, our observations indicate that boreal wildfires may significantly impact the hemispheric $\mathrm{O}_{3}$ budget during the fire season.

Given the current uncertainties in the $\mathrm{CO}$ emissions from boreal wildfires, the increase in dry and warm conditions over the boreal region Hassol, 2004, and the increase in human-ignited fires Mollicone et al. 2006, most likely the impact of boreal wildfires is significantly larger than previously believed.

\subsection{Conclusions}

North American boreal wildfire emissions frequently impacted the Pico Mountain station during summer 2004. Using MOZART simulations and enhancements of CO levels, we identified 21 events of long-range transport of boreal wildfire emissions to the site, which accounted for $16 \%$ of the time from July 1 to September 5, 2004. Fire-impacted boreal region outflow resulted in extremely high levels of $\mathrm{CO}, \mathrm{BC}$ and 
nitrogen oxides, relative to other observations at the station, along with significant enhancements of $\mathrm{O}_{3}$. Analysis of $\mathrm{CO}, \mathrm{BC}, \mathrm{NO}_{y}, \mathrm{NO}_{x}$ and $\mathrm{O}_{3}$ observations during the boreal wildfire events showed that levels of all these species were above those in background air from similar outflow in the absence of fires, and well above typical summertime background levels at the site. This indicates a significant contribution from the North American wildfire emissions to background levels of these species over the North Atlantic region during summer 2004.

Enhancement ratios relative to $\mathrm{CO}$ were somewhat variable, however. This is attributed to a combination of variation of fire types and emissions and removal during transport to the site. Analyses of $\Delta \mathrm{BC} / \Delta \mathrm{CO}$ and $\Delta \mathrm{NO}_{y} / \Delta \mathrm{CO}$ indicated that a significant fraction of $\mathrm{BC}$ and $\mathrm{NO}_{y}$ resulting from the fires was scavenged in some plumes, but on average $\mathrm{BC}$ and $\mathrm{NO}_{y}$ were efficiently exported to the lower FT over the North Atlantic region. Analyses of $\Delta \mathrm{NO}_{x} / \Delta \mathrm{CO}$ ratios suggested that decomposition of PAN to $\mathrm{NO}_{x}$, occurring as the plumes subside southward to the Azores, was an important source of $\mathrm{NO}_{x}$. High levels of $\mathrm{NO}$ and $\mathrm{NO}_{x}$ imply continuing $\mathrm{O}_{3}$ formation in these highly aged plumes.

Ozone levels were also significantly enhanced. Analysis of $\Delta \mathrm{O}_{3} / \Delta \mathrm{CO}$ ratios indicated a varying behavior from plume to plume, with significant to moderate $\mathrm{O}_{3}$ production, and included negative $\mathrm{O}_{3}-\mathrm{CO}$ slopes in some plumes. We discussed several mechanisms that may have contributed to the complex behavior of $\mathrm{O}_{3}$ in the fire plumes, and suggest that further work is needed to better understand this effect. However, the $\mathrm{O}_{3}$ enhancements present in all but one plume indicate that significant photochemical production occurred during transport, most likely as a result of decomposition of PAN to $\mathrm{NO}_{x}$. Lower $\mathrm{O}_{3}$ production in other plumes may have resulted from a reduction in the $\mathrm{O}_{3}$ production rates due to reduced $\mathrm{OH}$ concentrations and limited $\mathrm{NO}_{x}$, or from destruction of $\mathrm{O}_{3}$ during transport due to reaction with organic aerosols or nighttime chemistry.

Our analyses demonstrate that boreal wildfire emissions can result in a significant 
source of $\mathrm{BC}, \mathrm{NO}_{x}$ and $\mathrm{O}_{3}$ in the central North Atlantic lower FT. Since our observations were made very far downwind from the fires, this suggests very large-scale impacts of boreal wildfires both on direct radiative forcing by $\mathrm{BC}$ and on tropospheric $\mathrm{NO}_{x}$ and $\mathrm{O}_{3}$ budgets. Recent studies have shown a positive trend in the amount of areas burned over recent decades Gillett et al., 2004, Kasischke and Turetsky, 2006, likely as a result of warmer and drier conditions in the boreal region Hassol, 2004], and possibly in combination with direct human impacts [Mollicone et al. 2006]. Global Circulation Models predict more frequent and more severe fires as the climate changes Stocks et al. , 1998, Flannigan et al., 2000]. Thus, the impact of boreal wildfires may become even more important in the near future. 


\section{Chapter 4}

\section{Summary and Conclusions}

This work demonstrates the significance of the impact of long-range transport of boreal wildfire and anthropogenic emissions on the nitrogen oxides levels and their seasonal variation over the central North Atlantic lower FT.

A high-sensitivity instrument developed at Michigan Tech was modified and installed at the Pico Mountain station. The $\mathrm{NO}_{x, y}$ system was used to measure the NO, $\mathrm{NO}_{2}$ and $\mathrm{NO}_{y}$ mixing ratios presented in this work. These measurements were analyzed in combination with simultaneous observations of $\mathrm{CO}, \mathrm{O}_{3}$, aerosol $\mathrm{BC}$ and meteorological parameters made at the Pico Mountain station. In addition, HYSPLIT backward trajectories, FLEXPART simulations and results from two GCT models (MOZART and GEOS-Chem) were used to analyze the data.

Measurements of nitrogen oxides from July 2002 to August 2005 at the Pico Mountain observatory provide full seasonal coverage of observations over the central North Atlantic lower FT. The $\mathrm{NO}, \mathrm{NO}_{x}$ and $\mathrm{NO}_{y}$ measurements were analyzed to determine the seasonal variation of nitrogen oxides levels over the central North Atlantic lower FT and assess the processes controlling these levels. In particular, the data were analyzed to determine the impacts of transport of emissions from the boreal region and the U.S. on the nitrogen oxides and the further implications for the hemispheric $\mathrm{NO}_{x}$ 
and $\mathrm{O}_{3}$ budgets. The main results of these analyses are presented below, followed by a summary of the overall conclusions and future research.

\subsection{Seasonal Variation of Nitrogen Oxides}

Measurements at the Pico Mountain station show the presence of a clear seasonal variation of nitrogen oxides over the central North Atlantic lower FT, with higher levels during the summer season. Long-range transport of emissions in combination with removal processes en-route are responsible for the observed $\mathrm{NO}_{x}$ and $\mathrm{NO}_{y}$ levels at the measurement site.

Observations of $\mathrm{NO}_{x}$ and $\mathrm{NO}_{y}$ and estimates of $\mathrm{PAN}$ and $\mathrm{HNO}_{3}$ indicate that reactive nitrogen over the central North Atlantic lower FT largely exist in the form of $\mathrm{HNO}_{3}$ and PAN ( $\sim 80-90 \%$ of $\left.\mathrm{NO}_{y}\right)$. A change in the composition of $\mathrm{NO}_{y}$ from dominance of PAN to dominance of $\mathrm{HNO}_{3}$ occurs from winter-spring to summer-fall over the central North Atlantic region, as a result of changes in temperature and photochemistry over the region.

The large presence of $\mathrm{HNO}_{3}\left(53-71 \%\right.$ of $\left.\mathrm{NO}_{y}\right)$ during the summer and a significant removal of $\mathrm{NO}_{y}$ (expected via $\mathrm{HNO}_{3}$ ) during transport to the measurement site suggest that oxidation of $\mathrm{NO}_{x}$ released from PAN in the airmasses during subsidence, or advection over the ocean with minimal removal, results in a significant source of $\mathrm{HNO}_{3}$ over the central North Atlantic lower FT. The decomposition of PAN in the airmasses during transport suggests an important impact on the $\mathrm{O}_{3}$ production as released $\mathrm{NO}_{x}$ is available to form $\mathrm{O}_{3}$ before it oxidizes to $\mathrm{HNO}_{3}$.

\subsection{Impacts of Boreal Wildfire Emissions}

Boreal wildfire emissions significantly impact the nitrogen oxides levels over the central North Atlantic lower FT. These emissions are responsible for significant shifts in 
the nitrogen oxides distributions toward higher levels during the summer. Observations of $\mathrm{NO}_{x}$ and $\mathrm{NO}_{y}$ at the Pico Mountain station show that summertime medians of $\mathrm{NO}_{y}$ and $\mathrm{NO}_{x}$ were, respectively, 117-175 pptv and 9-30 pptv greater with the presence of boreal wildfire emissions. The extreme levels of $\mathrm{NO}_{x}$ (up to $150 \mathrm{pptv}$ ) and $\mathrm{NO}_{y}$ (up to 1100 pptv) observed in boreal wildfire plumes suggest that decomposition of PAN to $\mathrm{NO}_{x}$ is a significant source of $\mathrm{NO}_{x}$, and imply that $\mathrm{O}_{3}$ formation occurs during transport. Ozone levels are also significantly enhanced in boreal wildfire plumes. However, a complex behavior of $\mathrm{O}_{3}$ is observed in the plumes, which varies from significant to lower $\mathrm{O}_{3}$ production to $\mathrm{O}_{3}$ destruction.

Observed $\Delta \mathrm{NO}_{y} / \Delta \mathrm{CO}$ and $\Delta \mathrm{O}_{3} / \Delta \mathrm{CO}$ ratios at the Pico Mountain station and estimates of total boreal wildfire $\mathrm{CO}$ emissions indicate that boreal wildfires may result in a source of $\mathrm{NO}_{x}$ and $\mathrm{O}_{3}$ of $0.12-0.24 \mathrm{Tg} \mathrm{NO}_{y}\left(\right.$ as $\mathrm{N}$ ) and 19-21 $\mathrm{Tg} \mathrm{O}_{3}$. This estimated source of $\mathrm{NO}_{x}$ emissions from boreal wildfires was comparable to the contribution of U.S. anthropogenic $\mathrm{NO}_{x}$ emissions, and the estimated monthly $\mathrm{O}_{3}$ production from the wildfires is about $10-20 \%$ of the previously estimated net tropospheric $\mathrm{O}_{3}$ production rate in the northern middle and high latitudes. In addition, aerosol BC measurements were also significantly impacted by boreal wildfires. These results provide evidence of the very large-scale impact on the tropospheric $\mathrm{NO}_{x}$ and $\mathrm{O}_{3}$ budgets and the direct radiative forcing of the atmosphere by light-absorbing particles.

\subsection{Impacts of Anthropogenic Emissions}

Transport of pollution from North America causes significant enhancements on nitrogen oxides levels all year round. Enhancements of $\mathrm{CO}, \mathrm{NO}_{y}$ and $\mathrm{NO}_{x}$ indicate that, consistent with previous studies, the majority (95-97\%) of the $\mathrm{NO}_{x}$ emitted over the eastern U.S. is removed before and during export out of the U.S. BL. However, a comparison of the estimated $\mathrm{NO}_{y}$ transport efficiencies to those previously estimated 
upwind from the Pico Mountain station, indicate that about $30 \%$ of the emissions exported out of the U.S. boundary layer in the sampled air masses is efficiently transported to the central North Atlantic lower FT. Since the lifetime of $\mathrm{NO}_{x}$ is shorter than the transport timescale, PAN decomposition and potentially photolysis of $\mathrm{HNO}_{3}$ constitute a supply of $\mathrm{NO}_{x}$ over the central North Atlantic lower FT, in particular during the fall season.

While GCT models indicate that most of the net $\mathrm{O}_{3}$ production occurs near North America [e.g. Li et al. 2004], the observed $\Delta \mathrm{O}_{3} / \Delta \mathrm{NO}_{y}$ suggests that a substantial amount of additional ozone formation occurs in the anthropogenic plumes during transport to the central North Atlantic lower FT. Large levels of $\mathrm{NO}_{y}$ remaining in the North American plumes suggest a potential $\mathrm{O}_{3}$ formation well downwind from North America. For example, based on the average $\Delta \mathrm{NO}_{y} / \Delta \mathrm{CO}$ ratio observed at the Pico Mountain station, the eastern U.S. CO emissions and estimates of the $\mathrm{O}_{3}$ production efficiency, this work indicates that 1.8-3 $\mathrm{Gmol}$ of $\mathrm{O}_{3}$ are produced downwind per day as a result of the transport of nitrogen oxides. This estimated source of $\mathrm{O}_{3}$ may be comparable as the direct export of $\mathrm{O}_{3}$ produced within the U.S. BL.

\subsection{Conclusions and Additional Research}

The findings of this work provide an understanding of the seasonal variation and the magnitude of the nitrogen oxides over the central North Atlantic lower FT. In addition, this work provides evidence of the very large-scale impacts of boreal wildfire emissions on the nitrogen oxides and $\mathrm{O}_{3}$ levels during the summer season, and the significant influence of anthropogenic pollution from North America over the central North Atlantic lower FT all year round.

These measurements, analyses and results motivate future research. First, these measurements suggest that $\mathrm{NO}_{x}$ levels over the central North Atlantic lower FT are significantly influenced by decomposition of PAN, in particular PAN produced 
from boreal wildfire $\mathrm{NO}_{x}$ emissions. Therefore, additional measurements of PAN are recommended at the Pico Mountain station in order to determine to what degree the export of PAN from North America and boreal wildfires is responsible for the observed $\mathrm{NO}_{x}$.

Second, $\mathrm{NO}_{2}$ observations at the Pico Mountain station show the absence of a negative diurnal variation or no variation of $\mathrm{NO}_{2}$, which result in the presence of a diurnal cycle for $\mathrm{NO}_{x}$. This behavior was present all year round and was not well understood, in particular for winter and spring. Thus, additional measurements and analysis are recommended to clarify the unknown source of $\mathrm{NO}_{2}$ during the daytime.

Third, this study shows the complex behavior of $\mathrm{O}_{3}$ in the boreal wildfire plumes. An in-situ photochemical modeling analysis using measurements in boreal wildfire plumes at the Pico Mountain station is needed to further understand the behavior of $\mathrm{O}_{3}$ in the wildfire plumes, and also to determine whether the observed $\mathrm{NO}_{x}$ levels may explain the significant impacts of boreal wildfires on the $\mathrm{O}_{3}$ background.

Fourth, further research is needed to quantify the ultimate impact of North American outflow on the $\mathrm{O}_{3}$ photochemical tendency over the central North Atlantic lower FT. An in-situ modeling analysis constrained by measurements and conditions at the Pico Mountain station can be used for this purpose. This analysis could also be applied to understand how the photochemical perturbations caused by boreal wildfire emissions and by anthropogenic emissions differ from one another.

Finally, this work was focused on the impacts of anthropogenic emissions from North America. However, significant emissions from Asia and Europe reach the central North Atlantic region. Additional research is recommended to assess the influence of these sources in the lower FT over the Atlantic and their relative importance. 


\section{References}

Alley, R., et al., Climate Change 200\%: The Physical Science Basis. Contribution of Working Group I to the Fourth Assessment Report of the Intergovernmental Panel on Climate Change, in press, 2007.

Andreae, M., and P. Merlet, Emissions from trace gases and aerosols from biomass burning, Global Biogeochem. Cycles, 15, 955-966, 2001.

Atlas, E. L., et al., Partitioning and budget of $\mathrm{NO}_{y}$ species during the Mauna Loa observatory photochemistry experiment, J. Geophys. Res., 97, 10,449-10,462, 1992.

Auvray, M., and I. Bey, Long-range transport to Europe: Seasonal variations and implications for the European ozone budget, J. Geophys. Res., 110, 2005.

Auvray, M., I. Bey, E. Llull, M. G. Schultz, and S. Rast, A model investigation of tropospheric ozone chemical tendencies in long-range transported pollution plumes, J. Geophys. Res., 112, 1-17, 2007, doi:10.1029/2006JD007137.

Bertschi, I. T., and D. A. Jaffe, Long-range transport of ozone, carbon monoxide, and aerosols to the NE Pacific troposphere during the summer of 2003: Observations of smoke plumes from Asian boreal fires, J. Geophys. Res., 110, 2005.

Bertschi, I. T., D. A. Jaffe, L. Jaeglé, H. U. Price, and J. B. Dennison, PHOBEA/ITCT 2002 airborne observations of transpacific transport of ozone, CO, volatile organic compounds, and aerosols to the northeast Pacific: Impacts of Asian anthropogenic and Siberian boreal fire emissions, J. Geophys. Res., 109, 2004.

Bey, I., et al., Global modeling of tropospheric chemistry with assimilated meteorology: Model description and evaluation, J. Geophys. Res., 106, 23,073-23,096, 2001.

Bollinger, M. J., R. E. Sievers, D. W. Fahey, and F. C. Fehsenfeld, Conversion of nitrogen dioxide, nitric acid, and n-propyl nitrate to nitric oxide by gold-catalyzed reduction with carbon monoxide, Anal. Chem., 55, 1980-1986, 1983.

Bond, T. C., and H. Sun, Can reducing black carbon emissions counteract global warming?, Environ. Sci. Technol., 39, 5921-5926, 2005, doi:10.1021/es0480421. 
Bond, T. C., D. G. Streets, K. F. Yarber, S. M. Nelson, J.-H. Woo, and Z. Klimont, A technology-based global inventory of black and organic carbon emissions from combustion, J. Geophys. Res., 109, 1-43, 2004, doi:10.1029/2003JD003697.

Bradshaw, J., D. Davis, G. Grodzinsky, R. Newell, S. Sandholm, and S. Liu, Observed distributions of nitrogen oxides in the remote free troposphere from NASA global tropospheric Experiment programs, Rev. Geophys., 38, 61-116, 2000.

Brown, S. S., et al., Variability in nocturnal nitrogen oxide processing and its role in regional air quality, Science, 311, $67-70,2006$.

Carroll, M. A., and A. M. Thompson, $\mathrm{NO}_{x}$ in the non-urban troposphere, in Problems and Progress in Atmospheric Chemistry, edited by J. R. Barker, vol. 3, World Scientific Publishing Company, 1995.

Chameides, W. L., The photochemistry of a remote marine stratiform cloud, J. Geophys. Res., 89, 4739-4755, 1984.

Chandra, S., J. R. Ziemke, X. Tie, and G. Brasseur, Elevated ozone in the troposphere over the Atlantic and Pacific oceans in the Northern Hemisphere, Geophys. Res. Lett., 31, $1-4,2004$.

Chatfield, R. B., and A. C. Delany, Convection links biomass burning to increased tropical ozone: However, models will tend to overpredict $\mathrm{O}_{3}$, J. Geophys. Res., 95, 18,473-18,488, 1990 .

Chin, M., D. J. Jacob, J. W. Munger, D. D. Parrish, and B. G. Doddridge, Relationship of ozone and carbon monoxide over North America, J. Geophys. Res., 99, 14,565-14,573, 1994.

Cox, R. A., Ozone and peroxy radical budgets in the marine boundary layer: Modeling the effect of $\mathrm{NO}_{x}$, J. Geophys. Res., 104, 8047-8056, 1999.

Crutzen, P. J., The role of $\mathrm{NO}$ and $\mathrm{NO}_{2}$, Ann. Rev. Earth Planet. Sci., 7, 443-472, 1979.

Damoah, R., N. Spichtinger, C. Forster, P. James, I. Mattis, U. Wandinger, S. Beirle, T. Wagner, and A. Stohl, Around the world in 17 days-hemispheric-scale transport of forest fire smoke from Russia in May 2003, Atmos. Chem. and Phys., 4, 1449-1471, 2004.

Damoah, R., et al., A case study of pyro-convection using transport model and remote sensing data, Atmos. Chem. and Phys., 6, 173-185, 2006.

de Gouw, J., C. Warneke, D. D. Parrish, J. S. Holloway, M. Trainer, and F. C. Fehsenfeld, Emission sources and ocean uptake of acetonitrile $\left(\mathrm{CH}_{3} \mathrm{CN}\right)$ in the atmosphere, J. Geophys. Res., 108, 2003.

de Gouw, J. A., and E. R. Lovejoy, Reactive uptake of ozone by liquid organic compounds, Geophys. Res. Lett., 25, 931 - 934, 1998, doi:10.1029/98GL00515. 
de Gouw, J. A., et al., Volatile organic compounds composition of merged and aged forest fire plumes from Alaska and western Canada, J. Geophys. Res., 111, 2006.

DeBell, L. J., R. W. Talbot, J. E. Dibb, J. W. Munger, E. V. Fischer, and S. E. Frolking, A major regional air pollution event in the northeastern United States caused by extensive forest fires in Quebec, Canada, J. Geophys. Res., 109, 2004.

Derwent, R., P. J. Simmonds, S. Seuring, and C. Dimmer, Observation and interpretation of the seasonal cycles in the surface concentrations of ozone and carbon monoxide at Mace Head, Ireland from 1990 to 1994, Atmos. Environ., 32, 145-157, 1998.

Derwent, R., D. Stevenson, W. Collins, and C. Johnson, Intercontinental transport and the origins of the ozone observed at surface sites in Europe, Atmos. Environ., 38, 1891-1901, 2004 .

Dibb, J. E., E. Scheuer, S. I. Whitlow, M. Vozella, E. Williams, and B. M. Lerner, Shipbased nitric acid measurements in the Gulf of Maine during New England Air Quality Study 2002, J. Geophys. Res., 109, 1-13, 2004, doi:10.1029/2004JD004843.

DiNunno, B., et al., Central/eastern North Pacific photochemical precursors distributions for fall/spring seasons as defined by airborne field studies, J. Geophys. Res., 108, 10.1029/2001JD0010,044, 2003.

Draxler, R., and G. Rolph, HYSPLIT4 model (HYbrid Single-Particle Lagrangian Integrated Trajectory) model, Web address: http://www.arl.noaa.gov/ready/hysplit4.html, NOAA Air Resources Laboratory, Silver Spring, Maryland, 2003.

Duck, T. J., et al., Transport of forest fire emissions from Alaska and the Yukon Territory to Nova Scotia during summer 2004, J. Geophys. Res., 112, 1-13, 2007, doi:10.1029/2006JD007716.

Duncan, B., R. Martin, A. Staudt, R. Yevich, , and J. Logan, Interannual and seasonal variability of biomass burning emissions constrained by satellite observations, J. Geophys. Res., 108, 2003.

ECMWF, Users guide to ECMWF products 4.0, Tech. Rep. Meteorological Bulletin M3.2, European Center for Medium-Range Weather Forecasts (ECMWF), Reading, UK, 2005.

Edwards, D. P., et al., Observations of carbon monoxide and aerosols from the Terra satellite: Northern Hemisphere variability, J. Geophys. Res., 109, 2004.

EMEP, European monitoring and evaluation program (EMEP), transboundary air pollution in Europe I: Emissions, dispersion and trends of acidifying and eutrophying agents, Tech. Rep. EMEP/MSC-W Rep. 1/97, EMEP, 1997.

Emmons, L., et al., Climatologies of $\mathrm{NO}_{x}$ and $\mathrm{NO}_{y}$ : A comparison of data and models, Atmos. Environ., 31, 1851-1904, 1997. 
Emmons, L. K., D. A. Hauglustaine, J.-J. Müller, M. A. Carroll, G. P. Brasseur, D. Brunner, J. Staehelin, V. Thouret, and A. Marenco, Data composites of airborne observations of tropospheric ozone and its precursors, J. Geophys. Res., 105, 20,497-20,538, 2000.

Emmons, L. K., et al., Budget of tropospheric ozone during TOPSE from two chemical transport models, J. Geophys. Res., 108, 2003.

EPA, National air pollutant emission trends, 1990-1997, Tech. Rep. EPA 454/R-97-011, Environmental Protection Agency, 1997.

Fahey, D. W., C. S. Eubank, G. Hubler, and F. C. Fehsenfeld, Evaluation of a catalytic reduction technique for the measurement of total reactive odd-nitrogen $\mathrm{NO}_{y}$ in the atmosphere, J. Atmos. Chem., 3, 435-468, 1985.

Fan, S., et al., Origin of tropospheric $\mathrm{NO}_{x}$ over subarctic eastern Canada in summer, $J$. Geophys. Res., 99, 16,867 - 16,878, 1994, doi:10.1029/94JD01122.

Fehsenfeld, F. C., et al., International Consortium for Atmospheric Research on Transport and Transformation (ICARTT): North America to Europe: Overview of the 2004 summer field study, J. Geophys. Res., 111, 1-36, 2006, doi:10.1029/2006JD007829.

Fialho, P., A. D. A. Hansen, and R. E. Honrath, Absorption coefficients by aerosols in remote areas: A new approach to decouple dust and black carbon absorption coefficients using seven-wavelength aethalometer data, J. Aerosol Sci., 36, 267-282, 2005.

Fischer, H., et al., Trace gas measurements during the Oxidizing Capacity of the Tropospheric Atmosphere campaign 1993 at Izaña, J. Geophys. Res., 103, 13,505-13,518, 2004 .

Fishman, J., S. Solomon, and P. J. Crutzen, Observational and theoretical evidence in support of a significant in-situ photochemical source of tropospheric ozone, Tellus, 31, 432-446, 1979.

Flannigan, M., B. Stocks, and B. Wotton, Climate change and forest fires, Sci. Tot. Env., 262, 221-229, 2000.

Flocke, F., et al., Results from fast airborne measurements of PANs during the 2004 New England Air Quality Study, Eos Trans. AGU, 86, 2005, abstract A54C-03.

Forster, C., et al., Transport of boreal forest fire emissions from Canada to Europe, $J$. Geophys. Res., 106, 22,887-22,906, 2001.

Fromm, M., R. Bevilacqua, R. Servranckx, J. Rosen, J. P. Thayer, J. Herman, and D. Larko, Pyro-cumulonimbus injection of smoke to the stratosphere: Observations and impact of a super blowup in northwestern Canada on 3-4 August 1998, J. Geophys. Res., 110, 1-16, 2005, doi:10.1029/2004JD005350. 
Gao, R. S., E. R. Keim, E. L. Woodbridge, S. J. Cicora, M. H. Proffitt, T. L. Thompson, R. J. Mclaughlin, and D. W. Fahey, New photolysis system for $\mathrm{NO}_{2}$ measurements in the lower stratosphere, J. Geophys. Res., 99, 20,673-20,681, 1994.

Garrett, T. J., L. Avey, P. I. Palmer, A. Stohl, J. A. Neuman, C. A. Brock, T. B. Ryerson, and J. S. Holloway, Quantifying wet scavenging processes in aircraft observations of nitric acid and cloud condensation nuclei, J. Geophys. Res., 111, 1-12, 2006, doi:10.1029/2006JD007416.

Gillett, N., A. J. Weaver, F. W. Zwiers, and M. D. Flannigan, Detecting the effect of climate change on Canadian forest fires, Geophys. Res. Lett., 31, 2004.

Goode, J. G., R. J. Yokelson, D. E. Ward, R. A. Susott, R. E. Babbitt, M. A. Davies, and W. M. Hao, Measurements of excess $\mathrm{O}_{3}, \mathrm{CO}, \mathrm{CO}_{2}, \mathrm{CH}_{4}, \mathrm{C}_{2} \mathrm{H}_{6}, \mathrm{C}_{2} \mathrm{H}_{4}, \mathrm{HCN}, \mathrm{NO}$, $\mathrm{NH}_{3}, \mathrm{HCOOH}, \mathrm{CH}_{3} \mathrm{COOH}, \mathrm{HCHO}$ and $\mathrm{CH}_{3} \mathrm{OH}$ in 1997 Alaskan biomass burning plumes by airborne Fourier transform infrared spectroscopy (AFTIR), J. Geophys. Res., 105, $22,147-22,166,2000$.

Griffin, R. J., III, R. C. Flagan, and J. H. Seinfeld, Organic aerosol formation from the oxidation of biogenic hydrocarbons, J. Geophys. Res., 104, 3555-3568, 1999, doi:10.1029/1998JD100049.

Hangal, S., and K. Willeke, Overall efficiency of tubular inlets sampling at 0-90 degrees from horizontal aerosol flows, Atmos. Environ., 24A, 2379-2386, 1990.

Hansen, J., M. Sato, R. Ruedy, A. Lacis, and V. Oinas, Global warming in the twenty-first century: An alternative scenario, Proc. Natl. Acad. Sci. USA, 97, 9875-9880, 2000.

Hassol, S. J., Impacts of a warming Arctic: Arctic climate impact assessment, Cambridge University Press, 2004.

Honrath, R. E., R. C. Owen, M. Val Martín, J. S. Reid, K. Lapina, P. Fialho, M. P. Dziobak, J. Kleissl, and D. L. Westphal, Regional and hemispheric impacts of anthropogenic and biomass burning emissions on summertime $\mathrm{CO}$ and $\mathrm{O}_{3}$ in the North Atlantic lower free troposphere, J. Geophys. Res., 109, 2004.

Horowitz, L. W., J. Liang, G. M. Gardner, and D. J. Jacob, Export of reactive nitrogen from North America during summertime: Sensitivity to hydrocarbon chemistry, $J$. Geophys. Res., 103, 13,451-13,476, 1998.

Horowitz, L. W., et al., A global simulation of tropospheric ozone and related tracers: Description and evaluation of MOZART, version 2, J. Geophys. Res., 2003.

Hudman, R. C., et al., Surface and lightning sources of nitrogen oxides over the United States: magnitudes, chemical evolution, and outflow, J. Geophys. Res., 2007.

Jacob, D., et al., Summertime photochemistry of the troposphere at high northern latitudes, J. Geophys. Res., 97, 16,421-16,431, 1992. 
Jacob, D. J., J. A. Logan, G. M. Gardner, R. M. Yevich, C. M. Spivakovsky, S. C. Wofsy, S. Sillman, and M. J. Prather, Factors regulating ozone over the United States and its export to the global atmosphere, J. Geophys. Res., 98, 14,817 - 14,826, 1993, doi:10.1029/93JD01224.

Jaeglé, L., L. Steinberger, R. V. Martin, and K. Chance, Global partitioning of $\mathrm{NO}_{x}$ sources using satellite observations: Relative roles of fossil fuel combustion, biomass burning and soil emissions, Faraday Discuss., 130, 407-423, 2005.

Jaffe, D., H. Price, D. Parrish, A. Goldstein, and J. Harris, Increasing background ozone during spring on the west coast of North America, Geophys. Res. Lett., 30, 2003.

Jaffe, D., I. Bertschi, L. Jaeglé, P. Novelli, J. S. Reid, H. Tanimoto, R. Vingarzan, and D. L. Westphal, Long-range transport of Siberian biomass burning emissions and impact on surface ozone in western North America, Geophys. Res. Lett., 31, 2004.

Jain, A. K., Z. Tao, X. Yang, and C. Gillespie, Estimates of global biomass burning emissions for reactive greenhouse gases ( $\mathrm{CO}, \mathrm{NMHCs}$, and $\left.\mathrm{NO}_{x}\right)$ and $\mathrm{CO}_{2}, J$. Geophys. Res., 111, 2006.

Kasischke, E. S., and M. R. Turetsky, Recent changes in the fire regime across the North American boreal region-Spatial and temporal patterns of burning across Canada and Alaska, Geophys. Res. Lett., 33, 2006.

Kasischke, E. S., E. J. Hyer, P. C. Novelli, L. P. Bruhwiler, N. H. F. French, A. I. Suckhinin, J. H. Hewson, and B. J. Stocks, Influences of boreal fire emissions on Northern Hemisphere atmospheric carbon and carbon monoxide, Global Biogeochem. Cycles, 19, 2005.

Kleissl, J., R. Honrath, M. Dziobak, D. Tanner, M. Val Martín, R. Owen, and D. Helmig, The occurrence of upslope flows at the Pico mountaintop observatory: A case study of orographic flows on small, volcanic island, J. Geophys. Res., 112, 2007.

Kley, D., and M. McFarland, Chemiluminescence detector for $\mathrm{NO}$ and $\mathrm{NO}_{2}$, Atmos. Tech., 12, 63-69, 1980.

Kliner, D., B. Daube, J. Burley, and S. Wofsey, Laboratory investigation of the catalytic reduction technique for measurement of atmospheric $\mathrm{NO}_{y}$, J. Geophys. Res., 102, 10,75910,776, 1997.

Klonecki, A., and H. Levy, Tropospheric chemical ozone tendencies in CO-CH4-NOy-H2O system: Their sensitivity to variations in environmental parameters and their application to a global chemistry transport model study, J. Geophys. Res., 102, 21,221-21,237, 1997.

Kondo, Y., et al., Profiles and partitioning of reactive nitrogen over the Pacific Ocean in winter and early spring, J. Geophys. Res., 102, 28,405-28,424, 1997. 
Lapina, K., R. E. Honrath, R. C. Owen, M. Val Martín, and G. Pfister, Evidence of significant large-scale impacts of boreal fires on ozone levels in the midlatitude Northern Hemisphere free troposphere, Geophys. Res. Lett., 2006.

Lawrence, M. G., and P. J. Crutzen, The impact of cloud particle gravitational settling on soluble trace gas distributions, Tellus, 50B, 263-289, 1998.

Lawrence, M. G., and P. J. Crutzen, Influence of $\mathrm{NO}_{x}$ emissions from ships on tropospheric photochemistry and climate, Nature, 33, 167-170, 1999.

Leue, C., M. Wenig, T. Wagner, O. Klimm, U. Platt, and B. Jahne, Qualitative analysis of $\mathrm{NO}_{x}$ emissions from global ozone monitoring experiment satellite image sequences, $J$. Geophys. Res., 106, 5493-5505, 2001.

Leung, F.-Y. T., J. A. Logan, R. Park, E. Hyer, E. Kasischke, D. Streets, and L. Yurganov, Impacts of enhanced biomass burning in the boreal forests in 1998 on tropospheric chemistry and the sensitivity of model results to the injection height of emissions, J. Geophys. Res., 112, 1-15, 2007, doi:10.1029/2006JD008132.

Levy II, H., Normal atmosphere: Large radical and formaldehyde concentrations predicted, Science, 173, 141-143, 1971.

Li, Q., D. Jacob, J. Munger, R. Yantosca, and D. Parrish, Export of $\mathrm{NO}_{y}$ from the North American boundary layer: Reconciling aircraft observations and global model budgets, $J$. Geophys. Res., 109, 10.1029/2003JD004,086, 2004.

Li, Q., et al., Transatlantic transport of pollution and its effects on surface ozone in Europe and North America, J. Geophys. Res., 107, 2002.

Liang, J., L. W. Horowitz, D. J. Jacob, Y. Wang, A. M. Fiore, J. A. Logan, G. M. Gardner, and J. W. Munger, Seasonal budgets of reactive nitrogen species and ozone over the United States and export fluxes to the global atmosphere, J. Geophys. Res., 103, 13,435-13,450, 1998.

Lin, X., M. Trainer, and S. C. Liu, On the nonlinearity of the tropospheric ozone production, J. Geophys. Res., 93, 15,879-15,888, 1988.

Liu, S. C., M. Trainer, F. C. Fehsenfeld, D. D. Parrish, E. J. Williams, D. W. Fahey, G. Hübler, and P. C. Murphy, Ozone production in the rural troposphere and the implications for regional and global ozone distributions, J. Geophys. Res., 92, 4191-4207, 1987.

Liu, S. C., et al., A study of the photochemistry and ozone budget during the Mauna Loa Observatory photochemistry experiment, J. Geophys. Res., 97, 10,463-10,471, 1992.

Liu, X., et al., First directly retrieved global distribution of tropospheric column ozone from GOME: Comparison with the GEOS-CHEM model, J. Geophys. Res., 111, 1-17, 2006, doi:10.1029/2005JD006564. 
Logan, J. A., Nitrogen oxides in the troposphere: Global and regional budgets, J. Geophys. Res., 88, 10,785-10,807, 1983.

Martin, R. V., et al., Validation of GOME satellite measurements of tropospheric $\mathrm{NO}_{2}$ and $\mathrm{HCHO}$ using regional data from aircraft campaigns in the southeastern United States, J. Geophys. Res., 109, 2004.

Martin, R. V., et al., Evaluation of space-based constraints on global nitrogen oxide emissions with regional aircraft measurements over and downwind of eastern North America, J. Geophys. Res., 111, 1-15, 2006, doi:10.1029/2005JD006680.

Mauzerall, D. L., D. J. Jacob, S. M. Fan, J. D. Bradshaw, G. L. Gregory, G. W. Sachse, and D. R. Blake, Origin of tropospheric ozone at remote high northern latitudes in summer, J. Geophys. Res., 101, 4175-4188, 1996.

Mauzerall, D. L., et al., Photochemistry in biomass burning plumes and implications for tropospheric ozone over the tropical South Atlantic, J. Geophys. Res., 103, 8401-8423, 1998.

McKeen, S. A., G. Wotawa, D. D. Parrish, J. S. Holloway, M. P. Buhr, G. Hübler, F. C. Fehsenfeld, and J. F. Meagher, Ozone production from Canadian wildfires during June and July of 1995, J. Geophys. Res., 107, 2002.

Merrill, J. T., and J. L. Moody, Synoptic meteorology and transport during the North Atlantic Regional Experiment (NARE) intensive: Overview, J. Geophys. Res., 101, 28,90328,921, 1996.

Miyazaki, Y., et al., Contribution of particulate nitrate to airborne measurements of total reactive nitrogen, J. Geophys. Res., 110, 1-11, 2005, doi:10.1029/2004JD005502.

Mollicone, D., H. Eva, and F. Achard, Human role in Russian wildfires, Nature, 440, 436-437, 2006.

Morris, G., et al., Alaskan and Canadian forest fires exacerbate ozone pollution over Houston, Texas, on 19 and 20 July 2004, J. Geophys. Res., 111, 2006.

Moxim, W. J., H. Levy, and P. S. Kasibhatla, Simulated global tropospheric PAN: Its transport and impact, J. Geophys. Res., 101, 12,621-12,638, 1996.

Nesbitt, S. W., R. Whang, and R. Orville, Seasonal and global no production by lightning estimated from the Optical Transient Detector (OTD), J. Geophys. Res., 52, 1206-1215, 2000 .

Neuman, J. A., et al., Reactive nitrogen transport and photochemistry in urban plumes over the North Atlantic ocean, J. Geophys. Res., 111, 1-11, 2006, doi:10.1029/2005JD007010. 
Novelli, P. C., L. P. Steele, and P. P. Tans, Mixing ratios of carbon monoxide in the troposphere, J. Geophys. Res., 97, 20,731-20,750, 1992.

Novelli, P. C., K. A. Masarie, P. M. Lang, B. D. Hall, R. C. Myers, and J. W. Elkins, Reanalysis of tropospheric CO trends: Effects of the 1997-1998 wildfires, J. Geophys. Res., $108,2003$.

Olivier, J., and J. Berdowski, Global emissions sources and sinks, in The Climate System, edited by J. Berdowski, R. R. Guicherit, and B. Heij, vol. 33-78, A.A. Balkema Publishers / Swets and Zeitlinger Publishers, Lisse, The Netherlands, 2001.

Olszyna, K. J., E. M. Bailey, R. Simonaitis, and J. F. Meagher, $\mathrm{O}_{3}$ and $\mathrm{NO}_{y}$ relationships at a rural site, J. Geophys. Res., 99, 14,557-14,563, 1994.

Owen, R. C., O. R. Cooper, A. Stohl, and R. E. Honrath, An analysis of the mechanisms of North American pollutant transport to the central North Atlantic lower free troposphere, J. Geophys. Res., 111, 2006.

Park, R. J., et al., Export efficiency of black carbon aerosol in continental outflow: Global implications, J. Geophys. Res., 110, 1-7, 2005, doi:10.1029/2004JD005432.

Parrish, D. D., and F. C. Fehsenfeld, Methods for gas-phase measurements of ozone, ozone precursors and aerosol precursors, Atmos. Environ., 34, 1921-1957, 2000.

Parrish, D. D., J. S. Holloway, and F. C. Fehsenfeld, Routine, continuous measurement of carbon monoxide with parts per billion precision, Environ. Sci. Technol., 28, 1615-1618, 1994.

Parrish, D. D., M. Trainer, J. S. Holloway, J. E. Yee, M. S. Warshawsky, F. C. Fehsenfeld, G. Forbes, and J. L. Moody, Relationships between ozone and carbon monoxide at surface sites in the North Atlantic region, J. Geophys. Res., 103, 13,357-13,376, 1998.

Parrish, D. D., et al., Measurements of the $\mathrm{NO}_{x}-\mathrm{O}_{3}$ photostationary state at Niwot Ridge, Colorado, J. Geophys. Res., 91, 5361-5370, 1986.

Parrish, D. D., et al., Systematic variations in the concentration of $\mathrm{NO}_{x}\left(\mathrm{NO}\right.$ plus $\left.\mathrm{NO}_{2}\right)$ at Niwot Ridge, Colorado, J. Geophys. Res., 95, 1817-1836, 1990.

Parrish, D. D., et al., Fraction and composition of $\mathrm{NO}_{y}$ transported in air masses lofted from the North American boundary layer, J. Geophys. Res., 109, 2004.

Peterson, M. C., and R. E. Honrath, $\mathrm{NO}_{x}$ and $\mathrm{NO}_{y}$ over the northwestern North Atlantic: Measurements and measurement accuracy, J. Geophys. Res., 104, 11,695-11,707, 1999.

Peterson, M. C., R. E. Honrath, D. D. Parrish, and S. J. Oltmans, Measurements of nitrogen oxides and a simple model of $\mathrm{NO}_{y}$ fate in the remote North Atlantic marine atmosphere, J. Geophys. Res., 103, 13,489-13,503, 1998. 
Pfister, G., P. G. Hess, L. K. Emmons, J. Lamarque, C. Wiedinmyer, D. P. Edwards, G. Petron, J. C. Gille, and G. W. Sachse, Quantifying CO emissions from the 2004 Alaskan wildfires using MOPITT CO data, Geophys. Res. Lett., 2005.

Pfister, G. G., et al., Ozone production from the 2004 North American boreal fires, J. Geophys. Res., 111, 1-13, 2006, doi:10.1029/2006JD007695.

Real, E., et al., Processes influencing ozone levels in Alaskan forest fire plumes during long-range transport over the North Atlantic, J. Geophys. Res., 112, 1-19, 2007, doi:10.1029/2006JD007576.

Reeves, C. E., et al., Potential for photochemical ozone formation in the troposphere over the North Atlantic as derived from aircraft observations during ACSOE, J. Geophys. Res., 107, 10.1029/2002JD002,415, 2002.

Reeves, C. E., et al., Alkyl nitrates in outflow from North America over the North Atlantic during Intercontinental Transport of Ozone and Precursors 2004, J. Geophys. Res., 112, 1-21, 2007, doi:10.1029/2006JD007567.

Reid, J. S., R. Koppmann, T. F. Eck, and D. P. Eleuterio, A review of biomass burning emissions part II: Intensive physical properties of biomass burning particles, Atmos. Chem. and Phys., 5, 799-825, 2005.

Richter, A., J. Burrows, H. Nub, C. Granier, and U. Niemeier, Increase in tropospheric nitrogen dioxide over China observed from space, Nature, 437, 129-132, 2005.

Ridley, B., et al., Measurements of $\mathrm{NO}_{x}$ and PAN and estimates of $\mathrm{O}_{3}$ production over the seasons during Mauna Lao Observatory Photochemistry Experiment 2, J. Geophys. Res., 103, 8323-8339, 1998.

Ridley, B. A., and F. E. Grahek, A small, low flow, high sensitivity reaction vessel for NO chemiluminescence detectors, J. Atmos. Tech., 7, 307-311, 1990.

Ridley, B. A., J. G. Walega, J. E. Dye, and F. E. Grahek, Distributions of NO, $\mathrm{NO}_{x}$, $\mathrm{NO}_{y}$, and $\mathrm{O}_{3}$ to $12 \mathrm{~km}$ altitude during the summer monsoon season over New Mexico, $J$. Geophys. Res., 99, 25,519-25,534, 1994.

Roberts, J. M., et al., Episodic removal of $\mathrm{NO}_{y}$ species from the marine boundary layer over the North Atlantic, J. Geophys. Res., 101, 28,947-28,960, 1996.

Sander, S. P., et al., Chemical kinetics and photochemical data for use in atmospheric studies evaluation number 14, Tech. Rep. JPL Publication 02-25, NASA Jet Propulsion Laboratory, 2003.

Sandholm, S. T., et al., Summertime tropospheric observations related to $\mathrm{N}_{x} \mathrm{O}_{y}$ distributions and partitioning over Alaska: Arctic Boundary Layer Expedition 3A, J. Geophys. Res., 97, 16,481-16,509, 1992. 
Seibert, P., and A. Frank, Source-receptor matric calculation with a Lagrangian particle disperion model in backward mode, Atmos. Chem. and Phys., 4, 51-63, 2004.

Simmonds, P. G., R. G. Derwent, A. L. Manning, and G. Spain, Significant growth in surface ozone at Mace Head, Ireland, 1987-2003, Atmos. Environ., 38, 4769-4778, 2004.

Simmonds, P. G., A. J. Manning, R. G. Derwent, P. Ciais, M. Ramonet, V. Kazan, and D. Ryall, A burning question. Can recent growth rate anomalies in the greenhouse gases be attributed to large-scale biomass burning events?, Atmos. Environ., 39, 2513-2517, 2005.

Singh, H. B., Reactive nitrogen in the troposphere, Env. Sci. Tech., 21, 320-327, 1987.

Singh, H. B., et al., Summertime distribution of PAN and other reactive nitrogen species in the northern high-latitude atmosphere of eastern Canada, J. Geophys. Res., 99, 1821$1835,1994$.

Singh, H. B., et al., Reactive nitrogen distribution and partitioning in the North American troposphere and lowermost stratosphere, J. Geophys. Res., 112, 2007.

Spichtinger, N., M. Wenig, P. James, T. Wagner, U. Platt, and A. Stohl, Satellite detection of a continental-scale plume of nitrogen oxides from boreal forest fires, Geophys. Res. Lett., 28, 4579-4582, 2001.

Spivakovsky, C. M., et al., Three-dimensional climatological distribution of tropospheric OH: Update and evaluation, J. Geophys. Res., 105, 8931-8980, 2000.

Stocks, B., et al., Climate change and forest fire potential in Russian and Canadian boreal forests, Clim. Change, 38, 1-13, 1998.

Stohl, A., Computation, accuracy and applications of trajectories - a review and bibliography, Atmos. Environ., 32, 947-966, 1998.

Stohl, A., M. Trainer, T. Ryerson, J. Hollaway, and D. Parrish, Export of $\mathrm{NO}_{y}$ from the North American boundary layer during 1996 and 1997 North Atlantic Regional Experiments, J. Geophys. Res., 107, 10.1029/2001JD000,519, 2002.

Stohl, A., C. Forster, A. Frank, P. Seibert, and G. Wotawa, Technical note: The Lagrangian particle dispersion model FLEXPART version 6.2, Atmos. Chem. and Phys., 5, 2461-2474, 2005, sRef-ID:1680-7324/acp/2005-5-2461.

Stohl, A., et al., The influence of stratospheric intrusions on alpine ozone concentrations, Atmos. Environ., 34, 1323-1354, 2000.

Stohl, A., et al., Rapid intercontinental air pollution transport associated with a meteorological bomb, Atmos. Chem. and Phys., 3, 969-985, 2003.

Stohl, A., et al., Pan-arctic enhancements of light absorbing aerosol concentrations due to North American boreal forest fires during summer 2004, J. Geophys. Res., 111, 1-20, 2006, doi:10.1029/2006JD007216. 
Talbot, R. W., et al., Summertime distribution and relations of reactive odd nitrogen species and $\mathrm{NO}_{y}$ in the troposphere over Canada, J. Geophys. Res., 99, 1863-1885, 1994.

Tanimoto, H., Y. Kajii, J. Hirokawa, H. Akimoto, and N. P. Minko, The atmospheric impact of boreal forest fires in far eastern Siberia on the seasonal variation of carbon monoxide: Observations at Rishiri, a northern remote island in Japan, J. Geophys. Res., 27, 4073-4076, 2000.

Thakur, A. N., H. B. Singh, P. Mariani, Y. Chen, Y. Wang, D. J. Jacob, G. Brasseur, J.-F. Müller, and M. Lawrence, Distribution of reactive nitrogen species in the remote free troposphere: data and model comparisons, Atmos. Environ., 33, 1403-1422, 1999.

Thompson, A. M., et al., Intercontinental Chemical Transport Experiment Ozonesonde Network Study (IONS) 2004: 1.Summertime upper troposphere/lower stratosphere ozone over northeastern North America, J. Geophys. Res., 112, 1-15, 2007, doi:10.1029/2006JD007441.

Trainer, M., et al., Correlation of ozone with $\mathrm{NO}_{y}$ in photochemically aged air, J. Geophys. Res., 98, 2917-2925, 1993.

Turquety, S., et al., Inventory of boreal fire emissions for North America in 2004: Importance of peat burning and pyroconvective injection, J. Geophys. Res., 112, 1-13, 2007, doi:10.1029/2006JD007281.

Val Martín, M., Transport of ozone and nitrogen oxides from North America over the North Atlantic region, Master's thesis, Michigan Technological University, 2002.

Val Martin, M., R. Honrath, R. C. Owen, G. Pfister, P. Fialho, and F. Barata, Significant enhancements of nitrogen oxides, ozone and aerosol black carbon in the North Atlantic lower free troposphere resulting from North American boreal wildfires, J. Geophys. Res., $111,2006$.

Wang, Y., et al., Springtime photochemistry at northern mid and high latitudes, J. Geophys. Res., 108, 10.1029/2002JD002,227, 2003.

Wenig, M., N. Spichtinger, A. Stohl, G.Held, S. Beirle, T. Wagner, B. Jähne, and U. Platt, Intercontinental transport of nitrogen oxide pollution plumes, Atmos. Chem. and Phys., 3, 387-393, 2003.

Wofsy, S. C., S.-M. Fan, D. R. Blake, J. D. Bradshaw, S. T. Sandholm, H. B. Singh, G. W. Sachse, and R. C. Harriss, Factors influencing atmospheric composition over subarctic North America during summer, J. Geophys. Res., 99, 1887-1897, 1994.

Wofsy, S. C., et al., Atmospheric chemistry in the Arctic and subarctic: Influence of natural fires, industrial emissions, and stratospheric inputs, J. Geophys. Res., 97, 16,731-16,746, 1992. 
Wotawa, G., and M. Trainer, The influence of Canadian forest fires on pollutant concentrations in the United States, Science, 288(5464), 324-328, 2000.

Yamamoto, M., M. Tamaki, H. Bandow, and Y. Maeda, $\mathrm{HNO}_{3}$ analyzer by scrubber difference and the $\mathrm{NO}-\mathrm{O}_{3}$ chemiluminescence method, Atmos. Environ., 35, 5339-5346, 2001.

Yang, J., et al., Impacts of snowpack emissions on deduced levels of $\mathrm{OH}$ and peroxy radicals at Summit, Greenland, Atmos. Environ., 36, 2523-2534, 2002.

Yienger, J. J., A. A. Klonecki, H. Levy II, W. J. Moxim, and G. R. Carmichael, An evaluation of chemistry's role in the winter-spring ozone maximum found in the northern midlatitude free troposphere, J. Geophys. Res., 104, 3655-3667, 1999.

Yokelson, R. J., D. W. T. Griffith, and D. E. Ward, Open-path fourier transform infrared studies of large-scale laboratory biomass fires, J. Geophys. Res., 101, 21,067-21,080, 1996, doi:10.1029/96JD01800.

Zellweger, C., J. Forrer, P. Hofer, S. Nyeki, B. Schwarzenbach, E.Weingartner, M. Ammann, , and U. Baltensperger, Partitioning of reactive nitrogen $\left(\mathrm{NO}_{y}\right)$ and dependence on meteorological conditions in the lower free troposphere, Atmos. Chem. and Phys., 3, 779-796, 2003. 


\section{Appendix A}

\section{Data Documentation}

This appendix presents the documentation of the $\mathrm{NO}, \mathrm{NO}_{2}$ and $\mathrm{NO}_{y}$ measurements made at the Pico Mountain station from July 2002 to August 2005. The documentation is divided into four files:

1. PRE-ICARTT, which covers the data reduction from July 2002 to April 2004 documentation_plots_preicartt.pdf, $1.3 \mathrm{MB}$ ).

2. ICARTT, which presents the data reduction from May 2004 to September 2004 documentation_plots_icartt.pdf, $904 \mathrm{kB}$ ).

3. POST-ICARTT, which covers the data reduction from October 2004 to August 2005 documentation_plots_posticartt.pdf, $1.6 \mathrm{MB}$ ).

4. ACCURACY, which includes the determination of total accuracy of the instrument total_accuracy_measurements.pdf, $269 \mathrm{kB}$ ).

The files are included in the CD attached to this dissertation. 